William S. Gray, CFA

\title{
Long-Range Forecasting
}

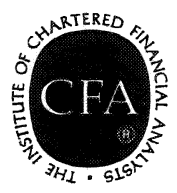

The Research Foundation of

The Institute of Chartered Financial Analysts 


\section{Research Foundation Publications}

Active Currency Management

by Murali Ramaswami

Analysts' Earnings Forecast Accuracy in Japan and the United States

by Robert M. Conroy, Robert S. Harris, and Young S. Park

Bankruptcy Prediction Using Artificial Neural Systems

by Robert E. Dorsey, Robert O. Edmister, and John D. Johnson

Blockholdings of Investment Professionals

by Sanjai Bhagat, Bernard Black, and Margaret Blair

Canadian Stocks, Bonds, Bills, and Inflation: 1950-1987

by James E. Hatch and Robert E. White

Company Performance and Measures of Value Added by Pamela P. Peterson, CFA, and David R. Peterson

Controlling Misfit Risk in Multiple-Manager Investment Programs

by Jeffery V. Bailey, CFA, and David E. Tierney

Corporate Bond Rating Drift: An Examination of Credit Quality Rating Changes over Time

by Edward I. Altman and Duen Li Kao

Corporate Governance and Firm Performance

by Jonathan M. Karpoff, M. Wayne Marr, Jr., and Morris G. Danielson

Country Risk in Global Financial Management by Claude B. Erb, CFA, Campbell R. Harvey, and Tadas E. Viskanta

Currency Management: Concepts and Practices by Roger G. Clarke and Mark P. Kritzman, CFA

Earnings Forecasts and Share Price Reversals by Werner F.M. De Bondt

Economic Foundations of Capital Market Returns by Brian D. Singer, CFA, and Kevin Terhaar, CFA

Economically Targeted and Social Investments: Investment Management and Pension Fund Performance

by M. Wayne Marr, John R. Nofsinger, and John L. Trimble

Emerging Stock Markets: Risk, Return, and Performance

by Christopher B. Barry, John W. Peavy III, CFA, and Mauricio Rodriguez

Equity Trading Costs

by Hans R. Stoll

Ethics, Faimess, Efficiency, and Financial Markets by Hersh Shefrin and Meir Statman
The Founders of Modern Finance: Their PrizeWinning Concepts and 1990 Nobel Lectures

Franchise Value and the Price/Earnings Ratio by Martin L. Leibowitz and Stanley Kogelman

Fundamental Considerations in Cross-Border Investment: The European View

by Bruno Solnik

Global Asset Management and Performance Attribution

by Denis S. Karnosky and Brian D. Singer, CFA

Initial Dividends and Implications for Investors by James W. Wansley, CFA, William R. Lane, CFA, and Phillip R. Daves

Initial Public Offerings: The Role of Venture Capitalists

by Joseph T. Lim and Anthony Saunders

Interest Rate and Currency Swaps: A Tutorial by Keith C. Brown, CFA, and Donald J. Smith

The International Equity Commitment

by Stephen A. Gorman, CFA

Investment Styles, Market Anomalies, and Global Stock Selection by Richard O. Michaud

Managed Futures and Their Role in Investment Pontfolios

by Don M. Chance, CFA

The Modern Role of Bond Covenants by Ileen B. Malitz

A New Perspective on Asset Allocation by Martin L. Leibowitz

Options and Futures: $A$ Tutorial

by Roger G. Clarke

The Poison Pill Anti-Takeover Defense: The Price of Strategic Deterrence

by Robert F. Bruner

A Practitioner's Guide to Factor Models

Predictable Time-Varying Components of International Asset Returns

by Bruno Solnik

The Role of Risk Tolerance in the Asset Allocation Process: A New Perspective by W.V. Harlow III, CFA, and Keith C. Brown, CFA

Sales-Driven Franchise Value by Martin L. Leibowitz

Selecting Superior Securities by Marc R. Reinganum

Time Diversification Revisited by William Reichenstein, CFA, and Dovalee Dorsett 


\section{Long-Range Forecasting}


(C) 1999 The Research Foundation of the Institute of Chartered Financial Analysts

All rights reserved. No part of this publication may be reproduced, stored in a retrieval system, or transmitted, in any form or by any means, electronic, mechanical, photocopying, recording, or otherwise, without the prior written permission of the copyright holder.

This publication is designed to provide accurate and authoritative information in regard to the subject matter covered. It is sold with the understanding that the publisher is not engaged in rendering legal, accounting, or other professional service. If legal advice or other expert assistance is required, the services of a competent professional should be sought.

The Institute of Chartered Financial Analysts is a subsidiary of the Association for Investment Management and Research.

ISBN 978-0-943205-47-2

Printed in the United States of America

March 1999

\title{
Editorial Staff \\ Bette Collins \\ Editor
}
Christine E. Kemper Assistant Editor
Donna C. Hancock Production Coordinator

\author{
Jaynee M. Dudley \\ Production Manager \\ Lois A. Carrier \\ Composition
}




\section{Mission}

The Research Foundation's mission is to identify, fund, and publish research that is relevant to the AIMMR Global Body of Knowledge and useful for AIMR member investment practitioners and investors. 


\section{Biography}

William S. Gray III, CFA, is now retired but continues as a financial/ investment consultant on a limited basis. Previously, he spent 45 years at Harris Trust and Savings Bank, where his positions included chair of the Trust Investment Committee and senior investment officer in the Trust Department. At Harris Bank, Mr. Gray focused on securities analysis, portfolio management, and investment strategy. In his work on securities analysis, he pioneered in the evaluation and reporting of relative market value opinions in research reports. Among many other board leadership positions, Mr. Gray has also served as president of the Investment Analysts Society of Chicago, chair of the board of the Financial Analysts Federation (FAF), and president of the Financial Analysts Research Foundation. He is a recipient of a Graham and Dodd Award from the Financial Analysts Journal for his article "The Application of Discount Rates in Forecasting Returns for Stocks and Bonds," of the FAF Distinguished Service Award, and of the University of Chicago Alumni Medal for extraordinary long-term service. He holds a Ph.B. and an M.B.A. from the University of Chicago. 


\section{Contents}

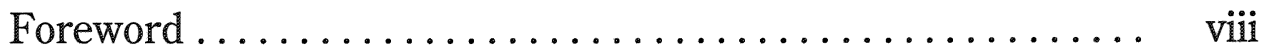

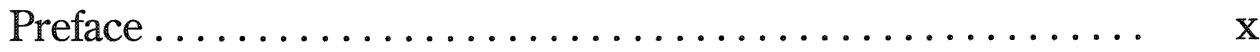

Introduction............................... xii

Chapter 1. The Models for Long-Term Forecasting........ . 1

Chapter 2. Behavior of the Model Factors.............. 8

Chapter 3. The Equivalency Model: Stocks versus Bonds ... 15

Chapter 4. IVM Governs Behavior of the U.S. Stock Market, 1929-1996........................ 24

Chapter 5. Income Yield: The Equilibrator ............ 39

Chapter 6. Applying the IVM Approach to Long-Term Forecasting........................ 45

Chapter 7. Using Long-Term Forecasts in Asset Allocation .. $\quad 59$

Chapter 8. Implications for the Future.............. 67

Appendix A. Yearly Average Expected Returns on the S\&P 400 Index ....................... 72

Appendix B. S\&P 400 Index, 1926-1996 .............. 74

Appendix C. The Tax Premium as a Component of the Discount Rate...................... 78

Appendix D. Expected Return Spread and Estimation of Two-Year Stock Market Forecast, 1978-79. . . . . 81

Appendix E. GDP, National Income, Corporate Profits, and S\&P 400 Earnings, $1929-96 \ldots \ldots \ldots \ldots \ldots \ldots \quad 82$

Appendix F. Historical Relationships among GDP, National Income, Corporate Profits, and S\&P 400 Earnings,

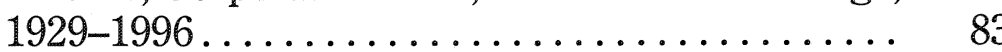

Appendix G. S\&P 400 Earnings, 1926-1996 . . . . . . . . . . 84

Appendix H. S\&P 400 Dividends, $1926-1996$. ........... 85

Appendix I. Expected Growth Rate and Expected Return

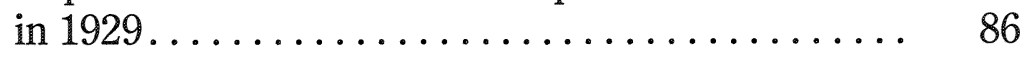

References.............................. 89

Selected AIMR Publications . . ..................... 91 


\section{Foreword}

In a gentler era, comedians appearing on television attacked only "safe" targets, such as mothers-in-law and weathermen. Unlike the confrontational approach adopted by the performers of today, 25 or 30 years ago, you seldom heard someone say anything worse than "if a weatherman predicts sunny skies, you better take an umbrella." While studying economics in college, I became painfully aware that there was another group of professionals whose power of prognostication was held in similarly low regard and that I was training myself to join their ranks. Economists, it seems, do not inspire any more confidence with their forecasts than meteorologists. (Who hasn't heard the old line that economists have predicted seven of the last five recessions?) Whether the focus of an economic forecast is the events of tomorrow or a decade in the future, most users of the forecast accept the predictions only if accompanied by a rather large grain of salt.

William S. Gray is something of an anomaly in the ranks of business economists. At a time when macroeconomic forecasters were content trying to explain the broad issues of business-cycle behavior and foreign trade imbalances, Gray was already pioneering the application of economic principles to security analysis and investment management. Long before it became fashionable for Wall Street firms to tout the expertise of their staffs of portfolio strategists, he was hard at work exploring the dynamics of the market forces that drive stock and bond returns. Starting with the well-established notion that a security is worth the present value of its future expected cash flows, his intuition led him to some deceptively simple conclusions about what really matters when predicting future price performance.

This monograph contains much of what Gray discovered about financial markets during the five decades he was active in the profession. As the reference list attests, he has already written a great deal on various aspects of this topic, but supplementing that work with new analysis and collecting it in one place lend a compelling synergy to the present effort. As you consider this research, you will see that a great deal of attention is paid to the investment value model - which should already be familiar to most readers of financial economic literature-and the connection between applying this model to predicting stock returns and to predicting bond returns. Indeed, it is the author's analysis of the economic factors that compose this model that provides the theoretical underpinning for his forecasting efforts and the most interesting part of the study.

Although not labeled explicitly in this manner, the work on the following pages can be divided into two distinct parts. In Chapters 1-5, the author first lays the foundation for his model and documents the myriad historical relationships between such variables as dividend yield, earnings growth, GDP 
growth, and inflation that have defined economic life in the past half century. A careful consideration of this rich and useful chronicle, although it is potentially ponderous because of the detail, will serve the reader well. Then in Chapters $6-8$, the author turns his attention to using these relationships to forecast future market behavior. Specifically, he details his experiences predicting aggregate stock and bond returns for the purposes of forecasting absolute levels and determining appropriate asset allocation. The work in this second section of the monograph is interesting and suggestive, even though independent corroboration of the forecasted results is not possible.

Anyone trained in econometric modeling will find reasons to criticize some of the methodology used in this research. For instance, the regressions testing the stock-bond equivalency model presented in Chapter 3 do not control for a possible serial correlation problem and the market forecasts summarized in Chapter 6 are based on overlapping sample periods. Furthermore, the stock-price forecasts are based on concurrent dividend yields rather than the expected dividend yields prescribed by theory. In this sense, what you have before you is not a "modern" piece of research that micromanages the statistical work it presents in support of its central hypothesis. For some readers, I suspect, that very indictment will be one of the monograph's principal charms. In any case, no reader should lose sight of the bigger picture the author is attempting to paint.

Forecasting the long-term behavior of the security markets is not now, of course, and never will be an exact science. It is also not the intellectual equivalent of flipping a coin, however; it is based on relationships that have proven tractable over time. Gray has devoted much of his professional life to understanding the basic nature of those relationships, and he has shared his accumulated wisdom in this work. The approach he adopts is a simple one, but the reader should resist the temptation to equate simplicity with a lack of conceptual rigor. Indeed, a careful examination of the past may be able to tell us much about the future, and the Research Foundation is pleased to provide you with such an opportunity.

Keith C. Brown, CFA Research Director

The Research Foundation of the Institute of Chartered Financial Analysts 


\section{Preface}

Looking back to 1950 and the ensuing first 15 years of my indoctrination to the investment management profession, I can see that the circumstances in which U.S. financial markets functioned were benign-indeed, almost utopian. The real economy grew about 4 percent a year, recessions were relatively short and mild, inflation was virtually nonexistent, and most working people who sought employment were employed most of the time. Interest rates were low by historical standards, albeit rising slowly, and the stock market (the S\&P 500 Index) enjoyed compound annual returns of more than 15 percent a year.

In 1966, when my activities and responsibilities shifted from securities analysis to portfolio policies and investment strategies, there were no particular indications that these extraordinary circumstances would change. But the United States became involved in the Vietnam War and proceeded with a deluded notion that an expanded need for military supplies and equipment need not curtail normal civilian goods activities (often referred to as a "Guns and Butter" policy). Although not recognized at the outset, the stage was being set for some profound changes that would later be described as a paradigm shift.

With respect to financial markets, a paradigm shift is often characterized by significant changes in the price behavior of one or more classes of financial assets. Such changes are very disruptive because they are not well understood and may cause many concerns. After three years of rising inflation in the late 1960s, my two primary concerns were (1) that monetary policy and changes in money supply growth might lose at least some reliability as indicators of the direction of asset prices and (2) that U.S. Treasury bond yields, rising 250 basis points to more than 7 percent, had become much more competitive with common stocks (which, at that time, had a historical record of an average 9 percent annual return.)

At that time, the popular measures of value for stocks and the stock market (i.e., the price-to-earnings ratio and dividend yields) were not at all comparable to the yield to maturity on bonds. The research that led to such a measure was set forth in an internal paper I wrote at Harris Trust and Savings Bank in Chicago, Illinois, in 1971. Initially, the measure was labeled "sustainable return," which is conceptually identical to what is now more commonly referred to as a discount rate or an "expected return."

In 1995, I came across a book that, had I found it earlier, would have expedited the development of the perspective and methods described in this monograph. Investment Values in a Dynamic World: The Collected Papers of Nicholas Molodovsky (Milne 1974) reported important progress in the application of an investment value approach to common stock valuation. Although finding this book has had considerable personal benefits, much of my understanding of stock market behavior and long-term forecasting methods had 
already evolved through a trial-and-error, do-it-yourself approach-such grubbing for meaningful insights is not without benefit to one's personal perspective.

In the late 1960s, at the inception of the research that led to the long-range forecasting methods presented in this monograph, I assumed that what seemed logical was so; that is, unless constrained by law or custom, investors pay for what they expect to receive in return, with suitable allowance for the amount of risk involved. For common stocks, that assumption implies that price relates to the current annual dividend, so dividend yield plus the expected growth rate in dividends (more recently, earnings) is an expected total rate of return that includes a suitable risk premium relative to the concurrent yield to maturity on fixed-income securities. This fundamental assumption is completely consistent with the pricing of stocks and bonds as set forth in The Theory of Investment Value (Williams 1938). The particular investment value models (IVMs) that I develop (or use) in this monograph are directly related to this fundamental approach to valuation.

The original purpose of this monograph was to serve the interests and needs of professional investment practitioners. Its usefulness should extend, however, to students of economics and finance, anyone with a practical interest in investments, and people who are concerned with legislation, regulation, and/ or policy pertaining to the economy, investment management, or the behavior of financial markets.

The ideas presented in this monograph will suggest innovative approaches to the structure of discount rates and the estimation of finite holding-period returns for bonds and the stock market. Significantly different magnitudes of estimated future returns from those now broadly accepted are likely from giving more emphasis to the IVM approach. As a corollary, the monograph should have major implications for the size of fund distributions that are consistent with the preservation of the inflation-adjusted value of principal. All such aspects have great relevance to the private management of investments and to the regulation of investment activities.

Finally, if the significance of the ideas presented here is recognized by others in the investment field, some shift should occur in the focus of financial market research. This shift might take the form of efforts to gain a better understanding of the factors that determine prices within the framework of the investment value models. Possibilities include increased attention to free cash flows instead of earnings per share in efforts to estimate future growth expectations and to the potential benefits of alternative discount rate structures on judging the riskiness of common stocks (income plus expected appreciation) and in acquiring an improved feel for long-range interest rate prospects for bonds (expected inflation plus real return).

Savannah, Georgia

February 1997 


\section{Introduction}

With some exceptions (e.g., the earth's complete rotation every 24 hours), about the only thing that is known about the future is its uncertainty. Not surprisingly, this uncertainty leads to endless conjecturing. The risks inherent in uncertainty, however, have resulted in investment prices that reward investors with real (inflation-adjusted) returns over long periods of time. These rewards may largely account for the existence of an investment management industry.

Uncertainty comes in many forms, and how people cope with it should depend on the nature of the uncertainty. For example, a future event may be uncertain because it is random, or the future event may be uncertain but predictable to some degree because it will be the effect of some cause or causes. Bernstein (1996a) noted:

Until we can distinguish between an event that is truly random and an event that is the result of cause and effect, we will never know whether what we see [or have seen] is what we'll get, nor how we got what we got. (p. 197)

This monograph offers considerable evidence that the pricing of financial assets (certainly bonds and stocks in the United States) fits into the "cause and effect" category.

The price of a stock relates directly to its current annual dividend, so the dividend yield plus the expected long-term growth rate compose the discount rate, or expected return (ER), which includes a suitable risk premium relative to the concurrent discount rate of alternative fixed-income securities. For publicly traded bonds, the discount rate-ER(B) - is the yield to maturity. The simple investment value models that I explain and use in this monograph are based on such fundamental valuation theory. All models reflect streams of payments and discount rates. Any stream must include an estimated or known terminal price or principal payment. The ERs, although crucial to forecasting, are not the same as estimated holding-period returns (HPRs), which are the ultimate forecasting product.

For bonds, the estimation of future HPRs depends on an estimate of their ER(B)s at the forecast horizon-say, 5 or 10 years hence. For stocks, the corresponding estimation depends partly on an estimate of the expected stock returns-ER(S) - but more importantly, it depends on the stock's dividend yield component and the estimated annual dividend payment at the forecast horizon. Such estimates lead to a valuation-based determination of price at the terminal date. The estimated terminal price may result in enormous differences between the estimated HPRs and the ER(S) at inception.

Like any other estimate of the future, estimated HPRs are hazardousprimarily because of the need to anticipate future circumstances. The problem 
in the case of stocks is compounded if the dividend yield is not dealt with explicitly. Its inclusion is especially important at the termination of any longrange forecast. As noted earlier, the estimated $\mathrm{ER}(\mathrm{S})$ in the investment value models presented here include the dividend yield.

A review of the U.S. stock market from 1926 through 1996 suggests that expectations of future earnings growth rates are significantly influenced by growth rates of the trailing 10-year to 15-year period. Furthermore, after cyclical impacts are removed, a strong inverse correlation between changes in longrange growth rate expectations and the dividend yield is evident. When growth rate expectations are rising, dividend yields are declining, and vice versa.

The clearest insightful view of long-term stock market behavior (e.g., price changes and HPRs) is most likely when the relevant time series are viewed in real (i.e., inflation-adjusted) terms. For U.S. investors, relevant time series include gross domestic product (primarily U.S. GDP but increasingly also the GDP of countries in which U.S. corporations have major economic exposures), earnings per share, dividends per share, and discount rates. During most of the past 70 years, trailing growth rates in both earnings and dividends per share served well to proxy future growth rate expectations. In recent years, a period of active stock-repurchase programs, the earnings per share data have been the best proxy.

Data on real expected returns and HPRs from 1926 through 1996 reveal four periods in which long-range growth rates exhibited distinctly different characteristics (intermittently "eroding" or "recovering") but, superimposed, only two periods that substantially differed in their inflation atmosphere. The four periods (1929-1941, 1941-1968, 1968-1981, and 1981-1996) varied greatly in stock market price experience and HPRs. The two periods in which inflation riskiness was the major factor (a predominantly noninflationary 1929-68 period and the 1968-96 period that was affected by changing rates of inflation) had distinctly different bond price and HPR experiences. From the late 1960s through 1996, inflation uncertainty imposed a significant incremental layer of riskiness on bonds, but it did so only temporarily (roughly from 1968 to 1974) in the case of common stocks.

From the perspective of the investment value models, the stock market had no paradigm changes between 1926 and 1996, only periodic cyclical movements around more enduring periods of significantly eroding or recovering real earnings growth rates. ${ }^{1}$ For the bond market, however, the transition from an essentially noninflationary environment (until the late 1960s) to a period of significant inflation uncertainty would seem to qualify as a paradigm shift, reflected in a significantly delayed but much enlarged risk premium in ER(B)s since the early 1980 s.

\footnotetext{
${ }^{1}$ See Bernstein (1996a) for an alternative perspective.
} 
Analysts have largely ignored these long-range patterns of financial market behavior, but the patterns are vital for understanding the past 70 years of HPRs. These long-range patterns are relevant to long-range forecasting endeavors and, therefore, to investment policy and strategy formulation. The patterns appear to be highly consistent with the notion that bond and stock market prices are determined by the factors indicated by investment value theory.

Because anticipation of future circumstances is unavoidably uncertain, forecasting depends on personal judgment. Judgment should benefit, however, from insights gained from the past behavior of the fundamental valuation factors (ERs, equity risk premiums, long-term growth rate expectations, and the dividend yield). Behavior includes the ranges within which each variable has moved, what (if any) central tendencies may be observed, and what factors have caused any upward or downward tendencies of each variable. This monograph's time-series data in real terms should be quite useful in the further refinement of such insights.

The monograph presents specific 5-and 10-year forecasts made from 1977 through 1990. All were based on the fundamental investment value theory. A total of 13 forecasts were made- 8 stock market (S\&P 400) forecasts and 5 long-term corporate bond forecasts. Except for forecasts made early in 1990, all of the forecasts had terminal dates that are now history. With some good luck, all those forecasts were quite accurate. Of the two 10-year forecasts made in early 1990 (with terminal dates of December 31, 1999), at the time of this writing (seven years into the period), the long-term bond forecast is very much on target-but the stock market forecast is in trouble. The equity market's cumulative HPR is (so far) 4-5 percentage points better than the model predicted for the full 10 years. Clearly, the unfolding pattern of real earnings growth rates has been quite a bit better than I had expected, resulting in a decline in dividend yield to almost 1.7 percent at year-end 1996 .

The strong inverse relationship between changes in expected growth rates and changes in the dividend yield is quite clear, although to my knowledge, not yet calibrated. Recognition of this long-standing (at least 70 years) relationship may be the single most important discovery reported in this monograph. Not only is it a quantum addition to long-term forecasting methodology, it makes clear that any potential erosion in the expected longterm growth rate is a very large risk consideration for the stock market, especially with the current level of such expectations high and still rising. Thus, even with the knowledge of this relationship, there remains the challenge of judging when and in what direction such expectations will change in the future and, of course, how changes in the perception of riskiness may affect prices and HPRs in the future. 


\section{The Models for Long-Term Forecasting}

The investment value models described here for forecasting price levels and holding-period returns of long-term corporate bonds and the U.S. stock market are structured to simplify the treatment of the income payment stream. Instead of the conventional semi-annual interest frequency for bonds and quarterly dividend frequency for common stocks, the models assume annual payments. ${ }^{1}$

The following sections set forth the simplified bond and stock market models and an equivalency model.

\section{Bond Model}

The present value or price of a bond is determined by the expected stream of payments discounted at an appropriate rate. The simplified form of the bond model may be expressed as

$$
P=\frac{I C_{1}}{(1+i)^{1}}+\ldots+\frac{I C_{n}+M V_{n}}{(1+i)^{n}}
$$

where

$P \quad=$ price (or present value)

$I C=$ annual interest coupon (dollar amount)

$M V=$ maturity value or estimated market value at time of sale

$i=$ annual discount rate

$n$ = number of years to maturity or time of sale

For an illustration, see Example 1.1.

Example 1.1: Assume $I C$ is $\$ 80, M V$ is $\$ 1,000$, and $n$ is five years. Then,

$$
\text { Price }=\frac{\$ 80}{(1+i)^{1}}+\frac{\$ 80}{(1+i)^{2}}+\ldots+\frac{\$ 80}{(1+i)^{5}}+\frac{\$ 1,000}{(1+i)^{5}} .
$$

If $i=9$ percent, price $=\$ 961.10$.

If $i=8$ percent, price $=\$ 1,000.00$.

If $i=7$ percent, price $=\$ 1,041.00 .^{2}$

\footnotetext{
${ }^{1}$ Given the inescapable problems of highly accurate forecasting, use of such simplified models does no significant harm to the resulting price or rate of return estimates.

${ }^{2}$ Prices would have been $\$ 960.40, \$ 1,000$, and $\$ 1,041.60$, respectively, had semi-annual $\$ 40$ payments been assumed.
} 
The interest payment for the first year (and at the end of each subsequent year) and the interest payment plus the maturity value (or estimated market value at expected time of sale) in the final year are discounted at the appropriate rate for the respective time intervals to determine the price or present value. Although unconventional, the appropriate discount rate may be viewed as composed of two parts-the expected rate of inflation and a risk premium. ${ }^{3}$ Established convention specifies three parts-inflation rate, expected real risk-free rate, and a risk premium. I have found the imposition of a real riskfree rate to be a distracting complication in attempting to forecast the discount rate several years in the future.

To provide a thoughtful forecast of future holding-period returns to any date other than maturity, an assumed level of interest rates at that date is required. This assumed rate (yield to maturity) will be more credible if it is supported by reasoned estimates of the expected rate of inflation and by my (all-encompassing) risk premium at that date (see Chapter 6).

Given the assumed future interest rate estimate and the remaining income and principal payments, the price or present value at that future date may be easily determined.

\section{Stock Market Model}

The stable-growth form of the stock market model is

$$
P=P / E(E)=\frac{D(1+g)^{1}}{(1+i)^{1}}+\frac{D(1+g)^{2}}{(1+i)^{2}}+\ldots+\frac{D(1+g)^{n}}{(1+i)^{n}}+\frac{(P / E)(E)(1+g)^{n}}{(1+i)^{n}}
$$

where

$D=$ current dividend (dollar amount)

$E=$ current normalized (i.e., with cyclical extreme influences and nonrecurring items eliminated) earnings (dollar amount)

$P / E=$ current price-to-earnings ratio

$g \quad=$ annual dividend growth rate

$n=$ number of years to time of sale

$i=$ annual discount rate

As noted earlier, this version treats dividend payments as received once each year instead of quarterly. Also, as discussed further shortly, the dividend growth rate assumed in this formula is quite likely to differ somewhat from the expected growth rate in the denominator of its shortened version.

${ }^{3}$ Chapter 2 expounds on the estimation of the expected rate of inflation and the risk premium. 
The first step toward the shortened version involves a transposition from any number of annual periods to a single period. Because the chosen discount rate is always stable and it is assumed that the growth rate is stable as well, those elements that provided for more than one period are removed, including the superscripts. The model then appears as follows:

$$
P / E(E)=\frac{D(1+g)}{1+i}+\frac{(P / E)(E)(1+g)}{(1+i)} .
$$

A series of additional transpositions results in the shortened version mentioned previously, which is widely used by those practitioners who use investment value models. This simplified model is stated as ${ }^{4}$

$$
P=\frac{D(1+g)}{i-g} .
$$

but this simplified model may be used without $1+g$ in the numerator when, as part of a long-range forecasting process, one is determining a future price that is based on an assumed dividend level $D$ and the concurrent $i$ and $g$. That is, the current annual dividend payment divided by the difference between the discount rate and the expected earnings growth rate provides an indication of price or present value. For a demonstration, see Example 1.2.

Example 1.2: Assume $D$ is $\$ 3.00$ and $g$ is 7 percent. Then,

$$
P=\frac{\$ 3.00}{(i-7 \%)} .
$$

If $i=11$ percent, price $=\$ 75.00$.

If $i=10$ percent, price $=\$ 100.00$.

If $i=9$ percent, price $=\$ 150.00$.

When this formula is used for long-range forecasting to determine an estimated terminal stock market price level, the time period chosen to represent the current dividend at the terminal date must be consistent with the time periods used for interim dividend payments to assure a valid computation of the estimated holding-period return (HPR).

Figure 1.1 provides a simplified graphic of the factors that determine $i$, $g$, and $D$. As in the bond model, the appropriate discount rate may be viewed in two parts-the expected rate of inflation and a risk premium.

\footnotetext{
${ }^{4}$ See Gray (1974) for more detail.

${ }^{5}$ This perspective on what constitutes the risk premium component of the discount rate or expected return for stocks differs from that specified by the capital asset pricing model. For a discussion of the reasoning behind this alternative, see Gray (1989).
} 
Figure 1.1. Market Valuation Factors

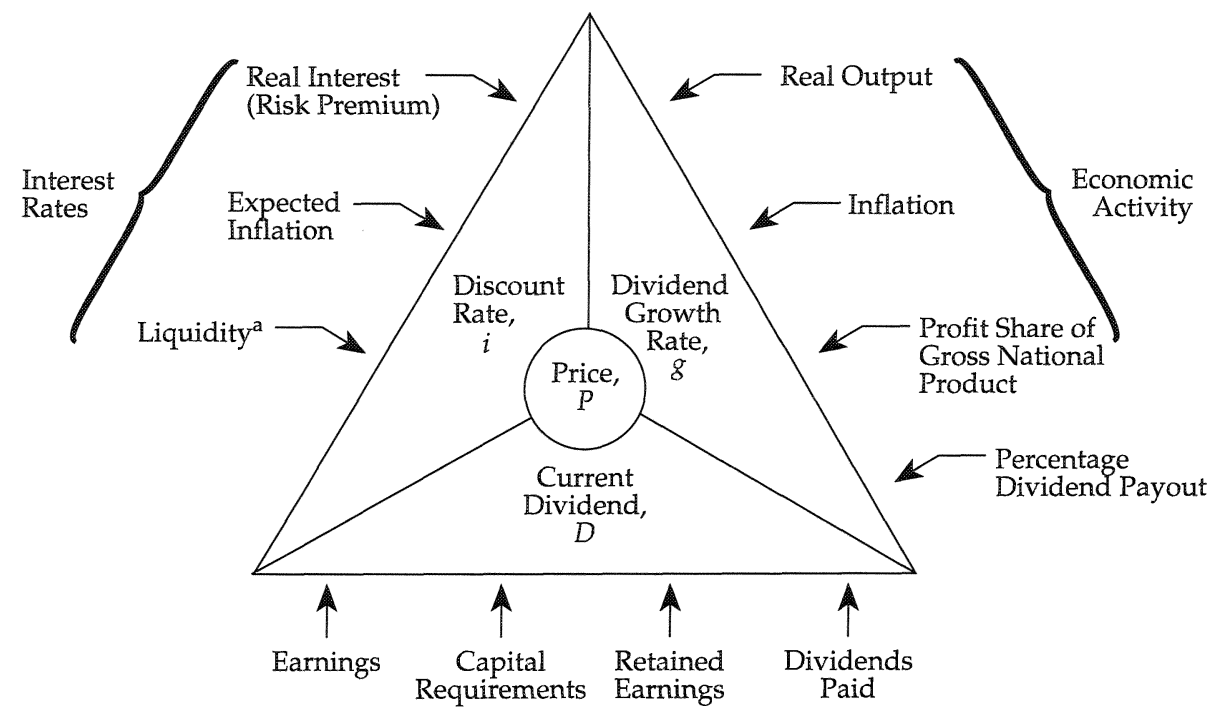

aThe liquidity factor is sometimes involved over short time periods (i.e., it is essentially neutral long term).

An important aspect is to recognize that the difference between the discount rate and the expected earnings growth rate is equal to the dividend yield. This equivalency is evident by rearranging terms:

$$
\frac{D}{P}=i-g
$$

Developments that increase the discount rate and/or decrease the expected long-term growth rate will increase dividend yield. Developments that decrease the discount rate and/or increase the growth rate expectation will decrease dividend yield. In forecasting applications, these variables are best viewed in real (inflation-adjusted) terms.

The real discount rate may be viewed as the expected reward for risk taking, although the capital asset pricing model (CAPM) at times specifies otherwise (i.e., when the risk-free rate and the expected inflation rate are not the same). The expected earnings growth rate appears to draw heavily on historical experience. ${ }^{6}$ That experience indicates that real growth approximates the long-term real rate of economic growth in the United States, roughly

${ }^{6}$ Chapter 2 considers issues that are important in selecting a long-term growth rate. 
3 percent a year, except during extended periods of a troubled economy. For example, the expected growth rate reflected in stock prices apparently declined gradually during the 13 years of generally rising inflation (1968 through 1981), when real earnings growth for the entire period turned out to be negligible.

Unfortunately, neither the discount rate nor the expected growth rate is observable in the market. Judgments are required. Fortunately, in most circumstances, a good estimate of the discount rate is possible by a further rearrangement of terms:

$$
i=\frac{D}{P}+g \text {. }
$$

Appendix A contains the data on average annual dividend yields, trailing real earnings growth rates (a proxy for future growth rate expectations), and expected returns on stocks for the 1940-96 period.

The sum of the expected real growth rate and the current dividend yield provides a useful estimate of the real discount rate. For example, assuming a real growth rate of 3 percent, if the current dividend yield is 2.5 percent, the estimated real discount rate is 5.5 percent.

Whenever the gap between the discount rate and expected growth rate changes, the corollary changes in dividend yield are brought about by changes in the level of stock prices. Thus, a change in stock prices enables the market to perform its wonders by constantly generating a real discount rate that best equates risk in the market with growth rate expectations. Within the stock market models, the dividend yield is the equilibrating variable. In effect, the dividend yield performs the crucial role of maintaining the proper balance between the major variables that govern stock prices.

Example 1.3, which explains how changes in the key variables drive stock prices, draws together some of the key notions discussed in this section.

\section{Equivalency Model}

The bond model and the stock market model each contain a discount rate. Such rates reflect the market's perception of the assets' respective riskiness. The difference in riskiness between bonds and stocks has narrowed since the late 1960s because, in large part, investors have come to perceive unexpected inflation as a major incremental risk for bonds. Even with the added risk premium for inflation uncertainty (as distinct from expected inflation), bonds are still priced as a somewhat lower risk vehicle than stocks. Therefore, a model that will show comparable discount rates for stocks and bonds will reflect the equity risk premium. 
Example 1.3: Assume the S\&P 400 Index is currently selling at 600 and has a current annual dividend of 18 . The dividend yield is 3 percent. The real growth rate is estimated to be about normal at 3 percent. Thus, the estimated real discount rate is 6 percent. Assume the beginning of a recession within the next four to six months; investor risk aversion will thus almost certainly increase. Assume the degree of greater risk aversion requires a 0.4 percentage point (pp) increase in the real discount rate and that a slight decline (of $0.1 \mathrm{pps}$ ) in the expectations for the real growth rate takes place. Together, those changes bring about a 3.5 percent dividend yield. During those four to six months, the annual dividend moves up to 18.20. Applying the higher dividend yield to this slightly higher dividend results in a price of 520 for the S\&P 400. A $131 / 3$ percent reduction in stock-price levels reflects the market's response to the indicated changes.

The basic equivalency model is

$E R(S)=E R(B)+S R P$

or

$S R P=E R(S)-E R(B)$,

where

$E R(S)=$ expected return for the stock market

$E R(B)=$ expected return for bonds

$S R P=$ equity (stock) risk premium

The second form is the generic formulation of the equity risk premium.

In a generally stable market environment (i.e., stable inflation, growth, and discount rates), the actual spread between stock and bond holding-period returns should approximate the expected equity risk premium. The best that may be reasonably expected, however, is a moderately unstable (at times, considerably worse) environment; therefore, one should expect at least some dissimilarity between $S R P$ and the actual spread between respective HPRs. ${ }^{7}$

\section{Inflation and the Equity Risk Premium}

To assure clarity, the equity risk premium in the equivalency model is conceptually different from the risk premium component in the discount rate of the stock market model. The equity risk premium in the equivalency model is only that portion of the real $E R(S)$ that exceeds the real $E R(B)$, whereas the risk premium in the stock market model is the total real $E R(S)$.

\footnotetext{
${ }^{7}$ Chapter 3 provides a review of the history of this relationship.
} 
The need for this distinction arises because the widely used CAPM representation of $E R(S)$ ran into perplexing limitations in the late 1960 s as the United States developed inflation problems. A U.S. Treasury rate is usually used as the risk-free rate in the CAPM. When inflation resulted in much higher T-bill and T-bond rates and historical spreads between stock and bond HPRs were used as the estimated $S R P \mathrm{~s}$, the result was high $E R(S)$ figures that often seemed very unrealistic. ${ }^{8}$

Table 1.1 highlights some dramatic changes around the mid-1960s in HPRs of four major asset classes and the U.S. Consumer Price Index (CPI). Because of inflation, the relationship between $E R(S)$ and $E R(B)$ has changed a great deal.

\begin{tabular}{|c|c|c|}
\hline Asset Class & $1926-65$ & 1966-96 \\
\hline Large-company stocks & $10.4 \%$ & $11.1 \%$ \\
\hline Long-term T-bonds & 3.2 & 7.6 \\
\hline Intermediate-term T-bonds & 3.0 & 8.2 \\
\hline T-bills & 1.5 & 6.7 \\
\hline Inflation (CPI) & 1.4 & 5.3 \\
\hline
\end{tabular}

Source: Ibbotson Associates (1997).

Using historical HPR experience as the best input to judge the current $S R P$ probably overlooks what have been nonrecurring components of stock market experience. Common stocks have become less risky since World War II. The history of the U.S. financial markets, particularly since 1968, indicates that a permanent loss of purchasing power is much more probable for bondholders than for stockholders. Accordingly, the riskiness of fixed-income assets is now perceived to be much closer to the riskiness of common stocks than in earlier times. Also, since early 1997, stock prices have been benefiting greatly from a trailing real earnings growth rate well above the 1926-96 average (3.5+ percent versus 2.22 percent). Together, these developments largely account for a current $S R P$ that is about as small as it has ever been.

\footnotetext{
${ }^{8}$ Although the CAPM appeared to have merit at the time of its formulation in the mid-1960s, the addition of significant inflation to the U.S. financial market environment in the late 1960s may have diminished that merit. Would the CAPM's formulation have differed if the history of financial market returns and U.S. inflation had been in the mid-1960s what it has been ever since?
} 


\section{Behavior of the Model Factors}

Use of the bond model, stock market model, and equivalency model to formulate long-term forecasts requires an understanding of the historical behavior of their variables but also credible insights about cause and effect. The impact of the business cycle has certainly been important, but changes in the inflation environment have been even more important. Regarding inflation, keep in mind that, based on changes in the level of the U.S. Consumer Price Index (CPI), the 1926-66 period was largely noninflationary, the 1967-81 period became increasingly inflationary, and since 1981, the United States has been in a primarily disinflationary period. This chapter provides a review of the behavior of the model variables that points out the most significant underlying economic conditions or developments that appear to heavily influence the variables.

\section{Bond Factors}

The key variables in the bond model are future payments and the discount rate. When the forecast horizon is the same as the bond maturity, the discount rate is the yield to maturity. Except in the case of zero-coupon bonds (for which the only payment is principal value at maturity), future payments include periodic interest throughout the life of the bond and the bond's principal value at maturity. The vast majority of all bonds make coupon payments.

Investors face little uncertainty about receiving specified interest and principal payments from U.S. government obligations and only somewhat more uncertainty in the case of high-grade corporate obligations. The incidence of default among high-grade corporate bond issues in the past have been few. The degree of uncertainty increases with non-investment-grade bonds, especially during periods of worsening economic conditions. This discussion of long-term forecasting focuses on bonds with relatively little credit risk.

Because interest and principal payments on high-grade bonds are reliable, the only significant risk is that the real value of such payments may decline. The risks of real loss resulting from inflation, primarily unexpected inflation, are greater than the risk of a default in payments because a real loss caused by inflation affects all long-term fixed-income issues. Example 2.1 illustrates the contrast. 
Example 2.1: A portfolio of 10 equally weighted bond issues, all of which mature in 20 years, will lose 62 percent of its real principal value if the rate of inflation is 5 percent a year in that time period. If the portfolio experiences complete default on principal payments of three of its issues at maturity (an extreme assumption) but no inflation-caused change, it will suffer only a 30 percent loss of real principal value.

When a high-grade bond issue first comes to market, its interest coupon rate is generally set to cover its risks and the expected rate of inflation. The inflation rate assumed for the coupon appears to be heavily influenced by retrospective inflation patterns plus some analysis of recent and prospective monetary and fiscal policies.

Because the discount rate on bonds should reflect both the expected rate of inflation and their riskiness at the time of analysis, the history of investmentgrade bond yields to maturity and their relationship to rates of inflation are useful in forecasting future yields to maturity and interim holding-period returns (HPRs). Table 2.1 provides a summary of the relationship between U.S. Treasury bond yields and inflation (the CPI) in each of the previously identified inflation periods.

Table 2.1. Twenty-Year T-Bond Yields and the Rate of Inflation

\begin{tabular}{lcccccccc}
\hline & \multicolumn{2}{c}{ Estimated Par T-Bond Yields $^{\mathrm{a}}$} & & \multicolumn{3}{c}{ CPI Rate of Inflation } \\
\cline { 2 - 3 } \cline { 7 - 8 } Periods & High & Low & Average & & High & Low & Average \\
\hline $1940-65$ & $4.54 \%$ & $2.05 \%$ & $3.08 \%$ & & $18.2 \%$ & $-1.8 \%$ & $3.2 \%$ \\
$1966-81$ & 13.74 & 4.59 & 7.82 & & 13.3 & 3.0 & 7.0 \\
$1982-92$ & 11.87 & 7.43 & 9.21 & & 6.1 & 1.1 & 3.8 \\
\hline
\end{tabular}

Note: Only since 1940 have fully taxable T-bonds been issued.

aBased on year-end yields from Coleman, Fisher, and Ibbotson (1993).

bBased on annual CPI data from Ibbotson Associates (1997).

The range of inflation between 1940 and 1965 shown in Table 2.1 is misleading. With the exception of the first two years of U.S. participation in World War II (1941 and 1942), the first two post-war years (1946 and 1947), and the first two years of the Korean War (1950 and 1951), calendar-year inflation rates varied within a range of 3.2 percent and -1.8 percent and averaged only 1.4 percent. Because interest rates were controlled in the United States during most of the 1940-51 period, the same may be said of the interest rate figures in the low-inflation period through 1965. In the absence of the controls, average interest rates probably would have been higher. 
While inflation was growing between 1966 and 1981, the bond market was very slow to respond. During this era, inflation was not expected to last as long as it did or grow at such a high rate. In hindsight, we can see that interest rates should have been moving up more rapidly than they did, but inflation expectations proved to be naive throughout most of the period. U.S. investors were unaccustomed to anything more than temporary inflation.

When disinflation began in 1982, again the bond market responded cautiously. This caution is reflected in the 5.4 percentage point spread between the average bond yield and the average CPI in the 1982-92 period. Even now, in early 1997, that spread is about 4.0 percentage points (pps), well above long-term historical norms. The 1966-81 bond losses (not only in price declines but especially in purchasing power) are still embedded in the psyche of the market (Gray 1984 and 1993). The abnormally large risk premiums and declining interest rates have generated extraordinary bond investment returns. Between 1982 and 1995, the HPR of 14.6 percent a year on long-term T-bonds was within 2 pps of the HPR on stocks.

As long as long-term bond risk premiums include a significant component for uncertainty about possible reinflation, bond returns should, unless inflation resumes an extended upward course, continue to be well above their historical average for long time periods.

\section{Stock Market Factors}

The key variables for the stock market are also future payments and the discount rate, but the characteristics of these factors are distinctly different from those of the same factors for bonds.

The future payments from stocks are dividends (usually quarterly) and, ultimately, the proceeds from investors selling or corporate issuers buying back their stocks. Dividends are paid at the discretion of a company's board of directors, and some stocks do not pay dividends, of course; for example, young and/or rapidly growing companies may not pay dividends because of internal capital requirements. Moreover, companies will sometimes suspend dividend payments because of a shrinking availability of liquid funds, which is often the result of business difficulties. A vast majority of stocks in the S\&P 400 or 500 indexes, however, make dividend payments during every calendar year.

The history of large samples of companies (for the S\&P 400 history, see Appendix B) indicates that dollar dividend payments have been in a moderately rising trend over the long run. The percentage increase tends to vary from year to year. Occasionally, the amount paid actually declines, but the only significant (i.e., more than 5 percent) declines in S\&P 400 dividends were during the Great Depression (when they declined 59 percent between 1929 
and 1933), during the severe recession of 1937 and 1938 (when they declined 42 percent), and in 1942, the first year of U.S. participation in World War II (when they declined 19 percent).

Earnings, which are the source of most dividend payments, are much more volatile than dividend payments. Nevertheless, historically, the S\&P 400 has also had a moderately rising pattern of reported earnings. In the 67 years since 1929, year-to-year earnings declined in 23 years, but in only 7 cases were the declines greater than 20 percent. Only two of those (1982 and 1991) occurred in the past 50 years, and both reflected business recessions.

Total dividend payments each year are important because the amount is the only fairly predictable payment to which stock prices can directly relate (because the ultimate selling price is much more uncertain). But dividend payments are most important as a component in calculating the return needed to cover the expected rate of inflation and a prospective real return that compensates for risk.

The long-term growth rate expectation implied in the pricing of stocks and the stock market draws heavily on long-term historical trends. Until the past decade or so, the trend in dividend payments might have been deemed the most relevant factor (Gray 1984). With the rise of stock-repurchase programs, however, which was an important phenomenon in the corporate restructuring era that began in the early 1980 s, earnings trends have become more important, at least for now. Because lower dividend payout ratios were the corollary of diverting cash to the repurchase of outstanding shares, the growth rate of dividends has fallen behind that of earnings. Furthermore, the repurchases have resulted in increased growth rates of earnings per share.

Whatever the source of long-term growth rate expectations, these expectations have a powerful influence on the valuation of common stocks. In effect, at any given time, they impart a sense of the potential for long-term price appreciation, which has important implications for price levels in the future when the end of the stream of payments occurs (for instance, at the time of sale). In addition, the growth rate expectations have two (sometimes unrecognized) effects on the other major variable in the stock market valuation model- the discount rate.

The discount rate should reflect a combination of the expected rate of inflation and risks perceived at the time of analysis. One risk seldom noted is that the expected long-term growth rate may fall, especially after it becomes unusually high. In such circumstances (and assuming other factors are unchanged), the real discount rate should be a bit higher than it would be otherwise. Such circumstances will most likely be accompanied by an increase in the dividend yield that, if it happens, will come about by means of a decline in stock prices. 
The other effect on stock prices involves the relationship between the growth rate expectation and the discount rate (i.e., what magnitude of dividend yield is required to provide the stock market's required return). When the dividend yield adjusts to changes in the growth rate expectation, everything else being equal, the absolute size of the dividend yield $(D / P)$ at that time has much to do with latent stock-price volatility, as shown in Example 2.2.

Example 2.2: A 20 basis point rise in dividend yield from 2 percent has about twice the impact on price as the same basis point rise has from a 4 percent dividend yield.

Dividend yields on the S\&P 400 and 500 of approximately 2 percent in early 1997 suggest that investors should anticipate more inherent price volatility from this factor than the stock market has ever had. By itself, that volatility should, when this latent aspect is more broadly recognized, increase the stock market discount rate. As a possible partial offset, the "tax premium," if any, within the discount rate will tend to be somewhat less to the extent that the tax rate on capital appreciation is less than it is on dividends. Whether stock prices in the long term are significantly affected by tax rates differences is discussed briefly in Appendix C.

The more conventional view of stock market riskiness is that it relates to uncertainty about the amount and timing of future dividends and proceeds of stock sales. ${ }^{1}$ Perceptions about such uncertainty appear to be affected by the volatility of earnings and stock prices. Such volatility reflects the stability/ volatility of the U.S. economy, its operating leverage, the leverage in its capital structures, and possibly, the extent to which corporate accounting flexibility may unsuccessfully disguise the underlying reality. ${ }^{2}$ Except for the early 1990 s, when volatility was affecting some new Financial Accounting Standards Board requirements, earnings volatility has moderated since World War II. Not surprisingly, the volatility of total returns in the stock market has also been lower than it was prior to 1966 . Table 2.2 shows HPR volatility for stocks (and bonds) in three subperiods of the 1926-96 period. Such changes are doubtless a major cause of post-1950 reduction in the real (inflation-adjusted) discount rate in the stock market.

The institutionalization of the market since World War II appears also to have reduced the real discount rate. Initially, institutionalization affected primarily blue chip stocks, but since 1974, when the U.S. Congress adopted the Employee Retirement Income Security Act, it has also enveloped smallcapitalization stocks. This phenomenon has resulted in much greater diversi-

\footnotetext{
${ }^{1}$ For an early discussion of key factors that affect perceptions of riskiness and their impact on the risk premium of common stock expected returns, see Gray (1984).

${ }^{2}$ For a discussion of the macroeconomic variable, see Diermeier (1990).
} 
Table 2.2. Rate of Return Volatility: Stocks and Bonds

\begin{tabular}{lccc}
\hline Asset Class & $\begin{array}{c}1926-66 \\
\text { (noninflation) }\end{array}$ & $\begin{array}{c}1967-81 \\
\text { (inflation) }\end{array}$ & $\begin{array}{c}1982-94 \\
\text { (disinflation) }\end{array}$ \\
\hline Annualized standard deviation & & & \\
S\&P 500 & $23.19 \%$ & $18.16 \%$ & $11.86 \%$ \\
Long-term corporate bonds & 4.19 & 8.59 & 12.56 \\
Long-term T-bonds & 5.01 & 7.38 & 13.56 \\
Intermediate-term T-bonds & 3.05 & 4.62 & 8.39 \\
30-day T-bills & 1.41 & 3.01 & 2.41 \\
Monthly standard deviation (annualized) & & & \\
S\&P 500 & 22.49 & 15.35 & 15.12 \\
Long-term corporate bonds & 3.67 & 10.46 & 8.70 \\
Long-term T-bonds & 4.23 & 10.90 & 10.51 \\
Intermediate-term T-bonds & 2.53 & 6.51 & 5.44 \\
30-day T-bills & 0.42 & 0.84 & 0.69 \\
\hline
\end{tabular}

Source: Wick (1995).

fication of common stock holdings, which reduces the relevance of the unsystematic risk inherent in individual common stocks. It may also be the most significant implication of the capital asset pricing model (CAPM).

Another phenomenon that clearly affects the stock market discount rate is the ebb and flow of investor risk aversion. It is most vividly apparent in the pattern of stock market price movements related to business cycles. ${ }^{3}$ Recognition of these well-established tendencies is important in attempting to forecast 5-year to 10-year HPRs. Whether any secular trend has occurred in risk tolerance is hard to judge, but any significant trend seems doubtful. Time will be needed to judge any lasting downward impact on the stock market discount rate arising from the proliferation and growth of $401(\mathrm{k})$ plans.

\section{Equivalency Factors}

The key variables in the equivalency model are the respective discount rates for bonds and stocks and the difference between the rates, which is the equity risk premium. My early studies in the development of long-term forecasting methods established that the spread between estimated stock returns and known bond returns had informational value. An initial study (Gray 1974) covering 1966 through mid-1973 that used a constant 5 percent nominal growth rate expectation for stock returns (compared with long-term bond yields)

\footnotetext{
${ }^{3}$ Vivid graphics on the magnitude of recession-related changes in the dividend yield are provided in Chapter 4.
} 
generated equity risk premiums that had strong inverse correlations with S\&P 400 price levels. A series of studies (Gray 1979) covering 1952 through 1977 that used three-year to five-year trailing dividend growth rates to represent growth rate expectations generated equity risk premiums that correlated highly with contemporaneous HPR spreads, especially those covering fouryear periods that straddled the respective risk-premium measurement dates. ${ }^{4}$

In summary, if bond and stock market expected returns are moderately stable, related equity risk premiums should be very useful forecasts. Because stability is only sometimes the case, however, credible estimates of expected bond and stock market HPRs are needed. The components of the equity risk premium that have the major effect on the price appreciation component of HPRs are dividend yields for stocks and risk premiums for bonds. Chapter 6 addresses these crucial aspects and the overall framework for long-term forecasts.

\footnotetext{
${ }^{4} \mathrm{~A}$ review of the real-time application of these risk-premium measures since 1976 is provided in Chapter 3.
} 


\section{The Equivalency Model: Stocks versus Bonds}

Prior to the establishment of expected return measures for the stock market, dividend yields or earnings yields were used, but they were clearly deficient measures of expected return. They might at times indicate that stock prices were "too high" or "too low," but they gave no indication of long-term holdingperiod returns (HPRs). When dividend or earnings yields were compared directly with bond yields to maturity, they provided no indication of the spread between stock and bond HPRs.

Casual examination of earlier stock market history indicates that, over long periods of time, stock prices have essentially paralleled earnings and dividends. For example, the level of the S\&P 400 Index (market index) rose from an average 21.35 in 1929 (a price-to-earnings ratio of 16.4 times) to an average 99.18 in 1967 (a P/E of 17.6 times) -an appreciation of 4.1 percent a year. The S\&P 400's earnings per share (EPS) went from 1.30 in 1929 to 5.62 in 1967 -an increase of 3.9 percent a year. ${ }^{1}$

In the early 1970s, my work at Harris Bank led me to believe that a credible proxy for likely future total return experience was long-term earnings or dividend growth rates (as a proxy for price appreciation) plus the current dividend yield. It seemed almost certain this measure would be superior to either dividend yield or earnings yield. This measure is commonly called "expected return," and it represents an estimated investment value model (IVM) discount rate for the stock market.

\section{Model Testing}

To examine the expected return measure in more detail, I compared the expected return on stocks with the expected return on bonds monthly for the period 1966 through mid-1973 (Gray 1974). The earnings growth rate was assumed to be 5 percent a year, the approximate growth rate since shortly after World War II. The equity (stock) risk premiums (SRPs) generated in that study and the bond yields to maturity were subjected to curvilinear regression analysis. A strong inverse correlation between the level of bond yield and the SRP was found. Panel A of Figure 3.1 plots monthly S\&P 400 prices, and

\footnotetext{
${ }^{1}$ Milne (1974) reported that S\&P 500 prices, earnings, and dividends increased, respectively, 3.04 percent, 3.00 percent, and 2.84 percent a year during the 99 years from 1871 to 1970 .
} 


\section{Figure 3.1. S\&P 400 (formerly S\&P 425) Price Movements around Regression on Bond Yields and Common Stock Expected Returns}

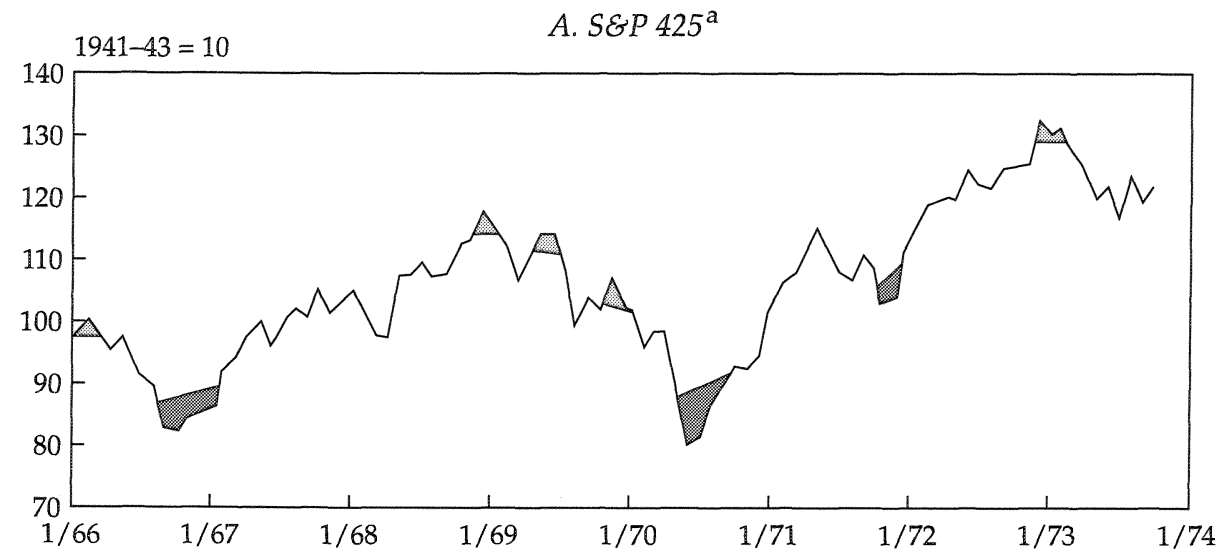

B. Spread between Expected Return on Common Stocks and Yield on AA-Rated Utility Bonds: Deviation from Regression Line

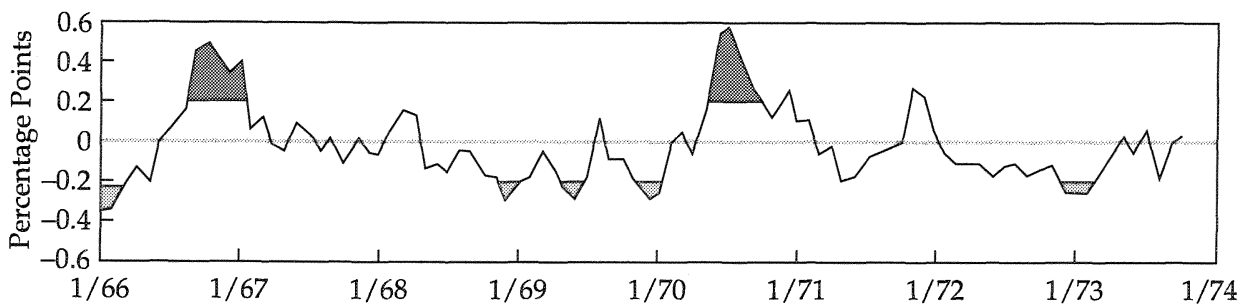

Monthly figures.

Source: Gray (1974).

Panel B shows the results of the regression study-the variation in spread between common stock expected returns and the yield on high-grade corporate bonds around a horizontal representation of the regression line.

The shaded areas around the peaks and troughs of these two time series suggested a potential opportunity for market timing: The timing of the two largest positive SRPs (late 1966 and mid-1970) coincided with the S\&P 400's two lowest points during the seven and a half years plotted. 
The price changes that followed the high and low points in this SRP measure were only part of the ensuing stock market total return, but they were a major part in all years except 1970 . Although not sufficient to validate SRPs as a credible indicator of the proximate HPR spreads, these results were encouraging.

Later, I undertook a more extensive study of somewhat similarly derived SRPs as an estimate of HPR spreads; it covered a 25-year period-from 1952 through 1977 (Gray 1979). In this study, expected growth rates at each yearend were based on a variety of trailing dividend growth rates, anywhere from the latest one-year period to the latest five-year period. Each growth rate was combined with the average dividend yield of the year then ended. The process provided five sets of expected returns on stocks (ER[S]) for each year. ${ }^{2}$

Each of the 25-year expected-return time series was compared with an ER(B) (expected bond yield-to-maturity series, namely, Standard \& Poor's composite bond yields). The result was five 25-year time series of SRPs. Each of these risk-premium series was compared with various time series of 1952-77 HPR spreads (stocks versus bonds) in which HPRs for any given year represented the experience of $1,2,3,4$, or 5 proximate years. Such experiences were lagged $0,1,2$, or 3 years. The result involved a total of 100 correlation studies for the 25-year period, as shown in Example 3.1.

Example 3.1: At the end of 1952, in one correlation study, the ER(S) was 16.7 percent (a trailing five-year dividend growth rate of 11.2 percent plus a current dividend yield of 5.5 percent) and the ER(B) was 3.0 percent (i.e., the SRP was 13.7 percent). The HPRs for stocks and bonds were, respectively, 22.0 percent and 2.4 percent for the four years ending in 1954 (two years later); that is, the HPR spread was 19.6 percent a year. This and 25 similar sets of calculations for the other years in the 1952-77 period were subjected to correlation analysis.

The correlation studies were very encouraging. Figure 3.2 shows the patterns of estimated ER(S)s and corporate bond yields (Panel A) and SRPs (Panel B) and Figure 3.3 shows the actual stock and bond returns (Panel A) and the HPR spreads (Panel B) for the 1952-77 period. ${ }^{3}$ In that period, all SRPs had positive correlations with all the series of HPR spreads examined. Not surprisingly, the strongest correlations were those using four or five years of dividend history for the growth rate assumption and four or five years of HPR spreads lagged by one to three years. The best correlation resulted from

\footnotetext{
${ }^{2}$ For other tested approaches to estimating expected returns, see Vandell and Kester (1983).

${ }^{3}$ At that time, I referred to the equity risk premium as "expected return point spreads."
} 
Figure 3.2. Expected Equity Returns, Corporate Bond Yields, and Equity Risk Premiums

A. Expected Common Stock Return and Corporate Bond Yield

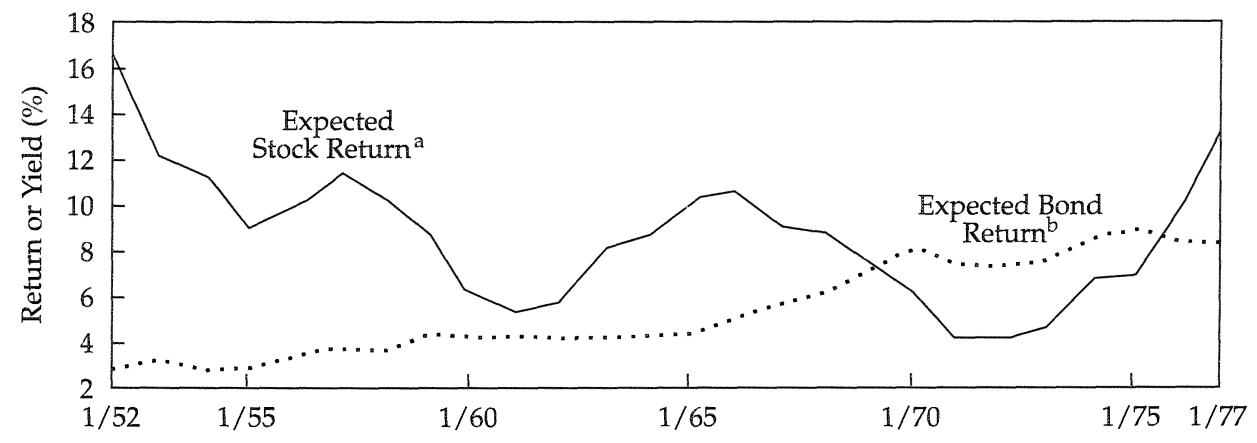

B. Expected Spread

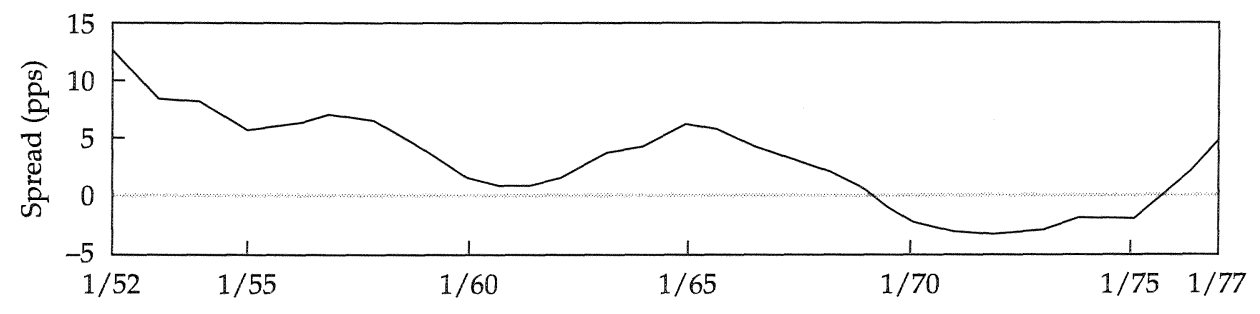

aDividend yield plus five-year compound rate of dividend increase.

bS\&P composite bond yields.

Source: Gray (1979).

a trailing five-year dividend history for the growth rate and four-year periods of HPR spreads lagged by two years (e.g., 1951-1954 for year-end 1952). The correlation coefficient was 0.919 in this case; in 17 other cases (out of 100), the correlation coefficient was 0.75 or better.

Although not evident from Figures 3.2 and 3.3, the dividend yield experienced a downward trend from 5.5 percent in 1952 to 2.6 percent in 1972 . The S\&P 400 appreciation-more than 8.3 percent a year-would have been only 4.4 percent a year if the dividend yield had remained at 5.5 percent. Between 1972 and 1977, the yield increased from 2.6 percent to 4.6 percent. During this latter period, the S\&P 400 level-down 2.3 percent a year-would have risen 9.3 percent a year if the dividend yield had stayed at 2.6 percent. I did not recognize the full significance of these yield changes at the time these studies 


\section{Figure 3.3. Actual Equity Returns, Bond Returns, and HPR Spreads}

A. Actual Common Stock Return and Corporate Bond Return ${ }^{\text {a }}$

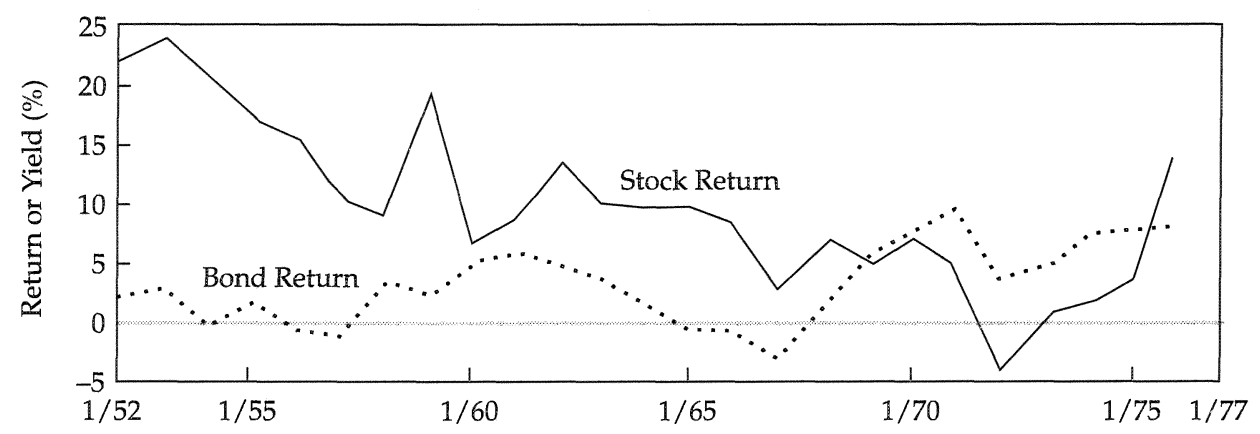

B. Actual Spread

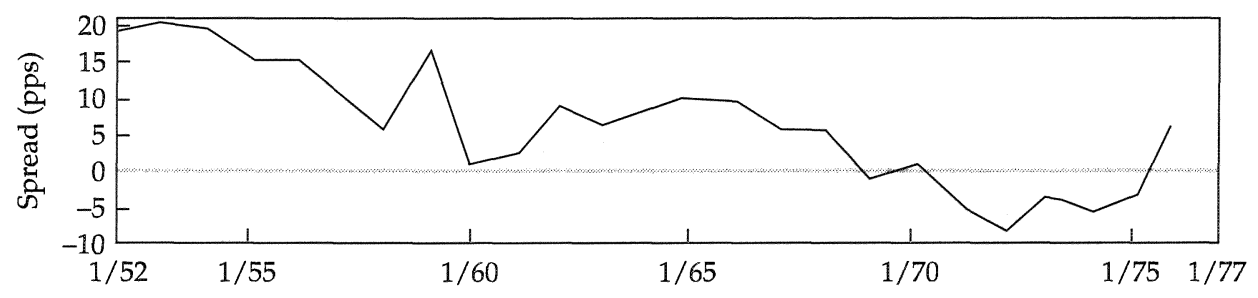

aFour-year annual compound rate lagged by two years.

Source: Ibbotson and Sinquefield (1977); Gray (1979).

were completed in 1978. The changes, however, largely accounted for the fact that HPR spreads were mostly somewhat larger than SRPs when the premiums were positive and the spreads were somewhat smaller than the risk premiums when they were negative. Figure 3.4, showing expected spreads against actual spreads and the regression line for the 1952-77 period, provides visual evidence of the high correlation between IVM-derived SRPs and proximate HPR spreads.

The equilibrating role of the dividend yield helps explain the 1952-77 experience. ${ }^{4}$ In general, understanding of the dividend yield's role is vital to the most effective use of the SRP for long-term forecasting.

${ }^{4}$ The equilibrating role of the dividend yield is examined in Chapters 4 and 5. 
Figure 3.4. Correlation of Expected Return

Spreads and Actual Return

Spreads, 1952-77

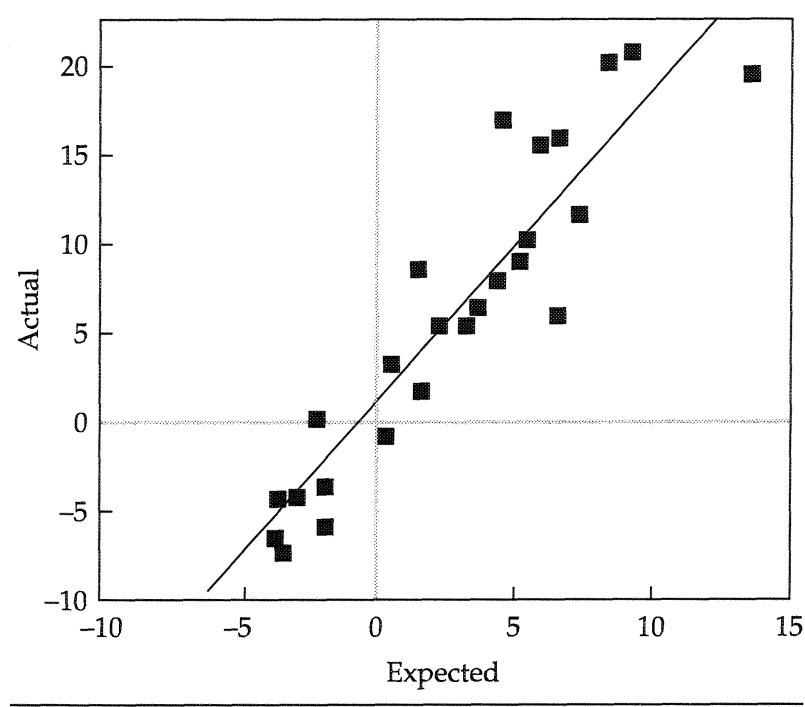

Source: Gray (1979).

\section{Application of Model}

As a result of these findings, use of the regression equation from the strongest correlation of the 1952-77 studies seemed promising. The equation was

$$
y=1.7929 x+0.7175,
$$

where $y$ is the HPR spread and $x$ is the SRP.

To start, because the four-year period HPR spread straddled year-end 1977, the actual HPR spread for the first two years was already known. I used these two years of experience to derive a residual estimated HPR spread for the remaining two years. The calculations are shown in Appendix D. In this case, the inferred HPR spread for the remaining two years was 22.9 percent a year. The actual HPR spread turned out to be 14.4 percent a year.

The next step was to translate the approach to quarterly measurement periods, which would be more useful than annual periods as a tool for tactical asset allocation. Accordingly, the test was rerun for the 1952-77 period with quarterly data (in other respects, the test was the same as the "best" of the original 100 correlation studies). The resulting regression equation was

$$
y=1.71177 x+1.14582 \text {, }
$$


with an $R^{2}$ of 0.787 . This $R^{2}$ was somewhat less than the best $R^{2}$ from the annual frequency studies.

Figure 3.5 shows the pattern of the two-year forecasted and actual HPR spreads. During the first eight years, the estimated two-year HPR spreads worked well for forecasting actual spreads, albeit less well toward the end of that period. Then, March 31, 1984, turned out to be the beginning of a fiveyear period in which the model-based estimates were consistently below the ensuing spreads. The last two quarterly estimates of 1984 were $15-18$ percentage points (pps) below the actual two-year return spreads. The first three quarterly estimates of 1985 suffered even larger discrepancies. Although the final outcome of each estimate was never known until the respective following

Figure 3.5. Two-Year Return Spreads between Stocks and Bonds: Forecast History, March 31, 1976, to December 31, 1992

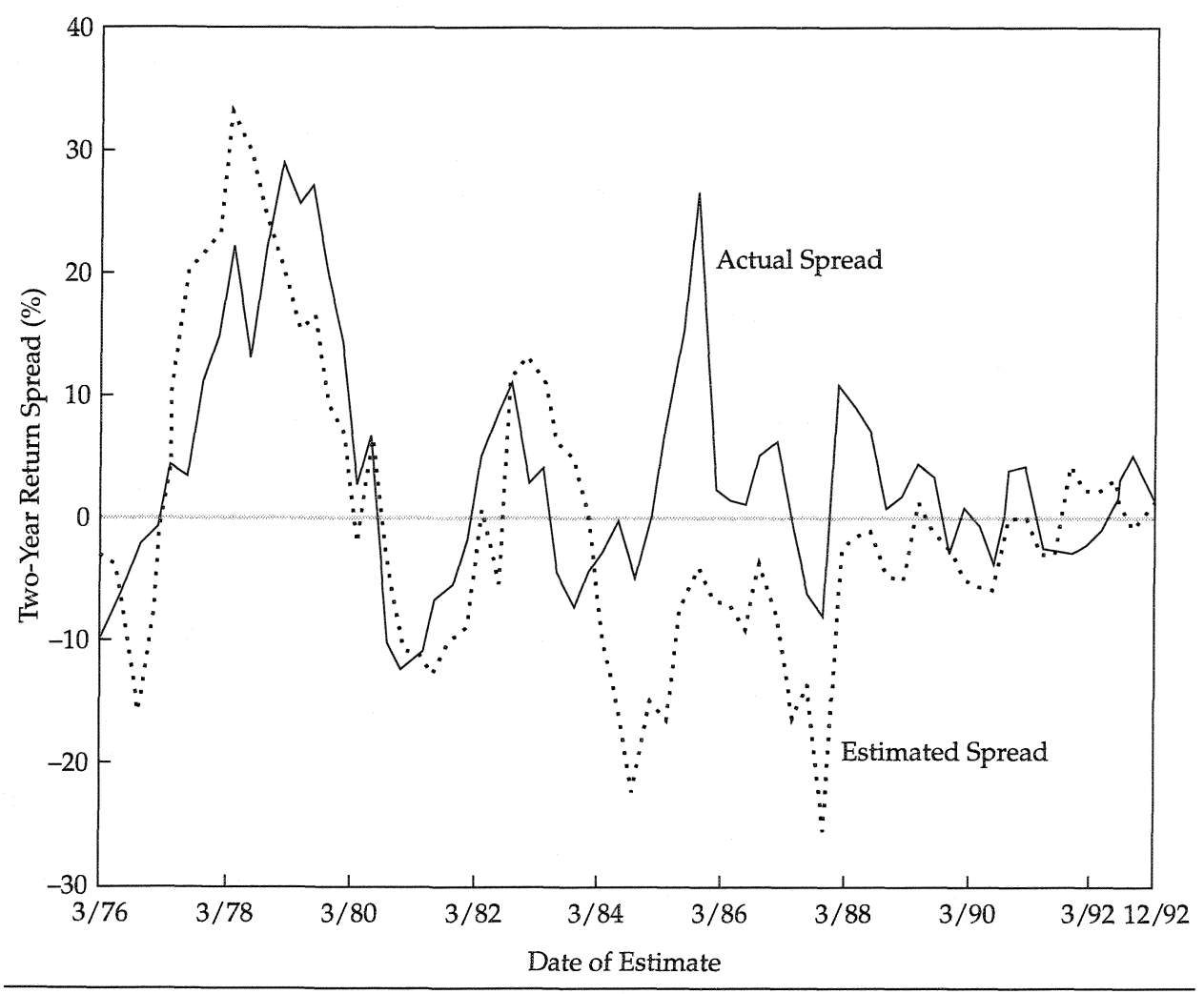

Notes: Dates as of March 31. Average $R^{2}$ is 0.42 by taking each of the first four forecast quarters as the starting point for a separate set of nine nonoverlapping two-year periods.

Source: Wick (1995). 
two-year period had ended, the interim experiences were becoming disturbing. Why, after more than 30 years of seemingly consistent behavior in the spreads, were these enormous aberrations occurring?

Two thoughts seem particularly pertinent:

- The trailing five-year dividend growth rates from year-end 1984 through 1987 were roughly $3.0-4.5$ percent. As of the same four year-ends, the trailing five-year growth rates in gross domestic product (GDP) were 7.28.8 percent. Clearly, the trailing dividend growth rates were not even close to indicating the market's sense of future prospects. Although not recognized at the time, the clearest indication of these improving growth prospects was provided by the dividend yield, which was moving significantly downward.

- Long-term bond yields declined almost 300 basis points (bps) between 1981 and 1985-from 14.3 percent to 11.4 percent-while the trailing three-year Consumer Price Index (CPI) inflation rate dropped about 770 bps-from 11.5 percent in 1981 to 3.8 percent in 1985. At first, corporate bond price appreciation seemed to be significantly limited by a pervasive lack of significant call protection. Later (by 1987), the bond risk premium (i.e., long-term bond yield minus the expected inflation rate) clearly had become enormous. The probable reason was a lingering need for bond investors to hedge against the possibility of higher inflation in the future.

\section{Reevaluation of the Model}

Because of these changes in the model's predictive power, a reevaluation of the model began in early 1987 . Some commentary on, or personal judgments about, the specific quantitative output of the model seemed necessary. From June 30,1987 , through September 30, 1988, the commentaries clearly advised that the model output was much too pessimistic. ${ }^{5}$ Even after personal judgments were expressed, however, the disparities in the two-year forecasts between the estimated and the actual two-year HPR spreads continued to be sizable through the end of 1988.

A factor that exacerbated the poor results of the various two-year estimates from late 1985 through late 1987 was the effect on the estimates of the stock market overvaluation and then crash of October 1987. From the S\&P 400 peak in August 1987 until late 1994, the index was up less than 5 percent a year. Because dividend returns averaged less than 3 percent a year during that period and inflation was about 4 percent a year, the real return from stocks was

\footnotetext{
${ }^{5}$ These commentaries were fairly explicit, which made it possible to extract a close approximation of the two-year HPR spreads through March 31, 1990, which were used instead of the model's output to represent the experience reflected in Figure 3.5.
} 
well below the long-term average of 6.5 percent. A period of that length (more than seven years) with below-average real returns is a pretty good indication of a market in which prices were too high at the beginning of the period. ${ }^{6}$

After five years of very disappointing estimation results (early 1984 through early 1989) some specific changes in the forecasting model itself were made (Gray 1987-1995, specifically, July 17, 1989):

- Henceforth, the growth rate reflected in the variable for expected return on stocks in the equivalency model would approximate the secular nominal GDP growth rate expectation unless strong reasons suggested otherwise. (At that time, a 7 percent growth rate was chosen, but in mid-1993, it was reduced to 6.5 percent.)

- I would no longer use the equation applied to each SRP $(y=1.71177 x+$ 1.14582) to generate the expected straddling four-year HPR spread. Clearly, the stock market discount rate had declined substantially from 1952 through 1987 (including a run-away stock market at the end). This decline could have accounted for at least a 1.5 percent a year increment of historical (1926-96) return that might have been "nonrecurring."

\section{Evaluation of Results}

Following these changes, the modified equivalency model generated two-year HPR spreads that were quite credible. In some instances, personal judgments led to modestly adjusted estimates, but in most cases, the model's estimate itself was used. Furthermore, as can be seen in Figure 3.5, the actual two-year HPR spreads have closely mirrored the estimated spreads since early 1989 (through 1992).

Taken as a whole (and considering its evolution), the model seems fine. Its limitations are related primarily to the assumptions about long-term growth rates on the equity side and the magnitude of the risk premium on the bond side. The equivalency model has been very useful in nurturing perspectives on long-term forecasting. In general, during periods in which key factors are fairly stable, an IVM-related equivalency model should perform well. When one (or both) of the factors undergoes significant change, judgment will be required to modify the model's output to produce estimates that better foretell actual experience. In any event, the model provides a framework that helps keep these crucial variables in perspective and provides discipline in the forecasting thought processes.

\footnotetext{
${ }^{6}$ A forecasting model that can foretell the timing and degree of financial market extremes seems very unlikely ever to be developed.
} 


\section{IVM Governs Behavior of the U.S. Stock Market, 1929-1996}

Most kinds of investigative work require good intuition about where to look for vital information and about how to examine it once it has been found. These requirements apply to investigating the behavior of financial markets as well as the work of intelligence agencies. With the plethora of economic and financial data on the U.S. markets reaching back to the mid-1920s, the challenge is not how to find information but how to view it. Essential elements of a useful view are summarized in the investment value model (IVM) approach as follows:

- Focus on the variables that influence long-term returns and how they are structured in the equity version of the IVM (i.e., the current dividend, the dividend yield, the expected growth rate, and the equity discount rate).

- Focus on real rates; that is, expected growth rates and estimated discount rates should be adjusted for inflation.

- Analyze historical data to identify long-term patterns. For growth rates, the data are macroeconomic (gross domestic product [GDP] and gross national product [GNP], national income, and corporate profits) and corporate (e.g., S\&P 500 Index and S\&P 400 Index earnings per share [EPS] and dividends per share [DPS]. ${ }^{1}$ For discount rates, the data are estimates based on the equity return model with an awareness of the behavior of equity returns in the proximate holding periods (which can be found in Ibbotson and Sinquefield 1977 and Ibbotson Associates 1997).

- Focus on normalized trends to minimize business cycle distortions; for example, calculate past growth rates using peak-to-peak earnings years (two or more cycles).

\section{Important Long-Term Findings}

When my long-term forecasting methodology was developing in the late 1970 s, a reasonable assumption for the real (inflation-adjusted) long-term growth rate was 3 percent because real GNP (and later, GDP) in the United States had grown at about that rate since the late 1880 s. A few years ago, recalculation of 1926-93 real EPS and DPS growth rates for the S\&P 400

\footnotetext{
${ }^{1}$ See Appendixes E, F, G, and H.
} 
showed the rates to be, respectively, 2.0 percent and 1.6 percent a year. Even after allowing for the heavy "charges" related to corporate restructurings since the early 1980s and the significant Financial Accounting Standards Board accounting requirements in the early $1990 \mathrm{~s}$, the 2.0 percent real growth rate for EPS appeared to be too low relative to the 3 percent rate for GDP.

Furthermore, the volatility statistics on common stock returns made clear that the risks of equity investing had decreased since World War II. In addition, as increasing proportions of common stocks went into diversified institutional portfolios, the significance of unsystematic risk was diminishing. All of these developments strongly suggested that the long-term average real holding-period return (HPR) from common stocks (about 6.5 percent a year) reflected an equilibrium discount rate that had been trending moderately downward, at least since World War II (Gray 1993).

The result of these observations was a project initiated in early 1994 to focus on the 1926-93 earnings experience. The 67-year period was divided into subperiods bounded by the S\&P 400 earnings cycle peak years. There were 13 subperiods, an average of 1 every 5.15 years. About half of those peaks coincided with peak years in the business cycle; some of the others were one year on either side of those peak years. Table 4.1 provides a summary, based on S\&P 400 EPS and DPS data (and U.S. Consumer Price Index [CPI] figures to calculate real growth rates), with the results updated through 1996.

The most significant data, perhaps, are those indicating the time periods in which real EPS and DPS growth was negligible or negative. Apart from anomalous experiences in the 1955-59 and 1981-84 periods, such poor showings fell between 1929 and 1941 (the Great Depression and its ensuing painful recovery) and between 1968 and 1981 (a period of sporadically rising inflation). During most of the other time periods, real EPS and DPS growth rates were about as good or better than the rate of real GDP growth. In both the Depression and the periods of rising inflation, however, although real GDP growth rates were below average (2.2 percent and 2.8 percent, respectively), real EPS and DPS growth rates suffered severely.

The patterns of earnings growth data suggested that growth rates in the 1929-96 span should be examined within four larger subperiods, as shown in Table 4.2. Real earnings growth underwent two periods of erosion, each followed by an extended period of recovery. Another combines the two eroding periods and, separately, the two recovering periods, excluding the World War II period, which is shown by itself.

As the final column in Table 4.2 shows, the combined recovering periods, excluding 1941-1945, averaged real returns of 10.9 percent a year in the stock market, and the combined eroding periods averaged real returns of -1.6 


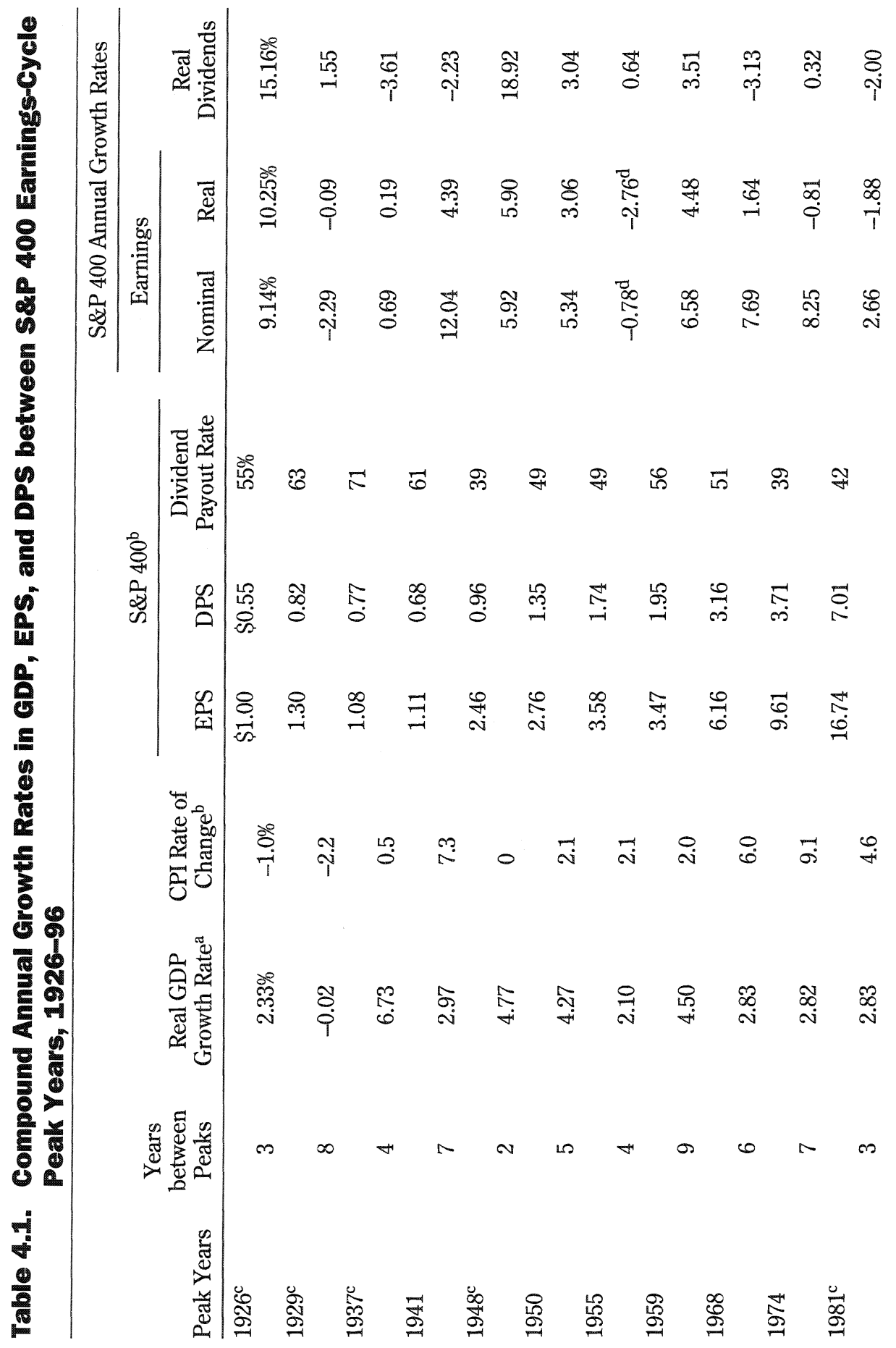




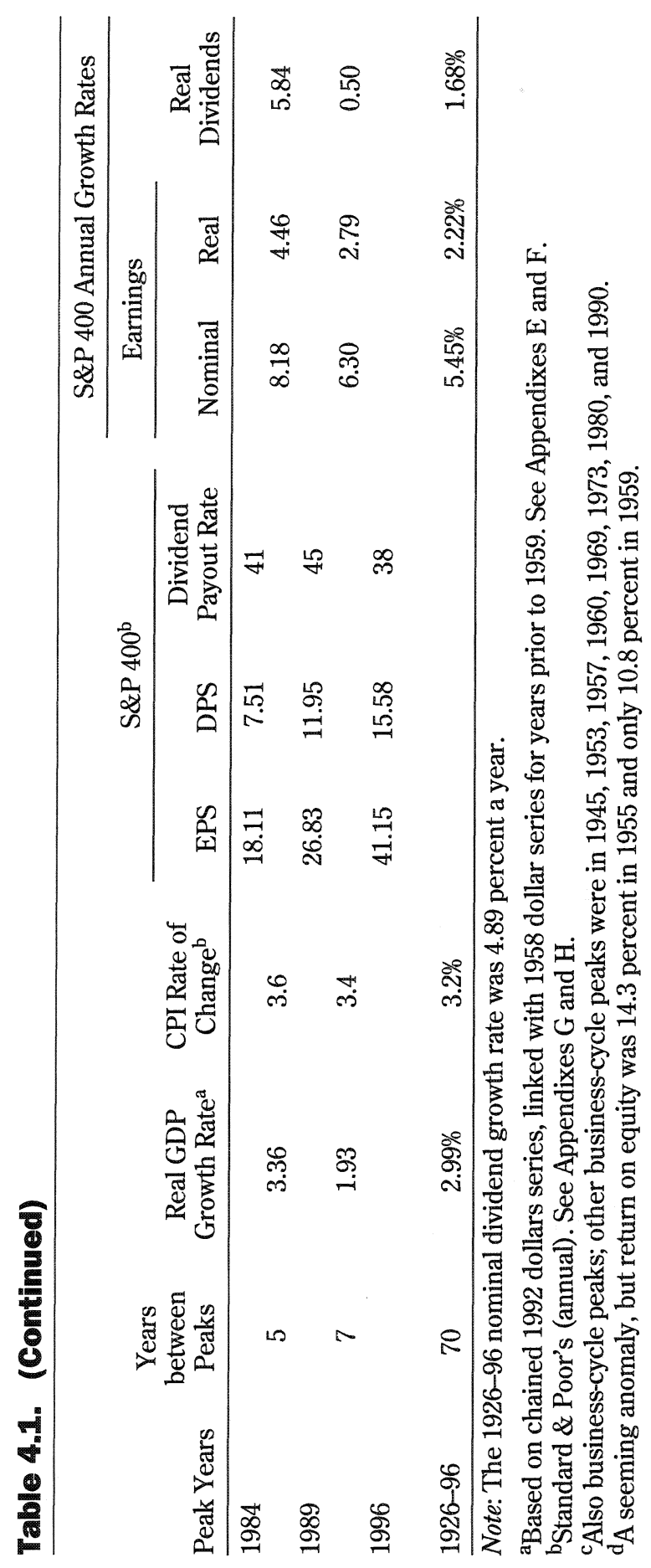

CThe Research Foundation of the ICFA 


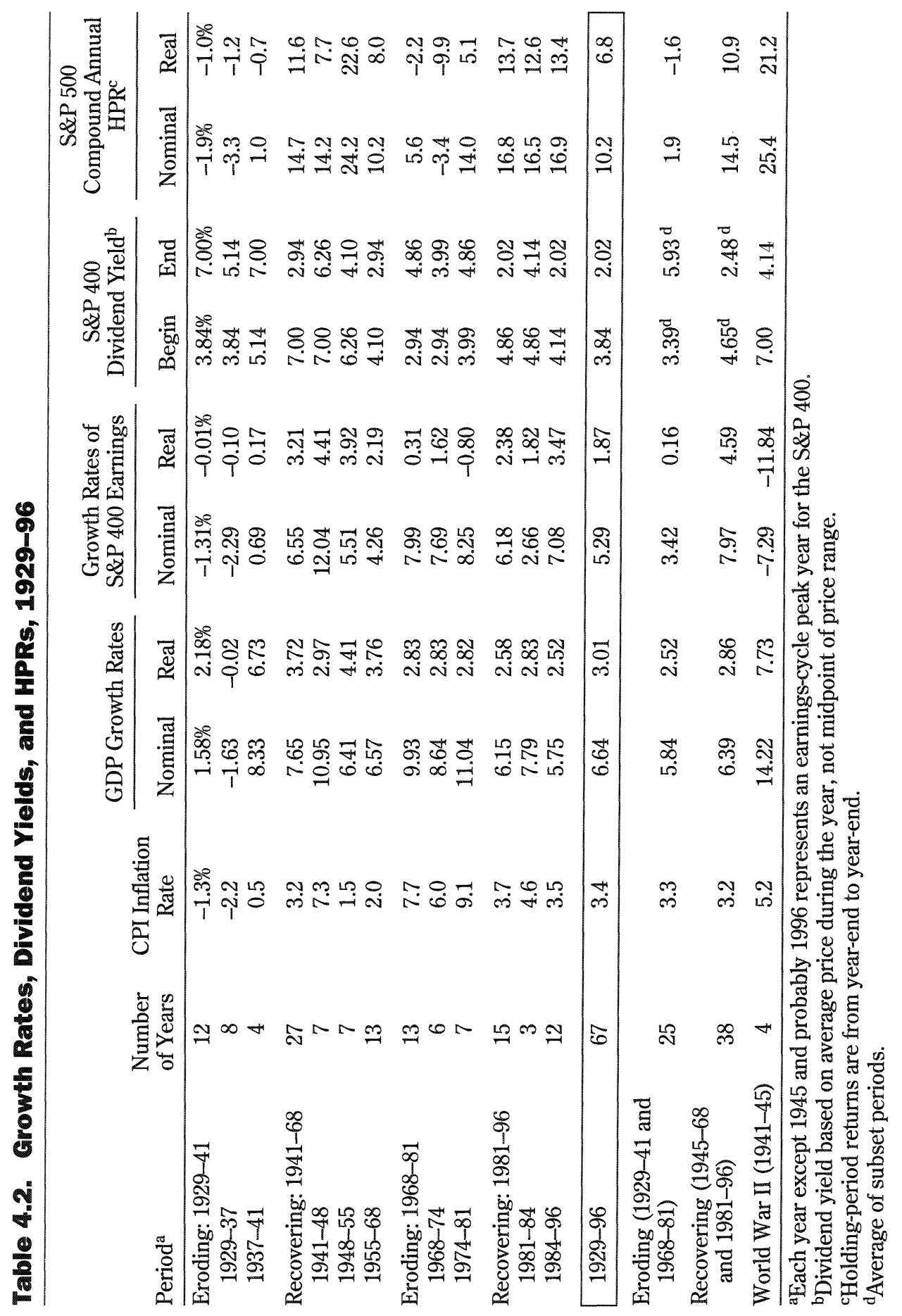


percent a year. During World War II, the S\&P 500 experienced large real returns. Because real earnings growth was sharply negative during those war years, the positive stock returns were probably attributable to perceptions of greatly diminished risk (that is, from investor fears in 1941 to considerable relief from ultimately winning the war without significant harm to U.S. production facilities) and the market's awareness of the extent to which profits were constrained by taxation and price administration during the war.

Viewed in chronological order, each eroding or recovering period reveals a stunning inverse relationship between the magnitude of dividend yields at the end of the period and respective trailing real earnings growth rates. When dividend yields were high, trailing real growth rates were low, and vice versa. Thus, at the end of each recovering period, dividend yields were 2.94 percent (1968) and 2.02 percent (1996); at the end of each eroding period, they were 7.0 percent (1941) and 4.86 percent (1981) ${ }^{2}$

At the era (i.e., large subperiod) boundary lines-1941, 1968, 1981, and 1996-trailing long-term real earnings growth rates appear to dominate future growth rate expectations; that is, as trailing experience changes over time, it appears to modify growth rate expectations. Based on the stock market patterns between 1929 and 1996, if the unfolding trailing pattern continues to change in the future (and assuming little or no change in either the riskiness of common stock holdings or the risk tolerance of investors), future growth rate expectations will also change. This behavior is implicit in the stock market model set forth in Chapter 1.

An increase in the expected real earnings growth rate tends to be accompanied by whatever price increase reduces the dividend yield by about the same amount. This powerful inverse relationship is shown in graphic form in Figure 4.1. A line (the "Yield Trend Line") links the dividend yields at the respective boundaries of each era, and a somewhat similar line (the "Expected Earnings Growth Rate") links the earnings expectations. In addition, the dividend yields of all other earnings-cycle peak years are shown. With the notable exception of 1950, when U.S. investors feared a post-World War II depression, the peak-year dividend yields fall somewhat along the straight lines connecting the boundary-line dividend yields. This picture is consistent with the perception that as a trailing earnings growth rate pattern unfolds, it is gradually accompanied by corollary inverse adjustment of the dividend yield.

At each of the boundaries, dividend yields and the respective trailing real earnings growth rates were added together. These five totals are indicated by

\footnotetext{
${ }^{2}$ The latest recovering period (which began in 1981) will not necessarily be followed by an extended eroding period. That outcome would certainly be possible, but an alternative would be the recovery followed by a "stable" period for some time.
} 
Figure 4.1. S\&P 400 Dividend Yield with Related Estimates of Expected Earnings Growth Rates and Discount Rates at Era Boundary Years

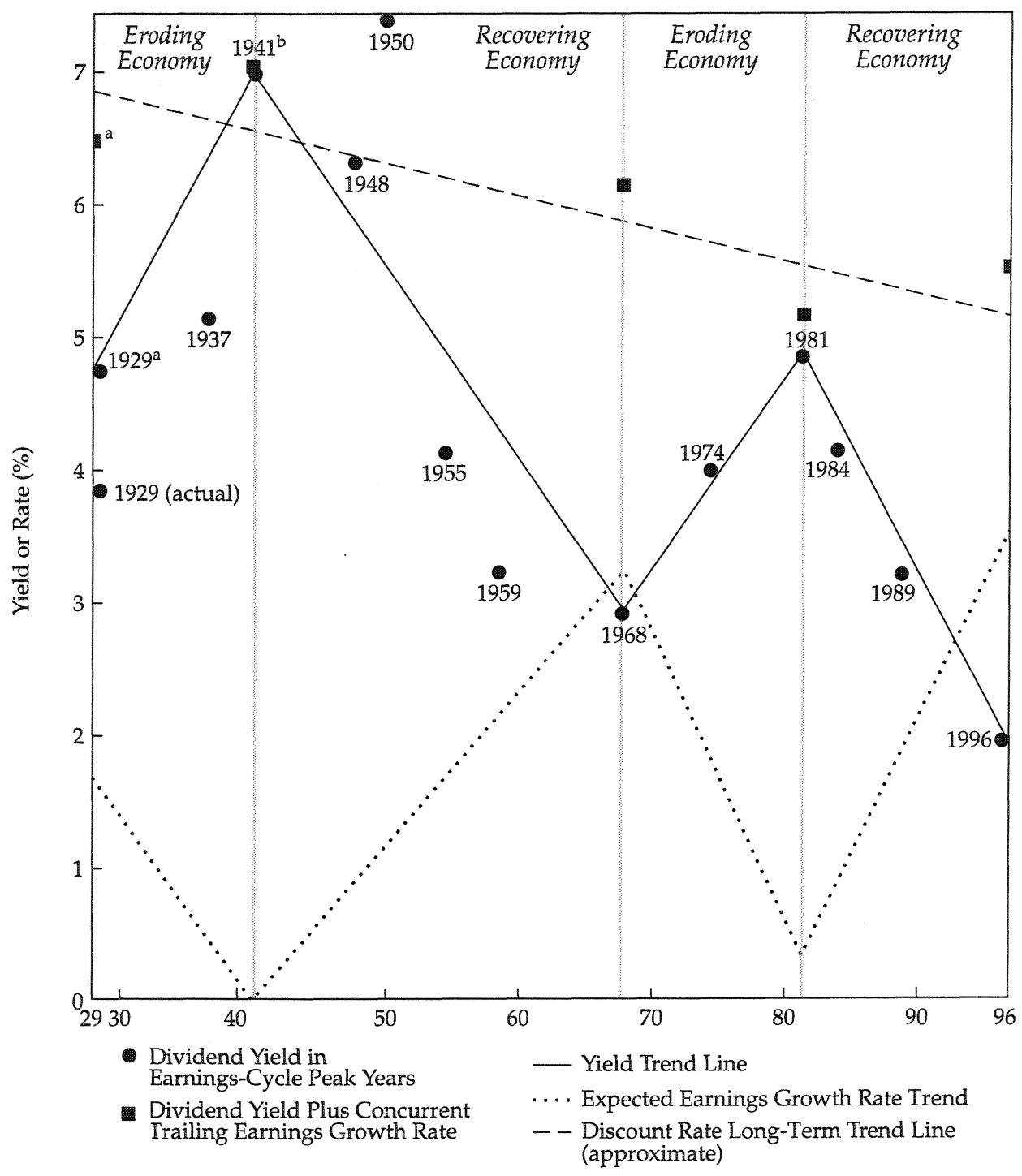

Note: Dividend yield based on average of daily closing prices in each year.

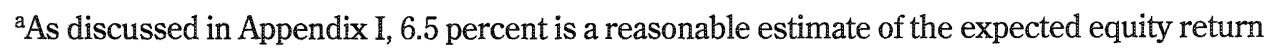
in 1929, and the use of a 4.8 percent yield proxy adjusts for a euphoric market in 1929 .

${ }^{b}$ At this point, the dividend yield and the dividend yield plus the trailing earnings growth rate are roughly equal because the trailing earnings growth rate was roughly equal to zero at this time. This equality occurred only at this point. 
squares, running from 6.50 percent in 1929 to 5.51 percent in 1996. An "eyeball" regression line drawn through the pattern of estimated real discount rates has a moderately descending slope; the total $67-y e a r$ decline is about 1.5 percentage points (pps) (Gray 1993). It is my judgement that most of this reduction in the real discount rate occurred between the early 1950s (the measurable riskiness of stock ownership declined after World War II) and the late 1970s.

Although real discount rates in the stock market may continue to move downward in the future, such a development should not be viewed as a foregone conclusion. The upward surge in stock prices after late 1994 could be perceived as symptomatic of further reduction in the discount rate, but the declining dividend yield in 1994-1996 can be explained entirely by the increasing long-term real earnings growth rate expectations based on the unfolding pattern of the trailing growth rate since 1984 .

\section{Short-Term Patterns}

Two kinds of periodic developments have consistently had noticeable impacts on economic experience in the United States-major wars and business recessions/depressions. Preambles to war include deteriorating domestic conditions that adversely affect large numbers of people and/or political leaders who appear to be losing the support of their constituents for other reasons. Precursors of recessions/depressions appear to be mismanagement of monetary/fiscal policies or the need to reduce growth in the money supply to constrain inflation.

In the 1929-96 period, 17 bear market episodes occurred, a few more than the number of complete earnings cycles (13). With three notable exceptions, these episodes seem to have been related to recession concerns or, in one case, the foreboding developments that preceded World War II. ${ }^{3}$ (The exceptions are the 1966-67, 1983-84, and 1987 bear markets.) The events to which these bear markets seem related are listed in Table 4.3 in chronological order within each of the four eroding or recovering eras. For each episode, the table shows the S\&P 400 peak and trough prices, related dividend yields, and interim changes in dividend yields.

Presented in this manner, the data provide a clear indication of the distinction between the dividend yield changes that were heavily influenced by short-term risk concerns and those that were influenced largely by changes in long-range growth rate expectations. During the 1929-41 period, the average dividend yield increased 3.2 pps. Because of the grave nature of the

\footnotetext{
${ }^{3}$ During World War II itself and also during the Korean War that followed (1950-1953), real stock market returns were up sharply, but to conclude from those two experiences that war periods are necessarily good for common stocks would seem unwise.
} 


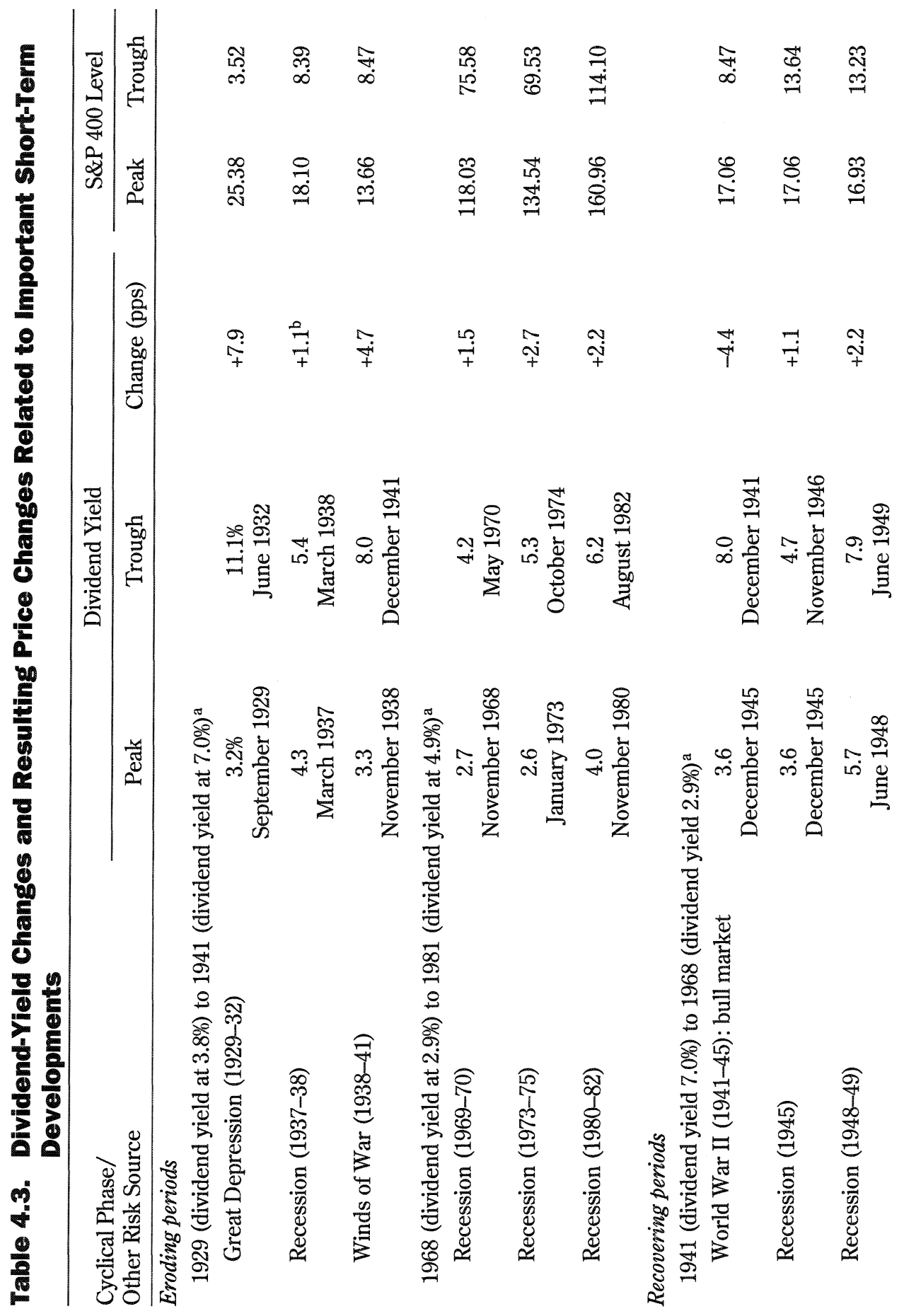




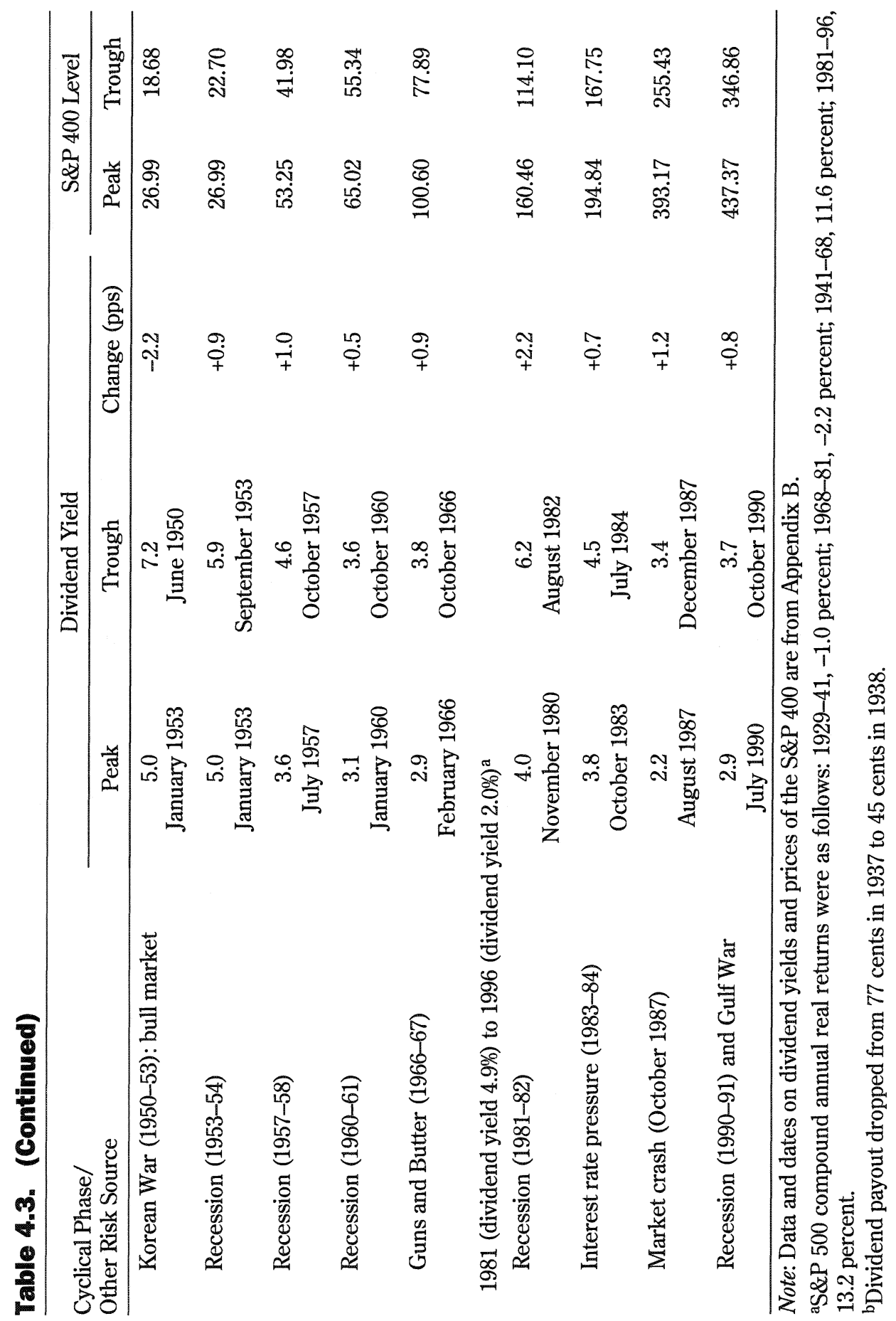


Depression itself, the increase in dividend yield in the 1929-32 bear market (market peak to trough) of $7.9 \mathrm{pps}$ is not surprising. During the bear market of the 1937-38 recession, the dividend yield increased only $1.1 \mathrm{pps}$. In the second eroding period (1968 through 1981), the average (annual) dividend yield increased $2.0 \mathrm{pps}$. The dividend yield increases from market peak to trough were between 1.5 and $2.7 \mathrm{pps}$ during the three bear markets of this era. ${ }^{4}$

During the 1941-68 recovering period, the dividend yield declined $4.1 \mathrm{pps}$. The bear markets witnessed peak-to-trough increases in dividend yield as small as 0.5 pps (1960-1961) and as large as 2.2 pps (1948-1949). The "Guns and Butter" bear market (1966-1967) experienced a yield increase of $0.9 \mathrm{pps}$. The stock market was quite bullish during both World War II and the Korean War subperiod: Dividend yields declined 4.4 pps during World War II and 2.2 pps during the Korean War. In the other recovering period, from 1981 to 1996 , the dividend yield declined $2.9 \mathrm{pps}$. The two recession-related bear markets in this era experienced peak-to-trough increases in dividend yield of $0.8 \mathrm{pps}$ (1990-1991) to 2.2 pps (1981-1982). In addition, the dramatic bear market that included the 508 point drop in the Dow Jones Industrial Average on October 19,1987 , experienced a dividend yield increase of $1.2 \mathrm{pps}$. As noted in the two eroding eras, the much larger decline in dividend yield in the first recovering era by itself would have contributed 141 percent to the price increase, less than the 145 percent price impact of a much smaller yield decline in the second recovering era.

Detailed views of the patterns of dividend yield changes during each of four major eras are shown in Figure $\mathbf{4 . 2}$ (for the eroding periods) and Figure 4.3 (for the recovering periods). Each figure shows not only the various bear markets discussed previously but also the high-low dividend yield for each calendar year. With the exception of the 1929-41 period, which was much more traumatic than the other three periods, the annual high-low range was relatively small much of the time. Most of the exceptions to that pattern occurred in years when investor concerns were somewhat dominated by the news of impending economic recession or war.

Table 4.4 provides a summary of these dividend yield patterns. The average high-low yield spreads reflect the relative uncertainty in each of the four eras. Clearly, the 1929-41 period was much more uncertain than the other

\footnotetext{
${ }^{4}$ The 2.0 pps increase in dividend yield during this era (after removing the impact of a contemporaneous change in the dividend payout level) would have had about the same relative impact on stock prices ( -41 percent) as the much larger $3.2 \mathrm{pp}$ increase (similarly adjusted) had on stock prices during the $1929-41$ period ( -46 percent). The lower the dividend yield at the beginning of the period, the greater the impact on the relative change in stock prices of any absolute change in the dividend yield.
} 
Figure 4.2. S\&P 400 Yearly High-Low Dividend Yields: Eroding Periods

A. 1929-41 Eroding Period

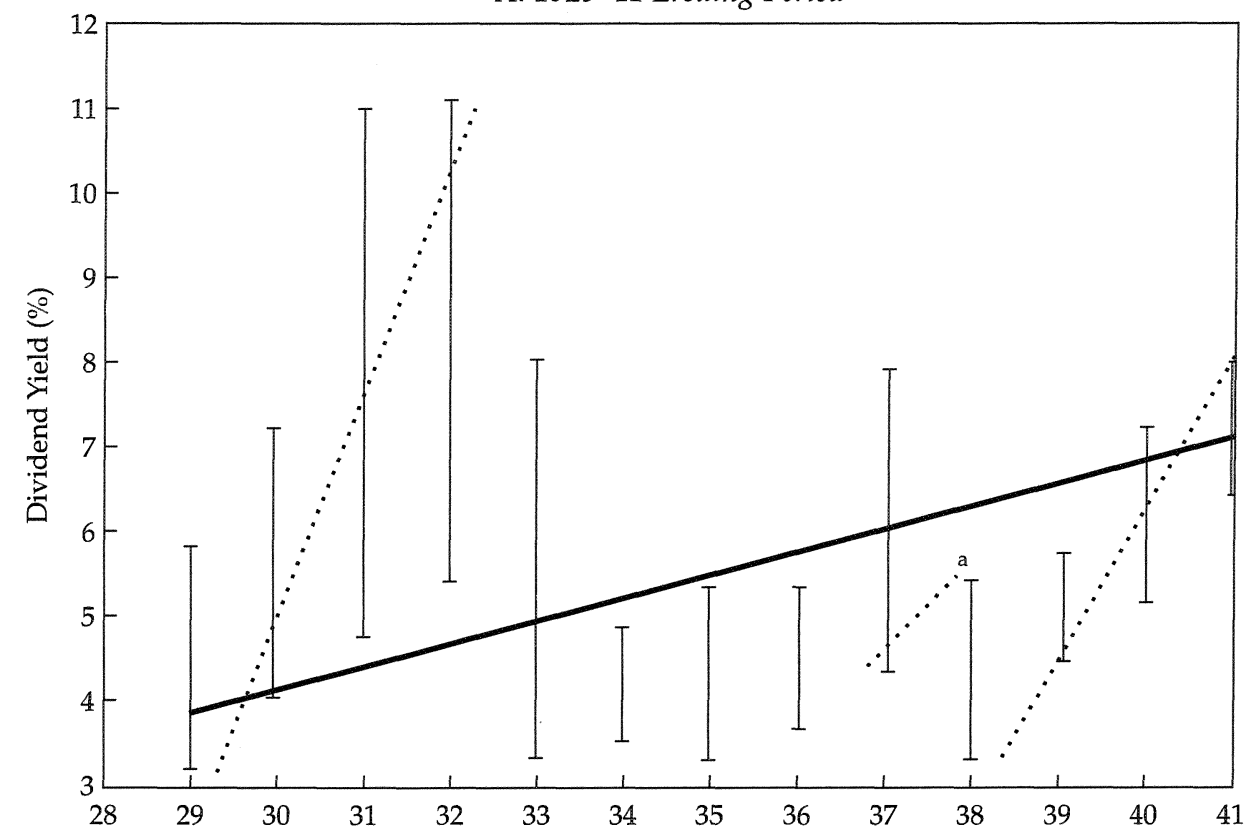

B. 1968-81 Eroding Period

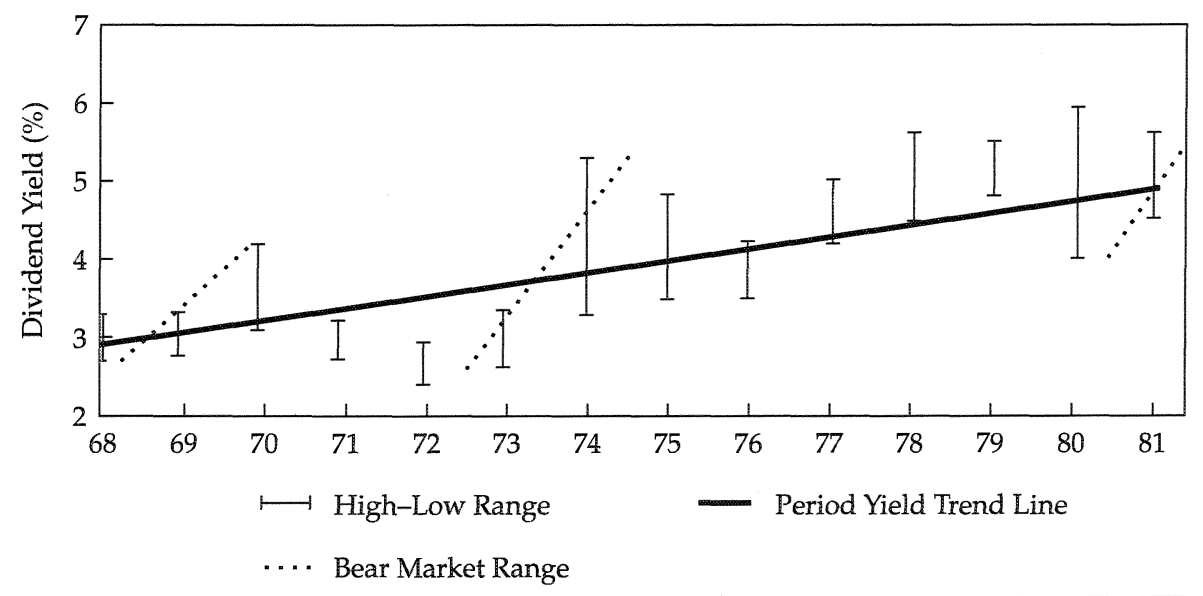

Notes: Dividend yield is based on the high-low prices of each year (see Appendix B).

aThe $1937-38$ bear market low price of $\$ 8.39$ versus a $\$ 0.45$ dividend ( $\$ 0.77$ dividend in 1937$)$. 
Figure 4.3. S\&P 400 Yearly High-Low Dividend Yields: Recovering Periods

A. 1941-68 Recovering Period

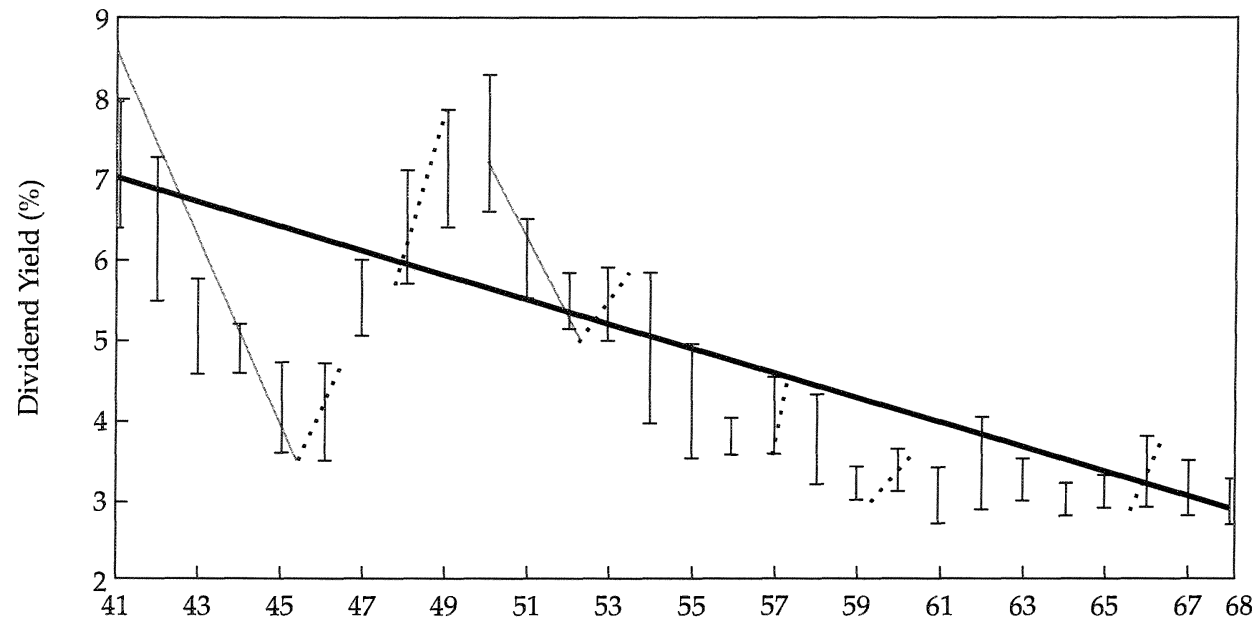

B. 1981-96 Recovering Period

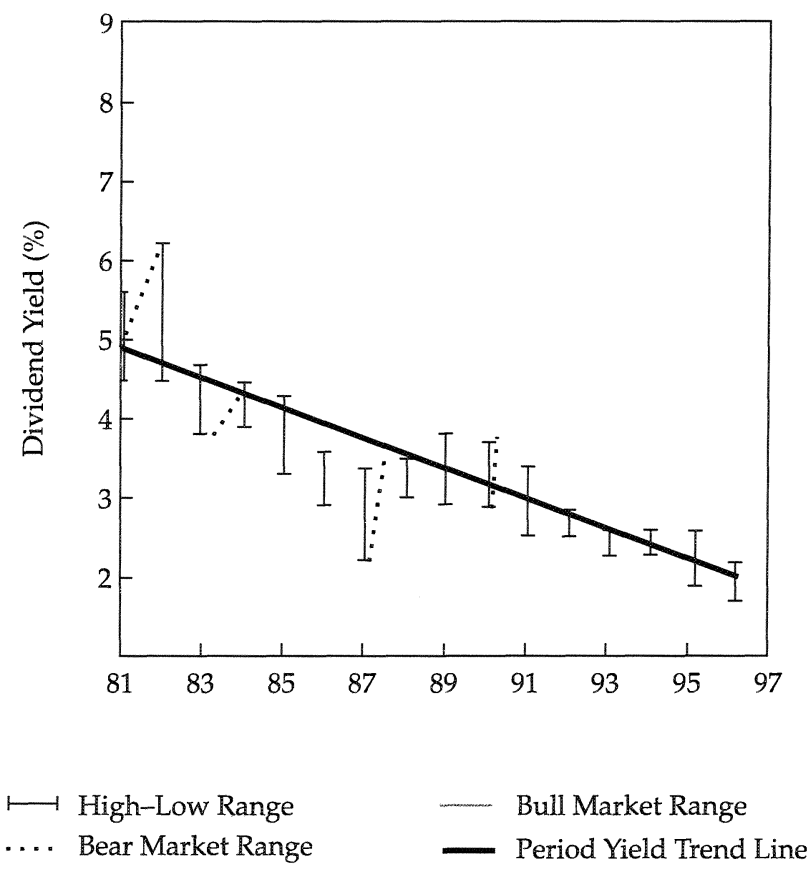

Note: Dividend yield is based on the high-low prices of each year (see Appendix B). 


\section{Table 4.4. Average Yearly Dividend Yield High-Low Spreads by Major Era}

\begin{tabular}{lcccc}
\hline Criterion/Number of Years & $1929-41$ & $1941-68$ & $1968-81$ & $1981-96$ \\
\hline All years (pps) & 2.92 & 0.99 & 0.96 & 0.77 \\
Number of years & 13 & 28 & 14 & 16 \\
Excluding recessions (pps) & 1.76 & 0.94 & 0.84 & 0.69 \\
Number of years & 7 & 25 & 12 & 14 \\
Recessions only (pps) & 4.27 & 1.40 & 1.65 & 1.30 \\
Number of years & 6 & 3 & 2 & 2 \\
\hline
\end{tabular}

Note: All of the interior era boundary years are reflected twice in this summary.

three periods. Of the total 71 years (interior boundary years are each represented twice in Table 4.4), 58 of them ( 82 percent of the total) were not afflicted by periodic recession problems. The 58 years not covering the $1929-41$ period included 51 years ( 88 percent of the total) without such problems.

Given this perspective on the behavior of the stock market, the changes in dividend yield within years not affected by recession or major war concerns appear to result from a wide variety of other factors, primarily transitory factors covered as news by the media.

\section{Implications for Investment Management}

The findings presented here support the members of the investment management profession who advocate a primary focus on fundamental long-term factors rather than short-term considerations. Until relationships between changes in many of the transitory factors and dividend yield changes are better understood, the transaction costs of trading on short-term factors are best avoided much of the time.

Of course, compartmentalization of information relating to particular investment decisions can be carried too far, but this monograph has focused primarily on those considerations known to be closely related to prospects for the long-term rates of return. The empirical evidence of the 1929-96 period strongly suggests that investment policy and investment strategy should focus on important sources of change in real discount rates (i.e., riskiness) and/or expectations for real long-term earnings and dividend growth. Together, these factors determine the dividend yield. In addition, the prospects for practitioner success with tactical asset allocation would probably improve if they examined established market-timing approaches against the backdrop of credible expectations for real long-term HPRs. 
The 1929-96 period had no extended intervals of flat dividend yields, but such yields are not out of the question in the future. The spread between the expectation for the real long-term earnings growth rate and the real discount rate (i.e., dividend yield) is not likely to remain stable, but certainly, it could fluctuate for quite some time around an essentially flat trend line.

If future real earnings growth rates average about 3 percent a year, real discount rates about 5 percent a year, and inflation about 3 percent a year, the dividend yield of about 2 percent will be accompanied by nominal HPRs of about 8 percent a year (compared with the 1926-96 HPRs of 10.7 percent). 


\section{Income Yield: The Equilibrator}

Webster's New World Dictionary defines "equilibrator" as a device that helps maintain equilibrium (i.e., a state of balance between opposing forces). In financial markets, the equilibrating function is carried out by continuous price adjustments, which relate to current annual income payments, to fulfill the market's expected return; that is, income yield can be viewed as the equilibrator. Its role as the equilibrator is evident in both the bond and the stock market.

\section{Background}

The history of income yield in the U.S. stock markets has differed markedly from its history in the bond markets since World War II. Most of a bond's longrun holding-period return (HPR) normally comes from income payments, so the primary focus in valuing bonds is the yield to maturity (or, at times, to a callable date). If a bond has a 7 percent yield to maturity and a change in expectations about risk or inflation takes place, the bond's price will change. The result will be a higher or lower yield to maturity, depending on the changed expectations. In the case of stocks, from the early 1870s through the end of World War II, a major portion of return came from dividend income. ${ }^{1}$ Furthermore, as shown in Table 5.1, in each of the (generally) 10-year periods from 1871 through 1945, the average dividend yield from the stock market was always above the average long-term bond yield to maturity.

Table 5.1 also shows that average bond yields tended downward between 1900 and 1909, then tended upward in the Roaring Twenties. The sharply lower bond yields in the 1930s reflected the Depression economy, and even lower yields in the 1940 s reflected the intervention of the U.S. government to keep the interest costs of financing World War II lower than they would have been otherwise.

Except during the 1940s, the average yield spreads between stocks and bonds have ranged between 0.94 and 1.57 percentage points (pps). The much larger yield spread in the 1940 s was exacerbated by the uncertainties of World War II and, in 1945, by problems of conversion to a peacetime economy. ${ }^{2}$ In 1957 , against a backdrop of rising interest rates, a historic event took place that caused much consternation at the time: Dividend yields fell

\footnotetext{
${ }^{1}$ The average dividend yield was 5.04 percent and capital appreciation was 1.80 percent a year from 1871 through 1925 (Ibbotson and Brinson 1987).

${ }^{2}$ The necessary postwar conversion (i.e., resumption of a normal level of output made up primarily of civilian goods) took five years, from 1945 to 1950 .
} 
Table 5.1. Stock and Bond Yields and Spreads, 1870-1949

\begin{tabular}{lccc}
\hline $\begin{array}{l}\text { Ten-Year } \\
\text { Periods }\end{array}$ & $\begin{array}{c}\text { Average Common } \\
\text { Stock Yields }\end{array}$ & $\begin{array}{c}\text { Average Long-Term } \\
\text { Bond Yields }\end{array}$ & $\begin{array}{c}\text { Yield Spread between } \\
\text { Stocks and Bonds }\end{array}$ \\
\hline $1870-79$ & $6.1 \%^{\mathrm{a}}$ & $4.98 \%$ & $1.12 \%^{\mathrm{b}}$ \\
$1880-89$ & 4.89 & 3.60 & 1.29 \\
$1890-99$ & 4.17 & 3.23 & 0.94 \\
$1900-09$ & 4.19 & 3.17 & 1.02 \\
$1910-19$ & 5.50 & 3.93 & 1.57 \\
$1920-29$ & 5.66 & 4.26 & 1.40 \\
$1930-39$ & 4.85 & 3.34 & 1.51 \\
$1940-49$ & $6.10^{\mathrm{c}}$ & $2.13^{\mathrm{d}}$ & $3.97^{\mathrm{b}}$ \\
\hline
\end{tabular}

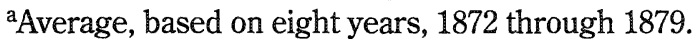

${ }^{b}$ Not entirely comparable with stock yields for the years noted.

cAverage based on six years, 1940 through 1945.

dEstimate.

Source: Ibbotson and Brinson (1987), Tables 5.3, 5.4, and 10.6 .

beneath long-term bond yields. They have remained below long-term bond yields ever since. During the early 1980 s, they were as much as $800-1,000$ basis points (bps) below bond yields. In short, a combination of tight monetary policy and a peak in inflation psychology, which caused risk premiums to soar, were wreaking havoc in the bond market.

This dramatic turn of events created an enigma for those who used dividend yield as a comparative valuation benchmark: Dividend yield was dethroned as the major source of common stock returns. Instead of representing more than 70 percent of stock returns, as during the 1871-1925 period, the dividend yield between 1926 and 1985 was closer to 50 percent of such returns. As part of recent expected stock returns (ER[S]), the dividend yield is 25 percent or less of reasonable current estimates of 8.0-8.5 percent and less than 20 percent of such estimates that are simply based on the 1926-96 HPR of 10.7 percent a year.

When the dividend yield is viewed within the framework of the equity investment value model (IVM), however, the enigma disappears. That is, dividend yield is then understood to be only a small part of the ER(S), which adds importance to its role as the equilibrator. ${ }^{3}$ The rest of this chapter

\footnotetext{
${ }^{3}$ Some may have viewed dividend yield in terms of an equilibrating role prior to the mid-1940s, but if so, they did not articulate the idea. Until Williams (1938) suggested that value is determined by discounting the expected payment streams and until real (inflation-adjusted) earnings growth became a legitimate source of significant real appreciation expectations, the necessary conditions to bring the dividend yield's equilibrating role into clear view were probably lacking. Even today, despite rapidly diminishing empirical support for the dividend yield as a credible valuation benchmark, perceptions of it's validity are not quickly discarded.
} 
examines two aspects of the dividend yield: the behavior of its determinants (i.e., the discount rate and the expected growth rate) and the price-volatility implications related to the absolute level of the dividend yield.

\section{Behavior of Determinants}

Because the spread between the discount rate and the expected earnings growth rate is the dividend yield, there is great need to understand as much as possible about the behavior of these two variables. Unfortunately, understanding is difficult because these variables are not explicitly available in the oceans of hard data relating to the stock market. Therefore, each variable must be estimated.

An IVM-focused examination of stock market history provides estimates of the dividend yield determinants, which are most useful when viewed in inflation-adjusted terms, which permits inferences as to "normalized" tendencies. Appendix A provides estimated annual average real discount rates on stocks (in the "Expected Return" columns) for each year from 1941 through 1996. The estimate for 1941 was 7.0 percent, and for 1996, 5.46 percent. In between, the estimates varied considerably. The highest expected stock return was 11.42 percent in 1950 , and the lowest was 2.97 percent in 1984 , 1986 , and 1987. The average for all 56 years was 5.95 percent. (The commentary in Appendix I suggests that the average expected stock return for the 58 years from 1871 to 1929 was 6.53 percent.)

The 1941-96 period contained two very abnormal periods of expectedstock-return estimates: the 1947-55 period (in which estimates were 7.8311.42 percent) and the 1981-89 period (in which estimates were 2.97-4.76 percent). These aberrations make clear that expectations are sometimes not based on the experience of (then) trailing years. The great fear of depression in the late 1940s and early 1950s was based on what had happened after World War I. The strong optimism of the 1980s was based, in part, on some very beneficial changes in economic policies and President Ronald Reagan's communication skills.

The other 38 years had an average expected stock return of about 5.65 percent. More important than the average, however, was the apparent trend, which has been downward for a total of roughly $150 \mathrm{bps}$. The most likely cause of the decline in expected stock returns was reduction in the riskiness of common stock exposures-a corollary of a more stable economy since World War II and greater stock diversification through greatly increased investment management intermediation (i.e., institutionalization) [Gray 1979]). In more recent years, as dividend yields have become smaller than ever (less than 2.0 percent), the stage has been set for high stock-price volatility. Such volatility 
has been evident, but so far has not been reflected in any significant upward shift in the market discount rate, ER[S]. Perhaps such a shift must await an extended downside phase of price volatility.

Other phenomena could be the source of additional basic changes in the magnitude of $\mathrm{ER}(\mathrm{S})$. On the one hand, the internationalization of investment exposures is often cited as a means of further risk reduction, and at the global level, it could involve some tendency toward lower discount rates for stocks in the United States. Also, as Bernstein (1996b) has remarked, with some clear precautions, the ingenuity of the financial markets and the proliferation of derivative instruments and products has transformed the pattern of volatility in the modern age into risks that are far more manageable for business corporations.

On the other hand, the increasingly interdependent social, economic, and financial market arrangements may increase the likelihood of "unforeseeable" adverse phenomena. Furthermore, a growing body of academic research has identified surprisingly irrational elements of human behavior related to investing (Bernstein 1996a), which could generate second thoughts in the minds of investors as to the wisdom of unbridled common stock exposure. Also, a little reflection on the potentially enormous impact of diminished growth in real earnings could be viewed as one of the greatest risks of all time. ${ }^{4}$

With regard to the real growth rate, the past behavior of the stock market has shown that pricing is based on expectations that usually draw heavily from the past 10-15 years. For example, apparently, what mattered to investors in 1981 was that the "trailing" (roughly 10-12 years) real earnings growth rate had eroded by -0.25 percent a year (the S\&P 400 Index closed at 137.12 that year). In 1996, what apparently mattered was that trailing earnings (1984-96) had grown at 3.46 percent a year (the S\&P 400 closed at 869.97 ). The fact that real earnings growth for the S\&P 400 was 2.22 percent between 1926 and 1996 (70 years) seems to have been entirely ignored.

The experience of the 1990s has made clear that real earnings growth can be considerably larger than growth in real gross domestic product for many years (2.79 percent real earnings growth versus 1.93 percent real GDP growth annually for 1989-1996). But of the 13 earnings cycles from 1926 through 1996 , only five (1926-1929, 1941-1948, 1948-1950, 1984-1989, and 1989-1996) had earnings growth rates that exceeded GDP growth rates. Therefore, even though growing foreign exposure and increased earnings from overseas activities may permit an improved relationship between reported real earnings

\footnotetext{
${ }^{4}$ If a 1 percent reduction in the earnings growth rate were accompanied by a $1 \mathrm{pp}$ increase in dividend yield - say, from 1.5 percent to 2.5 percent-over a five-year period (assuming also that the dividend itself rose 30 percent concurrently), the result would be $a-2.9$ percent a year HPR.
} 
growth of U.S. corporations and real GDP growth for some period ahead, GDP experience should continue to have considerable influence on earnings growth rates over the longer term.

Will the 1941-96 downward drift in real discount rates continue in the future? If it does, the most likely cause will be either some permanent increase in investor tolerance for risk and/or some sort of indexation of the cost basis in calculating long-term capital gains taxes.

\section{Price Volatility}

Unlike the behavior of the discount rate and expected growth in earnings, the relationship of dividend yield to price volatility is a simple matter of calculation; dividend yields are themselves hard data. The S\&P 400 dividend yield was about 7 percent in 1949, 4 percent in 1974, and 2 percent in 1996. Beyond the obvious differences in the amount of return from income payments, does this fall in the dividend yield matter? Yes, it significantly affects relative stock-price volatility!

Using the boundaries between periods of eroding and recovering real earnings growth rates (as portrayed in Figure 4.1) allows examination of the impact of various percentage point increases in yield on stock market price declines. As Table 5.2 shows, the effect of any percentage point increase in dividend yield on percentage price declines depends on the absolute dividend yield level to begin with. A 0.5 pp increase results in a 20.3 percent price decline if the yield is 1.97 percent at the start, but that same percentage point increase produces only a 6.7 percent price decline if the yield is 7.0 percent at the outset.

Although changes in stock prices cause changes in dividend yields (except when an offsetting contemporaneous change occurs in the dollar dividend payment), remember that changes in perceived riskiness and/or

\section{Table 5.2. Dividend Yield Levels and Stock Market Price Volatility}

\begin{tabular}{|c|c|c|c|c|c|c|c|c|}
\hline \multirow[b]{2}{*}{ Year $^{\mathrm{b}}$} & \multicolumn{2}{|c|}{ Dividend Yield $^{\mathrm{a}}$} & \multicolumn{6}{|c|}{$\begin{array}{l}\text { Percentage Price Decline Corresponding to Various } \\
\text { Percentage Point Increases in Yield }\end{array}$} \\
\hline & Low & High & 0.10 & 0.20 & 0.30 & 0.50 & 1.00 & 2.00 \\
\hline 1929 & $3.84 \%$ & & $-2.5 \%$ & $-5.0 \%$ & $-7.3 \%$ & $-11.5 \%$ & $-20.7 \%$ & $-34.2 \%$ \\
\hline 1941 & & $7.00 \%$ & -1.5 & -2.8 & -4.1 & -6.7 & -12.5 & -22.3 \\
\hline 1968 & 2.94 & & -3.3 & -6.4 & -9.3 & -14.5 & -25.4 & -40.5 \\
\hline 1981 & & 4.86 & -2.0 & -4.0 & -5.8 & -9.3 & -17.1 & -29.2 \\
\hline 1996 & 1.97 & & -4.8 & -9.2 & -13.2 & -20.3 & -33.7 & -50.4 \\
\hline
\end{tabular}

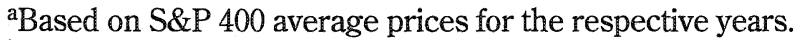

${ }^{b}$ Boundary years between eroding and recovering periods (see Chapter 4). 
growth rate expectations are the major underlying causes. It is such changes in expectations that drive market price changes. The latter reflect the relentless endeavor to achieve market levels of expected return.

Stock market volatility was considerably greater in the 1920 s and 1930 s than today. That well-known phenomenon may seem inconsistent with the fact that dividend yields tended to be quite a bit higher back then. The reason is that changes in the absolute dividend yield level tended to be larger in the earlier period. (This difference is reflected in Tables 4.3 and 4.4 in the peakto-trough yield changes during the 1929-41 period as compared with the three later periods.)

The most plausible explanation for the greater dividend yield changes prior to 1942 is the greater uncertainty in the economic environment at that time and its impact on financial circumstances at every level (the individual, family, and business). Such uncertainty was the source of large swings in risk and growth rate expectations. ${ }^{5}$ Despite the relatively stable economic conditions of 1996 , a seemingly small decline in the dividend yield, from 2.22 percent at the market low to 1.75 percent at the market high, accounted for a majority of the 26 percent increase in the S\&P 400 . It could be interpreted that an 11 percent dividend increase in 1996 accounted for the rest of it. Even if the dividend increases 10 percent in 1997 , the return to a 2.22 percent dividend yield late in the year would produce a S\&P 400 market level of about 772 , which illustrates the inherent price volatility of low dividend yields.

\footnotetext{
${ }^{5}$ Incidentally, major declines in the actual level of dividend payments occurred in 1931 ( -19.5 percent), 1932 (-40.9 percent), 1933 ( -12.8 percent), and 1938 ( -41.6 percent), which magnified price volatility in that earlier period. Since 1938 , only one other year has had a significant drop in dividend payments-1941 (-19.1 percent).
} 


\section{Applying the IVM Approach to Long-Term Forecasting}

Some participants in the professional investment management industry have spoken in terms of emphasizing long-term expectations, at least for the past 15-20 years. Managers are increasingly using long-term historical returns in gauging future prospects that influence the allocation of portfolio assets among the major asset classes (cash equivalents, bonds, stocks, and so on). This trend toward a long-term focus is encouraging, but the apparent reliance on 1926-96 returns as the best indication of future returns has a drawback. It may have reduced efforts to better understand the causes of holding-period return (HPR) differences among important subperiods of the past 70 years.

The results reported in this chapter support the importance of understanding subperiod returns. Between 1977 and 1990, I used the investment value model (IVM) conceptual framework set forth in Chapter 1 to make 13 explicit long-term forecasts-seven 10-year forecasts and six 5-year forecasts; eight forecasts for the S\&P 400 Index and five for long-term corporate bonds. The use of 5- and 10-year forecast horizons was based on the rough average length of business cycle in the United States since World War II. The hope was that such time horizons would moderate the distortion that business cycles impose on the HPRs of shorter periods. Nevertheless, actual market conditions at each inception date were carefully considered in developing estimated HPRs. All but two of the forecast periods have since passed their terminal dates. In all of the forecasts, attention was focused on the IVM factors discussed in Chapter 2.

\section{Model Assumptions}

Judging where the United States might be in a business cycle 5 or 10 years hence is not possible. Therefore, it seemed best to assume "normal" conditions for any forecast terminal date; that is, interest rates would not be at or near business-cycle peaks or valleys and the stock market would not be toward either of the extremes of investor risk tolerance. Of course, circumstances on certain terminal dates will inevitably be at variance with such an assumption. In such cases, if any HPR is significantly different from the forecast, the forecast may still be viewed as successful if actual returns closely approximate the estimated HPRs within a year or so on either side of the terminal date. Also, forecasts may qualify as successful if their ensuing HPRs turn out closer to actual than what 1926-96 HPRs might have indicated to other investors. 
Long-Term Bond Forecasts. A forecast of long-term bond returns is heavily influenced by the estimated terminal price, which is determined largely by three circumstances at the terminal date-the interest coupon, the yield to maturity, and years to maturity on the terminal date.

Interest coupon at terminal date. In the case of a single long-term bond, no assumptions about interest rates at termination are required; any given fixed-rate bond's coupon remains unchanged to maturity.

A bond portfolio presents a more difficult problem. Even when the bonds are not actively traded, portfolio turnover must be dealt with in some fashion because it arises whenever particular issues reach their maturity date, are called for redemption, or are sold. The proceeds, if reinvested, bring new bond issues into the portfolio, and most new holdings will have different coupon rates from the one on the issue being replaced. The impact of such changes in coupon rates will affect the HPRs of a bond portfolio. Computers allow an analyst to deal with these likely coupon changes with great precision, but the analyst must make assumptions about interest rates at the scheduled or estimated time of each change. The cost of such efforts must be weighed against the likelihood of such efforts improving the HPR forecasts. In many cases, using trend-line interest rate assumptions may be just as good as (or better than) spending time seeking to obtain precision.

Yield to maturity at terminal date. Using my expected return on bonds (ER[B]) structure (which does not separately consider the risk-free rate) the terminal yield to maturity is made up of the expected rate of inflation and the estimated bond risk premium. ${ }^{1}$ The expected rate of inflation is usually heavily influenced by the inflation experience leading up to the terminal date (the average and/or trend of the previous two or three years). It should also reflect the expected conduct of (or prospects for) monetary and fiscal policies, consistent with the normal-condition assumptions, unless there are known reasons for assuming other circumstances.

The inflation rate assumed is likely to be the most important factor in the estimated yield to maturity because of its probable impact on the estimated long-term bond risk premium. For the past 18 years (during which time, the rate of inflation has declined considerably), the long-term bond risk premium appears to have had a pronounced tendency to diminish in the wake of stable or diminishing inflation experience and vice versa. Example 6.1 illustrates the impact on the forecast of HPRs from the assumed expected inflation and the estimated bond risk premium at the terminal date.

\footnotetext{
${ }^{1}$ See the "Bond Model" of Chapter 1 for my justification of this alternative approach.
} 
Example 6.1: Assume the expected inflation rate is 3.0 percent and the long-term bond risk premium is 4.2 percent at the inception of a five-year forecast; that is, the long-term bond yield to maturity is 7.2 percent. The economy is currently characterized as having normal conditions, but there appears to be a 100 basis point hedge against higher inflation in the risk premium and thus in the yield to maturity. Normal conditions and an expected 3 percent inflation rate are assumed five years hence, so the bond risk premium is estimated to be 3.2 percent at the terminal date. Therefore, a yield to maturity at that time of 6.2 percent appears to be a reasonable assumption.

Years to maturity at terminal date. In the case of a single long-term bond, knowing years to maturity at the terminal date is a simple matter, as it was with the interest coupon. The maturity date remains unchanged.

Turnover affects a bond portfolio's years to maturity but to a lesser extent than it affects the interest coupon. Most diversified bond portfolios have a somewhat laddered distribution of maturities, so even with quite a bit of turnover, they are likely to have only modest changes in average life to maturity. Whatever the impact of turnover, the likely benefit of great precision in judging years to maturity must be weighed against its costs. Use of simplifying assumptions may suffice. ${ }^{2}$

Common Stock Market Forecasts. A long-term forecast of stock market HPRs depends on estimates of dividend payment streams during the forecast period. The final payment in that stream must be an estimated terminal price. The terminal price is far more crucial to the success of stock HPR forecasts than to that of long-term bond forecasts. ${ }^{3}$

The terminal price will be determined by the annual dividend payment, the estimated discount rate, and the future growth rate expected at the end of the terminal year. The difference between the estimated discount rate and the estimated future growth rate-that is, the dividend yield-will be most important.

\footnotetext{
${ }^{2}$ In all five long-term bond forecasts, a single hypothetical long-term bond was assumed. The actual HPRs used to judge the success of those forecasts were those of the Salomon Brothers Long-Term High-Grade Corporate Index (Ibbotson Associates 1997). The fact that this index represents a large number of bond issues with some inevitable turnover did not create a problem; that is, actual HPRs were close to the respective forecasts.

${ }^{3}$ Assume the stock market maintains a 2.5 percent dividend yield, that dividends increase at 6.0 percent a year for 10 years, and that the future growth rate expectation is 6 percent at the end of that period. The present value of the estimated terminal price in this case will be about 78 percent of the current price; the present value of the dividend stream will account for only 22 percent.
} 
Dividend payment in terminal year. Terminal-year dividend payment estimates can be approached by developing year-to-year projections of dividends. Such payments should be heavily influenced by expected changes in gross domestic product and earnings during the forecast period. However, earnings as a percentage of GDP and dividends as a percentage of earnings have changed in the past. The analyst must judge if and how much they are likely to change during the forecast period.

Although an assumed growth rate of dividends may be used to determine the dividend amount in the terminal year, a series of assumed yearly payments will be needed as an essential part of the estimated HPR calculation. An explicit year-by-year projection of payments should focus attention on the likely number of recessions during the forecast period. This should have some impact on the magnitude of the average growth rate assumed during the forecast period. Elements of the approach are shown in Example 6.2.

Example 6.2: Assume the most recent recession was 5 years ago. Two recessions during the next 10 years seem probable. An estimated nominal GDP growth rate of 5.5 percent is most likely. A rising trend in return on equity has taken ROEs well above normal levels. Some regression to the mean seems probable, so the estimate is that they will be closer to normal levels in 10 years. Nevertheless, growth in earnings per share (EPS) is expected to be slightly greater than that of GDP growth because of increasing selectivity in the corporate sector's exposures. The current dividend payout is unusually low and should be somewhat higher in the terminal year. Without belaboring the particulars, these assumptions, taken together, lead to a dividend growth rate estimate of about 7 percent a year.

Estimated discount rate at end of terminal year. The discount rate reflects the riskiness of common stocks relative to that of other assets and the risk tolerance or aversion of investors. Historically, risk tolerance/aversion appears to have been affected primarily by the business cycle.

The analysis of the stock market's behavior during the 1929-96 period in Chapter 4 indicated that its real discount rate is lower now than it was at the end of World War II. I believe that this longer-term downward trend is the result of stocks becoming less risky, not of increased risk tolerance. The real discount rate is currently estimated to be $5.0-5.5$ percent. Given this current estimate, factors that might influence the future real discount rate can be illustrated as shown in Example 6.3. 
Example 6.3: Assume the recent high volatility in the stock market is likely to persist and become recognized as a continuing problem during the next 10 years. Assume also that investors, as a whole, become slightly more risk tolerant in the future. Assume that rising volatility outweighs rising risk tolerance. The bottom line is a forecast that the real discount rate will be 5.5 percent at the end of the 10 th year.

Expected real earnings growth rate at end of terminal year. Analysis of the stock market's historical performance in Chapter 4 strongly suggests that the expected real growth rate reflected in the pricing of the stock market is usually drawn from the trailing 10-12 years of real earnings. Based on that pattern, the expected future growth rate now appears to be close to 3.5 percent. Example 6.4 demonstrates how to approach an estimated growth rate expectation as of the end of a 10-year forecast period.

Example 6.4: Real GDP has been growing at about 2 percent a year during the $1990 \mathrm{~s}$. A somewhat higher growth rate-say, 2.75 percent-seems likely in the next 10 years. With ROEs expected to remain quite good and dividend payout likely to remain fairly low, the trailing real growth rate should be lower in 10 years than now, most likely about 3 percent a year.

Summary Assumptions. The assumptions from the preceding examples (a discount rate of 5.5 percent and real growth expectations of 3.0 percent) lead to an estimated dividend yield in the 10th year of 2.5 percent. Applying that dividend yield to the projected dividend of 30.65 , the S\&P 400 would be at 1,226 in 10 years. Using a straight-line projection of dividends from 15.58 to 30.65 for the terminal year, the HPR for the S\&P 400 would be 5.7 percent a year. If inflation averaged 2.75 percent a year, the real $\mathrm{HPR}$ would be 2.95 percent a year.

This series of examples are intended only to identify some issues that are likely to be important but seem to have been largely ignored in either simple or adaptive extrapolations of historical HPRs. ${ }^{4}$

\section{Results of Long-Term Bond and Stock Forecasts}

This section reports the results of the 11 long-term forecasts made between 1977 and 1987. For the stock market, there were three 10-year forecasts and four 5-year forecasts. Each forecast (except those done midway through a 10year forecast period) was made at a time when an IVM perspective seemed particularly desirable.

\footnotetext{
${ }^{4}$ This example is not intended to constitute a credible forecast; it lacks a reasonable basis, which is necessary for credibility under AIMR Standard IV[A.1]) (see AIMR 1996).
} 
Table 6.1 provides a summary of the stock market forecasts, and Table 6.2 provides the same for the long-term bond forecasts. Each table contains a comparison of forecasted with actual HPRs. The tables also provide historical HPRs from January 1, 1926, through the calendar year-end closest to the forecast inception date and the average spread between (1) historical and forecasted HPRs and between (2) actual and forecasted HPRs.

Based on these average spreads, the forecasts, particularly the bond forecasts, were much closer to the actual HPRs than the historical HPRs alone would have suggested. The relatively greater success of the long-term bond forecasts appears to be a result of my expectation that the inception (in 1967) and persistence of variable inflation in the United States would cause a sizable

\section{Table 6.1. Record of Long-Range Forecasts of U.S. Stock Market Returns}

\begin{tabular}{|c|c|c|c|c|c|}
\hline \multicolumn{2}{|c|}{ Forecast Period } & \multirow{2}{*}{$\begin{array}{l}\text { Length of } \\
\text { Forecast } \\
\text { (years) }\end{array}$} & \multicolumn{3}{|c|}{ Compound Annual Total Return } \\
\hline Inception & Termination & & $\begin{array}{l}1926 \text { to } \\
\text { Inception }^{\text {a }}\end{array}$ & Forecast & Actual \\
\hline $11 / 22 / 77$ & $11 / 22 / 87$ & 10 & $8.9 \%$ & $13.7 \%$ & $14.5 \%$ \\
\hline $10 / 15 / 78$ & $10 / 15 / 88$ & 10 & 8.9 & 17.0 & 15.0 \\
\hline $12 / 31 / 81$ & $12 / 31 / 91$ & 10 & 9.1 & 17.6 & 17.6 \\
\hline $04 / 15 / 83$ & $10 / 15 / 88$ & $51 / 2$ & 9.3 & 14.5 & 15.1 \\
\hline $12 / 31 / 86$ & $12 / 31 / 91$ & 5 & 10.0 & 15.5 & 15.4 \\
\hline 02/05/87 & 02/05/92 & 5 & 10.0 & 10.0 & 12.1 \\
\hline $07 / 15 / 87$ & $07 / 15 / 92$ & 5 & 10.2 & 8.0 & 8.2 \\
\hline \multicolumn{2}{|c|}{ Average spread to actual } & & $5.1 \mathrm{pps}^{\mathrm{b}}$ & $0.8 \mathrm{pps}^{\mathrm{b}}$ & \\
\hline
\end{tabular}

aReturns from Ibbotson Associates, Large-Company Stocks (1997).

${ }^{\mathrm{b}}$ Percentage points.

Table 6.2. Record of Long-Range Forecasts of Long-Term U.S. Corporate Bond Returns

\begin{tabular}{|c|c|c|c|c|c|}
\hline \multicolumn{2}{|c|}{ Forecast Periods } & \multirow{2}{*}{$\begin{array}{l}\text { Length of } \\
\text { Forecast } \\
\text { (years) }\end{array}$} & \multicolumn{3}{|c|}{ Compound Annual Total Return } \\
\hline Inception & Termination & & $\begin{array}{l}1926 \text { to } \\
\text { Inception }^{\mathrm{a}}\end{array}$ & Forecast & Actual \\
\hline $10 / 15 / 78$ & $10 / 15 / 88$ & 10 & $4.0 \%$ & $9.0 \%$ & $10.7 \%$ \\
\hline $12 / 31 / 81$ & $12 / 31 / 91$ & 10 & 3.6 & 15.5 & 16.3 \\
\hline $10 / 15 / 83$ & $10 / 15 / 88$ & 5 & 4.3 & 14.7 & 15.2 \\
\hline $12 / 31 / 86$ & $12 / 31 / 91$ & 5 & 5.0 & 9.1 & 10.4 \\
\hline \multicolumn{2}{|c|}{ Average spread to actual } & & $8.8 \mathrm{pps}$ & $1.1 \mathrm{pps}$ & \\
\hline
\end{tabular}

Returns from Ibbotson Associates, Long-Term Corporate Bonds (1997). 
increase in the perceived riskiness (i.e., risk premium) of long-term bonds compared with the riskiness of a diversified stock portfolio. It may have been a once-in-a-lifetime opportunity.

More impressive than the average success of these forecasts is that none of the individual historical-to-actual spreads in the case of long-term bonds was anywhere close to the forecast-to-actual spreads and, with two exceptions, the same is true in the case of the stock market forecasts. The exceptions were the stock forecasts for the five-year periods beginning February 5, 1987, and July $15,1987$.

This set of 11 forecasts contained no bad forecasts. The least successful of the stock market forecasts missed the actual HPR by only 2.1 percent a year, and the least successful of the long-term bond forecast missed by 1.7 percent a year.

\section{Long-Term Forecasts for the 1990s}

These long-term forecasts for the decade of the $1990 \mathrm{~s}$, not completed until mid-1990, covered both long-term bonds and the stock market (the S\&P 400). ${ }^{5}$ A copy of the forecasts showing the three scenarios is in Exhibit 6.1. The expectation was that actual outcomes would fall midway between the projections shown in Scenarios 1 and 2. Thus, the specific predictions for January 1, 2000, were as follows:

Dividend yield

Long-term interest rates (Aa industrial bonds)

S\&P 400 terminal market level

Estimated 10-year HPR:

Long-term bonds

S\&P 400
2.92 percent

7.25 percent

792

10.5 percent a year

10.2 percent a year

These predictions had three particularly abnormal aspects: First, the estimated real GDP growth rate of 2.625 percent was well below the historical norm (about 3 percent); second, the dividend growth rate of 6.625 percent (equal to the nominal GDP prediction) was much better than the historical average relationship between those factors; and third, the HPR for long-term bonds was slightly better than the predicted HPR for the S\&P 400.

Setting at Inception. At the beginning of the 1990s, real GDP had been advancing for seven years and was showing some signs of approaching a cyclical peak. For example, the U.S. Consumer Price Index had averaged 4.5 percent during the 1987-89 period. Long-term interest rates (Aa industrial

${ }^{5}$ These forecasts appeared in the July 15, 1990, issue of Harris Bank's "Stock-Bond Values" (Gray 1987-1995). 


\section{Exhibit 6.1. Stock Market Forecast for the Year 2000 as of July 20, 1990}

A 10-year forecast may seem foolish, with so many unexpected things that can happen during such a long period of time. Yet, it may be the best approach available for those who must make asset mix decisions, if it is done with careful attention given to the important variables and how they tend to interact with one another. Using three inflation scenarios, here is my 1990-2000 forecast.

\begin{tabular}{lccc} 
Measure & Scenario 1 & Scenario 2 & Scenario 3 \\
\hline Year 2000 & $2-3 \%$ & & \\
Inflation rate & 3.0 & $4-5 \%$ & $6-7 \%$ \\
Real growth rate & & 2.5 & 2.0 \\
1990-2000 Period & 3.50 & & \\
Average inflation & $\underline{2.75}$ & 4.50 & 5.50 \\
Average real growth & $6.25 \%$ & $\underline{2.50}$ & $\underline{2.25}$ \\
Average nominal GNP & $6.25 \%$ & $7.00 \%$ & $7.75 \%$ \\
S\&P 400 dividend growth & & & $7.75 \%$
\end{tabular}

The above figures assume a gradual movement of the inflation rate from 4.5 percent at the beginning of 1990 to the midpoint of the indicated ranges in the year 2000. Real growth is projected to be a bit higher in the disinflation scenario (Scenario 1) and a bit lower in the reinflation scenario (Scenario 3 ) than the 2.5 percent rate projected for the steady-state inflation environment. S\&P 400 dividend growth is projected to parallel nominal GNP in each case. Expectations and conditions for the key stock-price variables are projected below as of January 1, 2000:

Future growth rate

Dividend yield

Discount rate

Long-term interest rate

Risk premium

The "expected" future dividend growth rate is projected to be a bit better than, the same as, and a bit worse than the respective GNP growth rate for the terminal date of each scenario. This allows for the chronic "rear view mirror" syndrome that affects future expectations. The relative riskiness of long-term bonds should differ, at least somewhat, as reflected in the implicit real rates of 3.5 percent, 4.0 percent, and 4.5 percent in the respective long-term interest rate projections. The dividend yields are projected to correlate and the risk premiums correlate inversely with higher/lower interest rates as they have tended to do historically. Combining relevant elements from the above tables and making the necessary internal rate of return calculations produces the following results:

Year 2000

S\&P 400 dividends 
Applying the IVM Approach to Long-Term Forecasting

\begin{tabular}{|c|c|c|c|}
\hline \multicolumn{4}{|c|}{ Exhibit 6.1. (Continued) } \\
\hline Measure & Scenario 1 & Scenario 2 & Scenario 3 \\
\hline \multicolumn{4}{|l|}{ 1990-2000 Period } \\
\hline S\&P 400 compound return & $10.5 \%$ & $10.0 \%$ & $9.0 \%$ \\
\hline Long-term bond return & 11.2 & 9.7 & 8.4 \\
\hline \multicolumn{4}{|c|}{$\begin{array}{l}\text { The annual compound returns for stocks versus bonds do not differ greatly within each } \\
\text { scenario, albeit a bit better for bonds in the disinflation scenario (Scenario } 1 \text { ) and a bit better } \\
\text { for stocks in Scenarios } 2 \text { and } 3 \text {. That bonds would do so relatively well is suspect when viewed } \\
\text { against the backdrop of long-term historical experience. However, it may lend comfort to note } \\
\text { that bonds outperformed stocks in } 20 \text { percent of all } 10 \text {-year periods since } 1926 \text {. The most } \\
\text { recent such period was } 1970-1979 \text {. On that basis, bonds outperforming stocks (or coming } \\
\text { close to doing so) appears to be overdue, especially with bond yields ( } 9.3 \text { percent) almost } 6.5 \\
\text { percentage points above stock yields ( } 2.9 \text { percent) at the inception of this } 10 \text {-year period } \\
\text { (January } 1,1990) \text {. }\end{array}$} \\
\hline
\end{tabular}

Source: Gray (1987-1995, specifically, July 20, 1990).

bonds) were about 9.35 percent, suggesting a risk premium of close to 5 percent-way above the historical norm. Under the circumstances, the 1990s seemed likely to contain two recessions. That expectation, together with eroding attitudes about responsible personal behavior, led me to be skeptical about the prospects for real GDP growth.

A seemingly imminent recession and slower-than-normal long-term real growth implied that long-term interest rates would tend to move downward in the early 1990s. Furthermore, stock market returns had been 17.5 percent a year during the 1980s and, in the past, decades of high HPRs were never followed by decades in which the returns came even close to such highs.

Impact of Subsequent Developments. By mid-1993, some adjustments in this forecast were needed. Recovery from the 1990-91 recession had been about the slowest on record; S\&P 400 earnings were still below their prior peak of 26.83 (achieved in 1989), partly because of some very harsh Financial Accounting Standards Board requirements (especially Financial Accounting Statement No. 106). It seemed that the FASB impacts were subsiding, but the slower GDP growth was expected to persist. S\&P 400 dividend payments had been up less than 3 percent a year since 1989; part of the reason was that significant funds were being used by corporations to buy back stock during this period. Under the circumstances, I revised the terminal forecasts for dividends and stock prices down about 10 percent.

In the next two and a half years (mid-1993 through 1995), I made two sets of forecast revisions, both of an optimistic nature. On April 14, 1995, I raised the terminal market forecast for the S\&P 400 to 735 . The upward tilt to EPS 
growth rates resulting from stock-repurchase programs, the long-delayed benefits of corporate restructuring, and what seemed at that time like a groundswell in favor of indexation of the cost basis used in capital gains tax calculations were the main reasons. I raised the terminal price again on December 3, 1995, this time to 792, and raised the S\&P 400 dividend to 21.80 . At about the same time, I was discovering the apparent significance of the trailing (roughly 10-12 year) real earnings growth rate, and by late 1995, the 1984-95 real earnings growth rate appeared to be on its way to 3 percent a year.

The visual history provided in Figure 6.1 shows the S\&P 400 market

\section{Figure 6.1. S\&P 400 Forecast for the 1990 s versus Actual Experience through Mid-1995}

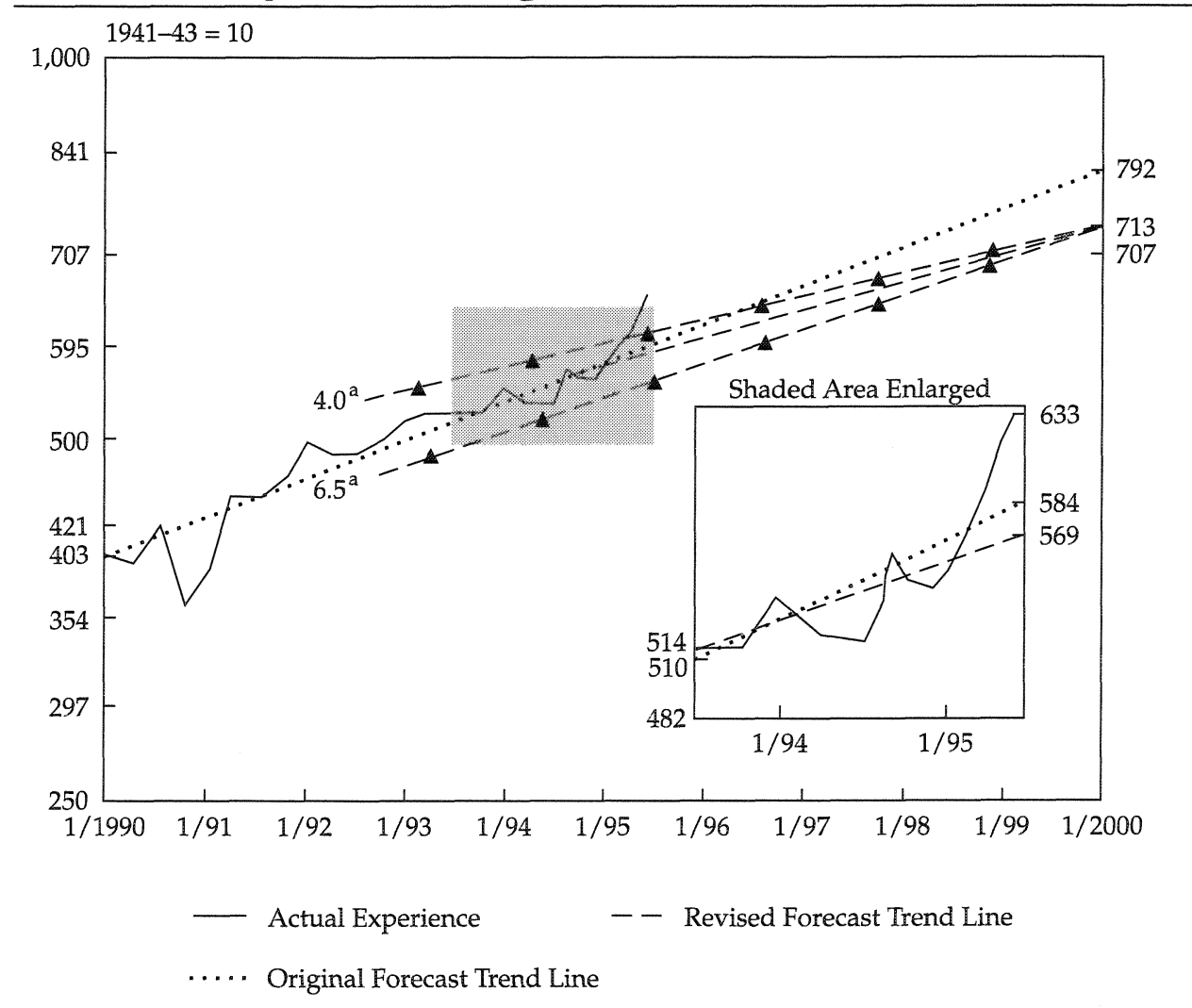

Note: Last S\&P 400 price level entries made as of June 9, 1995. Marked lines beyond that date are projections.

aTrend line for annual rate of market appreciation of, respectively, 4.0 percent and 6.5 percent. Source: Gray (1987-1995, specifically, June 12, 1995). 
movements and the forecast trend lines for the 1990s. It may be noted that, other than the recession-related market dip during the third quarter of 1990 , the S\&P 400 mirrored the original forecast trend line (which connects 403 on January 1, 1990, with 792 on January 1, 2000) until mid-1993. From that time, when the terminal market forecast was lowered to 713 , until the end of 1994 , the S\&P 400 level continued to mirror both the original and the new forecast lines, which were still fairly close together. At the beginning of 1995 , however, the stock market began to soar. A significant part of the 1995-96 gains are believed to be directly related to the much improved trailing real earnings growth rate pattern shown in Table 6.3.

Table 6.3. Real Growth Rates Reflected in Stock Market Valuation

\begin{tabular}{|c|c|c|c|c|c|}
\hline \multirow[b]{2}{*}{ Years } & \multicolumn{2}{|c|}{ Gross Domestic Product } & \multicolumn{3}{|c|}{ S\&P 400 Earnings } \\
\hline & $\begin{array}{l}1992 \text { Dollars } \\
\text { (billions) }\end{array}$ & $\begin{array}{l}\text { Cumulative } \\
\text { Compound } \\
\text { Growth Rate }\end{array}$ & $\begin{array}{c}\text { As } \\
\text { Reported }^{\mathrm{b}}\end{array}$ & $\begin{array}{c}1992 \\
\text { Dollars }\end{array}$ & $\begin{array}{l}\text { Cumulative } \\
\text { Compound } \\
\text { Growth Rate }\end{array}$ \\
\hline $1981^{\mathrm{c}}$ & $4,724.9$ & - & 16.74 & 25.83 & - \\
\hline 1982 & $4,623.6$ & $-2.14 \%$ & 13.20 & 19.19 & $-25.71 \%$ \\
\hline 1983 & $4,810.0$ & 0.90 & 14.77 & 20.80 & -10.26 \\
\hline $1984^{\mathrm{c}}$ & $5,138.2$ & 2.83 & 18.11 & 24.46 & -1.80 \\
\hline 1985 & $5,329.5$ & 3.06 & 15.28 & 19.92 & -6.29 \\
\hline 1986 & $5,489.9$ & 3.05 & 14.53 & 18.60 & -6.35 \\
\hline 1987 & $5,648.4$ & 3.02 & 20.28 & 25.04 & -0.52 \\
\hline 1988 & $5,862.9$ & 3.13 & 26.59 & 31.53 & 2.89 \\
\hline $1989^{c}$ & $6,060.4$ & 3.16 & 26.83 & 30.36 & 2.04 \\
\hline 1990 & $6,138.7$ & 2.95 & 24.77 & 26.59 & 0.32 \\
\hline 1991 & $6,079.0$ & 2.55 & 16.91 & 17.41 & -3.87 \\
\hline 1992 & $6,244.4$ & 2.57 & 19.05 & 19.05 & -2.73 \\
\hline 1993 & $6,386.4$ & 2.54 & 21.93 & 21.29 & -1.60 \\
\hline 1994 & $6,608.7$ & 2.61 & 32.83 & 31.08 & 1.43 \\
\hline 1995 & $6,742.9$ & 2.57 & 35.44 & 32.63 & 1.68 \\
\hline $1996^{\mathrm{c}}$ & $6,928.4$ & 2.58 & 41.15 & 36.80 & 2.39 \\
\hline $1984-89$ & & 3.36 & & & 4.42 \\
\hline 1989-96 & & 1.93 & & & 2.79 \\
\hline $1984-96$ & & 2.52 & & & 3.46 \\
\hline
\end{tabular}

${ }^{a}$ Council of Economic Advisors (1997) and U.S. Government Printing Office (1997).

bStandard \& Poor's Corporation (annual).

'S\&P 400 earnings peak years (1996 highest so far in latest cycle). 
Retrospective on 1990s Forecast to Date. The 1990 s period has proved to be more incorrigible than any of the earlier forecasts periods. In seven years, I made three changes in the terminal price forecast, whereas each of my previous 10-year forecasts had been revised only once. The 1990s forecast seems to be in greater jeopardy than any earlier 10-year forecast with one notable exception-the mid-October 1978 forecast for a few months before the October 19, 1987, crash. $^{6}$

If a failed 1990s stock market forecast does tarnish an otherwise solid record of long-term forecasts, it will have an important silver lining. The events of this decade-mainly a surprisingly large improvement in real earnings growth rate expectations-confirm the significance of the trailing long-term real EPS growth rate and its typical impact on future growth rate expectations.

The interaction of the trailing 10- to 12-year real EPS growth rate and the dividend yield either largely explains or is coincidental with the basic longterm pattern of stock market price movements and real HPRs for the entire 1929-96 period. So far, the 1990s experience strongly suggests that the expected growth rate, which so importantly influences pricing in the stock market, is better proxied by the growth rate of real EPS than by real dividends per share.

Concern about the Remainder of the 1990s. The patterns of the two major variables that govern the stock market-the earnings growth rate expectation and the discount rate-pose interesting questions for the 1997-99 period.

Growth rate. The upward explosion in EPS since 1993 has been phenomenal. It is closely related to increases in corporate profits as a percentage of national income and GDP. Although such percentages are still somewhat below their historical (past 40-year) averages, it may be difficult for them to move much higher. An important consideration behind this comment is that the volume of sales of the Fortune 500 U.S. corporations, provided in Table 6.4, increased much less rapidly after 1979 than did nominal GDP.

Because of the likelihood of a recession during the next three years and the expectation of below-average real GDP growth otherwise, the real EPS growth rate could peak in 1997 or 1998. Certainly, further increase in the growth rate does not seem likely in the next few years. (At the time of this writing, February 1997, the 1984-96 real EPS growth rate expectation was about 3.5 percent a year.)

\footnotetext{
${ }^{6}$ Only time will tell whether the December 31,1996 , market level is vulnerable to a similar fate. Such a development would probably require the threat of a significant recession or a downward shift in the trailing real earnings growth rate.
} 
Table 6.4. Characteristics of Fortune 500 U.S. Industrial Corporations, 1979-94

\begin{tabular}{|c|c|c|c|c|c|c|}
\hline Year & $\begin{array}{c}\text { Sales } \\
\text { (billions) }\end{array}$ & $\begin{array}{l}\text { Profits } \\
\text { (billions) }\end{array}$ & $\begin{array}{l}\text { Assets } \\
\text { (billions) }\end{array}$ & $\begin{array}{l}\text { Median } \\
\text { Return on } \\
\text { Equity }\end{array}$ & $\begin{array}{l}\text { Median } \\
\text { Return for } \\
\text { Investors }\end{array}$ & $\begin{array}{l}\text { Number of } \\
\text { Employees } \\
\text { (millions) }\end{array}$ \\
\hline 1979 & $\$ 1,445.3$ & $\$ 78.3$ & $\$ 1,034.7$ & $15.9 \%$ & $21.31 \%$ & 16.2 \\
\hline 1980 & $1,650.3$ & 81.2 & $1,175.5$ & 14.4 & 21.05 & 15.9 \\
\hline 1981 & $1,773.4$ & 84.2 & $1,282.8$ & 13.8 & -0.35 & 15.6 \\
\hline 1982 & $1,672.2$ & 61.4 & $1,308.7$ & 10.9 & 21.22 & 14.4 \\
\hline 1983 & $1,686.7$ & 68.8 & $1,353.9$ & 10.6 & 30.21 & 14.1 \\
\hline 1984 & $1,758.7$ & 86.4 & $1,409.4$ & 13.6 & -0.75 & 14.2 \\
\hline 1985 & $1,807.1$ & 69.6 & $1,519.4$ & 11.6 & 26.31 & 14.0 \\
\hline 1986 & $1,723.4$ & 65.0 & $1,560.8$ & 11.6 & 15.55 & 13.4 \\
\hline 1987 & $1,879.5$ & 90.6 & $1,705.6$ & 13.2 & 6.8 & 13.1 \\
\hline 1988 & $2,023.1$ & 115.0 & $2,078.8$ & 16.2 & 14.1 & 12.7 \\
\hline 1989 & $2,164.3$ & 105.6 & $2,288.1$ & 15.0 & 17.5 & 12.5 \\
\hline 1990 & $2,304.3$ & 93.3 & $2,416.3$ & 13.0 & -10.2 & 12.4 \\
\hline 1991 & $2,263.9$ & $55.1^{\mathrm{a}}$ & $2,457.6$ & 10.2 & 29.5 & 12.0 \\
\hline 1992 & $2,365.5$ & $0.0^{\mathrm{a}}$ & $2,551.4$ & 9.0 & 9.1 & 11.8 \\
\hline 1993 & $2,370.2$ & $62.6^{\mathrm{a}}$ & $2,676.1$ & 10.3 & 11.1 & 11.5 \\
\hline $1993^{b}$ & $3,943.6$ & 139.6 & $8,575.3$ & 11.9 & NA & 19.7 \\
\hline $1994^{\mathrm{b}}$ & $4,267.0$ & 215.0 & $9,563.0$ & 13.7 & -1.0 & 20.2 \\
\hline 1979-93 & \multicolumn{3}{|c|}{ Percent Change } & Average & $\begin{array}{c}\text { Compounded } \\
\text { Annually }\end{array}$ & $\begin{array}{l}\text { Percent } \\
\text { Change }\end{array}$ \\
\hline Fortune 500 & $64.0 \%$ & $-20.1 \%$ & $158.6 \%$ & $12.6 \%$ & $13.6 \%^{\mathrm{e}}$ & $-29.0 \%$ \\
\hline $\begin{array}{l}\text { Comparative } \\
\text { data }\end{array}$ & $152.6^{\mathrm{c}}$ & $37.3^{\mathrm{d}}$ & - & $14.4^{\mathrm{d}}$ & $15.7^{\mathrm{e}}$ & $20.7^{f}$ \\
\hline \multicolumn{7}{|c|}{ NA = not available. } \\
\hline \multicolumn{7}{|c|}{$\begin{array}{l}\text { aCarried to the next decimal place, the figure for } 1992 \text { is } 0.01 \text {. Without companies' recognition } \\
\text { of cumulative past liabilities for retiree health benefits, which was mandated by the end of } 1993 \\
\text { under Statement of Financial Accounting Standards No. } 106 \text {, profits would have been } \$ 60 \text { billion } \\
\text { in } 1991, \$ 71 \text { billion in } 1992 \text {, and } \$ 81.7 \text { billion in } 1993 \text {. } \\
\text { bIn 1994, Fortune merged industrial and service companies to compose the Fortune } 500 \text {. In } \\
\text { 1994, the Fortune } 500 \text { U.S. corporations accounted for } 64 \text { percent of GDP. } \\
\text { cEconomic series used for comparison: GDP. } \\
\text { dEconomic series used for comparison: S\&P } 400 \text {. } \\
\text { eEconomic series used for comparison: S\&P } 500 \text {. } \\
\text { fEconomic series used for comparison: civilian employment. }\end{array}$} \\
\hline
\end{tabular}


Discount rate. The December 31,1996 , real discount rate for the S\&P 400 was approximately 5.3 percent (an expected real growth rate of 3.5 percent plus a dividend yield of 1.8 percent). That rate is well below consensus estimates, partly because of differences of opinion as to its appropriate calculation. In any event, the 5.3 percent real equity discount rate seems close to or below an appropriate equilibrium rate. This opinion is very important in attempting to judge the current level of the stock market.

Although a fairly stable economy has been maintained in the United States in the past 20 years (only two recessions have occurred since 1975), I believe that this risk-reducing development has been more than offset by the increase in stock-price volatility, which is directly associated with lower dividend yields (1.8 percent in December 1996 versus, for example, a 3.9 percent average in 1975).

Perhaps the most unpredictable factor that might further reduce the discount rate is a possible change in the risk tolerance of investors. In the past, risk tolerance appears to have changed primarily when investors became fearful of recession or euphoric after unusually good times. Of course, the future pattern could depart from this apparent long-term historical behavior. The increasing flow of $401(\mathrm{k})$ funds, especially into stock mutual funds, almost regardless of stock-price levels, may represent a form of substantive risk indifference. For quite some time, the historical (since 1926) returns on common stocks-recently, 10-11 percent a year-have been viewed by many as virtually automatic. Risk indifference may not be tested until there is a significant bear market of some duration.

I firmly believe that the enhanced understanding of the equilibrating role of the dividend yield, which emerged from the constant monitoring and evaluation of my various forecasting efforts, should be very helpful in making better long-term forecasts in the future. Nevertheless, the ability to anticipate (or judge) the direction of change (and even better, the magnitude) will remain crucial to the attainment of successful long-term forecasts. 


\section{Using Long-Term Forecasts in Asset Allocation}

In the past 20 years, there appears to have been a growing awareness that asset allocation is the most important aspect of portfolio management. This awareness appears to reflect, in large part, the impact of modern portfolio theory (MPT), which recognizes a broadened perspective of traditional diversification (Markowitz 1959). Asset allocation is much more than a means of moderating the riskiness of individual investment exposures. To the extent that the enriched perspective of MPT has infiltrated investment management practice, it has focused attention on risk-return relationships in achieving, within any portfolio as a whole, the ideal-that is, overall portfolio efficiency guided by investment objectives, risk tolerance of the investor, and expected rates of return from various assets.

Primary attention has been focused on diversification of assets by socalled asset classes, the three major classes being stocks, bonds, and cash equivalents (including short-term money market instruments). A $\$ 1,000,000$ portfolio with $\$ 600,000$ in stocks, $\$ 300,000$ in bonds, and $\$ 100,000$ in cash equivalents may be said to have a 60 percent $/ 30$ percent $/ 10$ percent asset mix.

When asset allocation is primarily concerned with diversification on a long-term basis, it is often referred to as the "strategic mix" of assets, with the implication that this mix will be maintained for 5-10 years or more. But because of the historical volatility of stock market prices and the volatility of bond prices during the past 30 years, managers and investors are naturally tempted to engage in market timing. At the asset class level, market timing involves shifting the proportional representations of such exposures, usually for limited periods of time, away from the strategic mix. Recently, such shifts have been called "tactical asset allocation" (TAA).

Credible long-term forecasts can make significant contributions to the appropriate strategic asset mix for a portfolio. In addition, they may provide an important frame of reference for those who choose to use TAA.

\section{Asset Mix}

MPT prescribes that individual assets should be mixed in a portfolio in a way that achieves efficiency-that is, the optimal relationship between risk and expected return for the portfolio as a whole. This requires separate estimates 
of expected return and risk for each asset in a portfolio and estimates of return correlations between each set of individual assets. For a variety of practical reasons, such an issue-by-issue approach is seldom used. Instead, expected holding-period returns (HPRs) for each of the major asset classes have been widely used. Dealing with three asset classes (or even four to eight asset classes) is much simpler than dealing with hundreds or thousands of individual assets. Of course, the efficacy of this adaptive MPT approach depends on the extent to which credible estimates of future HPRs can be developed for each major asset class.

The work on long-term forecasting reviewed in this monograph has been limited to estimated HPRs, but alternatives to using estimated HPRs include using historical HPRs and using historical holding-period equity risk premiums added to current fixed-income yields. This section discusses the results of these alternatives and briefly summarizes the use of 5-year and 10-year forecasts of HPRs, based on the investment value model (IVM) framework.

Historical Returns from 1926 to the Present. Historical HPRs are often considered to have important implications for the future. ${ }^{1}$ Many commentators have cited such return figures as a reasonable expectation for the future. Unfortunately, experience with this approach has not been encouraging, at least not since the mid-1960s. ${ }^{2}$ Table 7.1 contains data on annual historical HPRs from 1926 through each year from 1966 through 1996 and the ensuing HPRs from each of those years through 1995.

The spreads between the 30 historical HPRs and the respective ensuing HPRs were as small as 1.3 percentage points in 1967 and as large as 19.9 pps in 1994 . The 1994 spread was quite abnormal because from 1994 forward, the ensuing HPR represented only a two-year experience. The average for the 30 spreads shown was 6.13 pps. Excluding the abnormal spreads for 1994 and 1995 , the average spread was 5.40 pps.

Remember that the $1968-81$ period was characterized by the virtual disappearance of any real earnings growth. As the stock market adjusted to this growth erosion, partly through recession-related bear markets, the stage was being set for increases in the ensuing HPRs that were much larger than normal. The experience of the past 30 years is not fully representative of all possible experiences. But that experience does show that extended abnormal return patterns can occur, so credible estimation approaches should be very valuable.

\footnotetext{
${ }^{1}$ For instance, when the latest annual figures were available in early 1991, the S\&P 500 Index holding-period return from 1926 through 1990 was 10.1 percent a year.

${ }^{2}$ See Gray (1993) for additional reasons for the inherent limitations of historical returns as a guide to the future.
} 


\section{Table 7.1. Historical Returns as a Guide to Expected Returns in the Future}

\begin{tabular}{|c|c|c|c|c|}
\hline Year & $\begin{array}{l}\text { HPRs from } 1926 \\
\text { through Year }\end{array}$ & $\begin{array}{l}\text { HPRs from End of } \\
\text { Year through } 1996\end{array}$ & $\begin{array}{l}\text { Percentage Point } \\
\text { Spread }\end{array}$ & $\begin{array}{l}\text { Cumulative Average } \\
\text { Spread through Year } \\
\text { (pps) }\end{array}$ \\
\hline 1966 & $9.9 \%$ & $11.8 \%$ & 1.9 & 1.90 \\
\hline 1967 & 10.2 & 11.5 & 1.3 & \\
\hline 1968 & 10.2 & 11.5 & 1.3 & \\
\hline 1969 & 9.8 & 12.3 & 2.5 & \\
\hline 1970 & 9.6 & 12.6 & 3.0 & 2.00 \\
\hline 1971 & 9.7 & 12.5 & 2.8 & \\
\hline 1972 & 9.9 & 12.3 & 2.4 & \\
\hline 1973 & 9.3 & 13.6 & 4.3 & \\
\hline 1974 & 8.5 & 15.9 & 7.4 & \\
\hline 1975 & 9.0 & 15.0 & 6.0 & 3.29 \\
\hline 1976 & 9.2 & 14.6 & 5.4 & \\
\hline 1977 & 8.9 & 15.8 & 6.9 & \\
\hline 1978 & 8.9 & 16.4 & 7.5 & \\
\hline 1979 & 9.0 & 16.2 & 7.2 & \\
\hline 1980 & 9.4 & 15.3 & 5.9 & 4.39 \\
\hline 1981 & 9.1 & 16.8 & 7.7 & \\
\hline 1982 & 9.3 & 16.5 & 7.2 & \\
\hline 1983 & 9.6 & 16.0 & 6.4 & \\
\hline 1984 & 9.5 & 16.9 & 7.4 & \\
\hline 1985 & 9.8 & 15.6 & 5.8 & 5.02 \\
\hline 1986 & 10.0 & 15.3 & 5.3 & \\
\hline 1987 & 9.9 & 16.5 & 6.6 & \\
\hline 1988 & 10.0 & 16.4 & 6.4 & \\
\hline 1989 & 10.3 & 14.4 & 4.1 & \\
\hline 1990 & 10.1 & 17.6 & 7.5 & 5.21 \\
\hline 1991 & 10.4 & 15.2 & 4.8 & \\
\hline 1992 & 10.3 & 17.2 & 6.9 & \\
\hline 1993 & 10.3 & 19.7 & 9.4 & \\
\hline 1994 & 10.2 & 30.1 & 19.9 & \\
\hline 1995 & 10.5 & 23.1 & 12.6 & 6.13 \\
\hline 1996 & 10.7 & & & \\
\hline
\end{tabular}

Source: HPRs from Ibbotson Associates (1997). 
Historical Equity Risk Premiums Added to Current Fixed-Income Yields. About 20 years ago, an approach to estimating expected returns was developed using historical estimates of equity risk premiums (see Ibbotson and Sinquefield 1982 and Ibbotson Associates 1997). This risk premium measure is based on the simple difference between the historical (1926 through the latest year) arithmetic mean return of the stock market (S\&P 500 Index) and the similar historical mean return on U.S. government obligations. For instance, using a five-year planning horizon, the risk premium for the S\&P 500 was 7.3 percent at the end of 1996 . Added to the five-year U.S. Treasury note yield (often called a "risk-free" rate) at that time of 6.2 percent, the expected return at that time for large stocks was 13.5 percent.

This approach generated expected returns for the stock market in the range of 12 percent to 14 percent during most of the 1987-96 period. Actual HPRs for the S\&P 500 were 15.3 percent a year for that period, a seemingly very credible result. The question is: Is this a spurious or a valid indication of the efficacy of the approach? Believers in the IVM approach would be careful to note that the dividend yield on the S\&P 400 Index dropped from 3.0 percent at year-end 1986 to 1.8 percent at year-end 1996. In the same interval, the trailing 10- to 12 -year real earnings growth rate went from a slightly negative figure to a positive 3.46 percent. The actual price appreciation of about 12.4 percent a year would have been only about 6.8 percent a year if the dividend yield had remained unchanged.

Five-Year and Ten-Year Dividend and Price Forecasts. As reported in Chapter 6, the long-term forecasts using the IVM framework provided very good estimated future HPRs with one possible exception (for which the terminal data has not yet arrived). For the seven stock market forecasts, the average discrepancy between the forecasts and actual returns experienced was $0.8 \mathrm{pp}$. For the four long-term bond forecasts, the average discrepancy was $1.1 \mathrm{pps}$.

\section{Tactical Asset Allocation}

Opinions differ about when the repositioning of assets should be called TAA. Some say TAA should be driven by relative asset value judgments rather than the prospect of future price movements. If one asset is judged to be a better value than another, however, that judgment implies that the disparity will be corrected by the market in the future. Whether or not this question is strictly a semantic issue, long-term forecasts can aid decisions to reposition asset classes temporarily. Long-range forecasts involve elements of future price expectations and current relative value. 
A forecast market trend line and its annualized rate of increase provide a useful frame of reference as actual market movements unfold. Any departure from the trend line suggests the likelihood of larger or smaller HPRs than were estimated at the inception of the long-term forecast. The following examples will illustrate.

1978-88 Forecast. The inception of this 10 -year forecast was midOctober 1978. The S\&P 400-113 at the time-was forecasted to be 343 on October 15,1988 . The 10-year HPR was predicted to be 17.0 percent a year. The implicit annual price appreciation was 11.7 percent a year. Given the 9 percent inflation rate in 1978 and the expectation that it would be at least somewhat lower by 1988 , this forecast indicated well-above-normal real rates of return for the stock market. Figure $\mathbf{7 . 1}$ shows the original trend line, a subsequent trend line reflecting a revised terminal market level (299) and annual price appreciation of 9.7 percent that was adopted in 1983, and the actual quarterly price movement of the S\&P 400 in those 10 years.

Because of the extraordinary real HPRs in the original forecast and no significant price movements above either trend line until 1987, there was no call for any strategic defensive action for more than eight years. However, investors who understood the significance of a restrictive monetary policy should have noted an excellent opportunity to consider a reduction in common stock holdings around the beginning of 1981 because the Federal Reserve Board's policy objective was to at least shrink the growth rate in the money supply. With the inflation reduction that the policy was seeking and the favorable long-term real HPRs in prospect, such reductions, if any, would probably have been modest. With $20 / 20$ hindsight, we can see that the 27 percent decline in stock prices would have been a significant TAA stock reduction opportunity.

As stock prices in 1987 moved up well above the original trend line, a clear opportunity for a reduction in common stock exposures arrived. The IVMbased approach to TAA decisions using a long-term forecast trend line was the major influence in my mid-August 1987 comment that characterized the level of the stock market as reflecting "temporary insanity" (see Gray 1987-1995, specifically, August 14, 1987). Then, on October 19, the Dow Jones Industrial Average (DJIA) fell 500 points, and within four months, the S\&P 400 had dropped more than 30 percent.

1987-92 Forecast. The inception of this five-year forecast was mid-July 1987. The S\&P 400 had risen about 34 percent since the start of the year and closed at 363 on July 15 . From a strategic perspective, market levels appeared to be too high (see Figure 7.1, based on the 1978-88 forecast). In an effort to determine whether that view could be substantiated, I prepared a 1987-92 
Figure 7.1. S\&P 400 Forecasted and Actual Quarterly Movement, October 15, 1978, to October 15, 1988

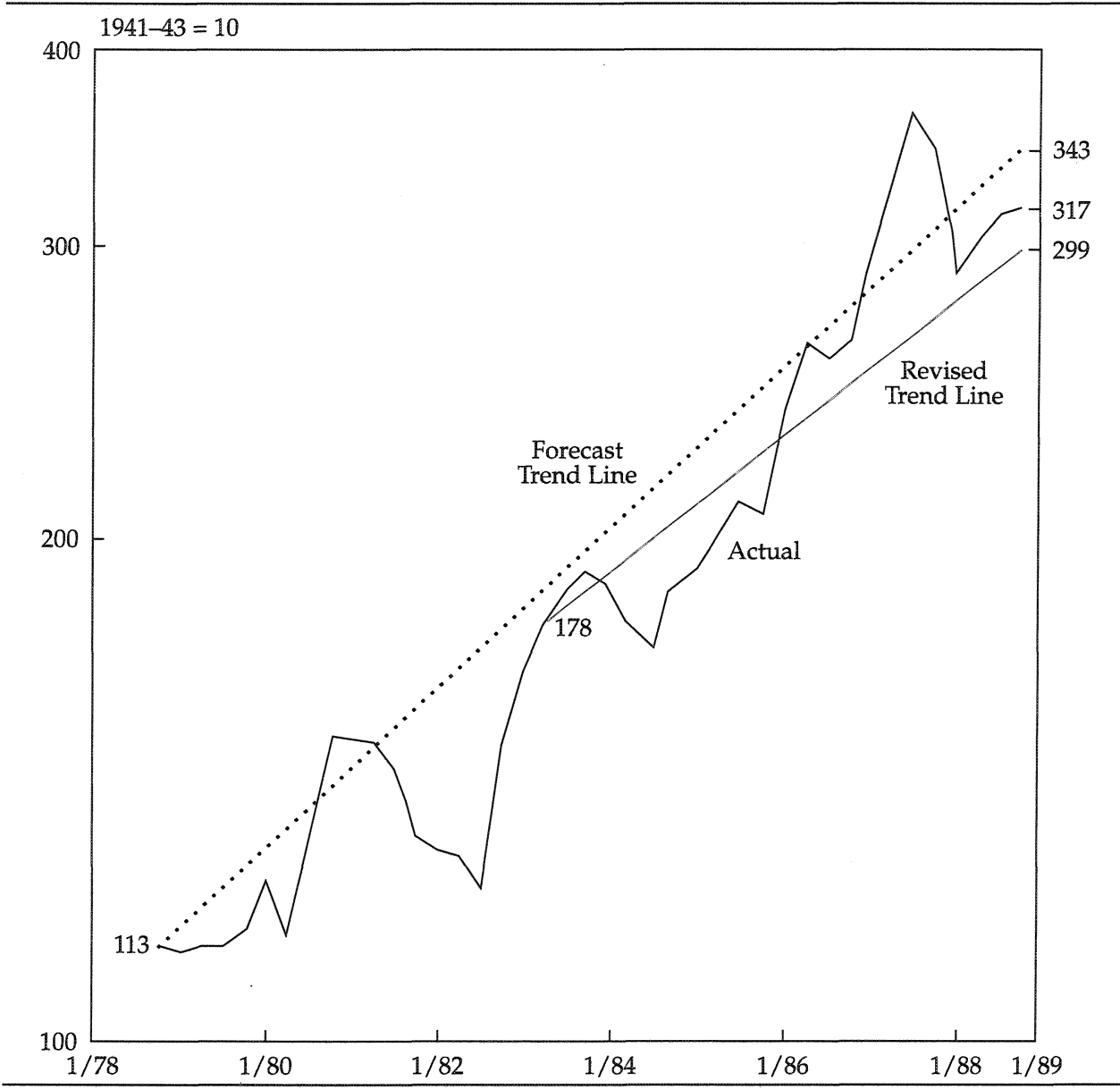

Note: Based on quarterly closing prices. The annual rate of increase for the forecast trend line is 11.7 percent; the annual rate of increase for the revised trend line is 9.7 percent.

forecast that was somewhat optimistic but still reasonable. It resulted in a terminal (July 15,1992$)$ market level of 475 for the S\&P 400 . With projected dividends included, this stream of payments implied an annualized HPR of 8.0 percent. With the U.S. Consumer Price Index running between 4 percent and 5 percent in mid-July 1987 (long-term corporate bond yields were about 9.25 percent), real returns from the equity market were expected to be well below the long-term historical average equity return (at that time, about 6.5 percent a year). 
The original trend line of this forecast is shown in Figure 7.2. Within a month or so after the original forecast, the S\&P 400 reached a peak of 393. Thereafter, the stock market tended downward, but on October 19, 1987, the market took a terrible beating. The DJIA fell more than 500 points, and the S\&P 400 closed at 258. I described this decline as an overreaction to the market level excesses evident since the first of the year (Gray 1987-1995, specifically, October 20,1987). The 258 market level of the S\&P 400 implied a potential price appreciation of 13.7 percent a year in relation to the 475 terminal price in my July 15,1987 , five-year forecast. ${ }^{3}$

For the next year or so, the original and the revised (as of late 1987) forecast trend line indicated that the time was good to build (or rebuild) equity market exposures. Beyond that, the TAA implications of the forecast

\section{Figure 7.2. S\&P 400 Forecasted and Actual Quarterly Movement, July 15, 1987, through July 15, 1992}

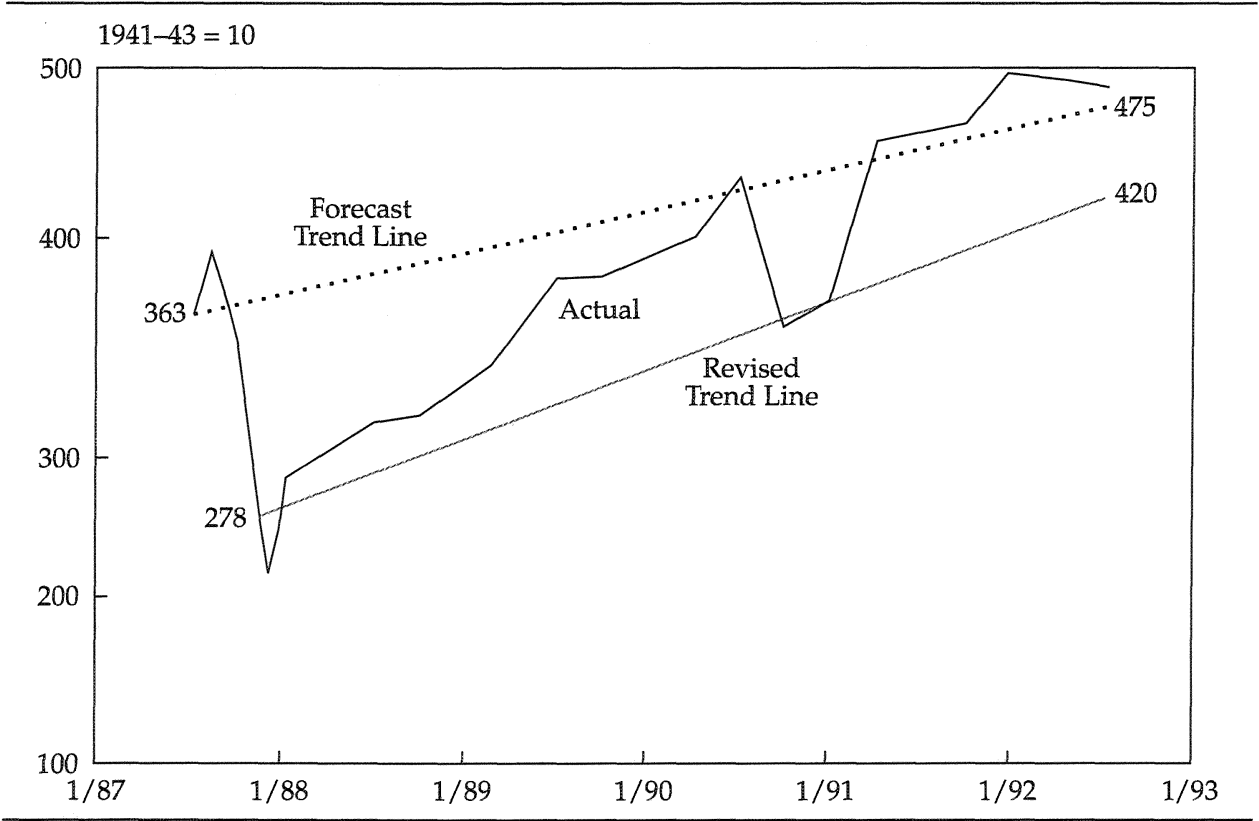

Notes: Based on quarterly closing prices. The annual rate of increase for the forecast trend line is 5.5 percent; the annual rate of increase for the revised trend line is 9.2 percent. For 1987, the market high was 393 and the low was 255; for 1990, the high was 437 and the low was 347.

\footnotetext{
${ }^{3}$ I must admit that by the end of 1987 , with the market still near its low of the year, I displayed a weak-kneed moment by noting that a totally realistic terminal level for the S\&P 400 would be 420 . Even on that basis, however, the implied price appreciation was very attractive- 9 percent a year.
} 
depended on which terminal price you believed the most. The revised forecast should have suggested cutting back U.S. equity exposures no later than mid1989, the original forecast perhaps by mid-1990. In either case, the bear market of 1990 (when the S\&P 400 dropped 21 percent between July and October) should have triggered consideration of that opportunity to rebuild equities. In mid-October 1990, I wrote, "Excellent returns (about 12 percent a year) seemed most likely."

These examples illustrate how long-term forecast trend lines may be used to help make TAA decisions. Two things should be quite clear. First, credible long-term forecasts can be very useful in maintaining perspective on the dayto-day (week-to-week, and so on) movements in the market. Second, we humans have difficulty sticking with an original forecast when market action veers off the long-term trend line. Of course, this problem is inescapable in any approach to TAA.

\section{Conclusion}

The IVM framework involves two benefits for either strategic or TAA decisions. First, it focuses on the fundamental factors that guide the valuation of marketable assets-levels of current income payments, growth rates, and discount rates. Second, it demands a highly disciplined understanding and use of history in making inherently difficult decisions. 


\section{Implications for the Future}

Viewing the prospects for financial asset returns within the framework of the investment value model (IVM) means putting a major focus on estimated discount rates and earnings growth rates, including the difference between them (i.e., the dividend yield). Also, specifically at the forecast horizon (5 or 10 years hence), an estimated future level of dividend payments is needed to estimate the stock market level at the chosen termination date. Given the market level at the inception, a credible estimate of the stream of dividend payments, and the estimated/calculated terminal market level, the analyst can calculate the holding-period returns (HPRs).

The historical experience of each IVM factor provides useful perspective for any effort that attempts to gauge the range within which future HPRs are likely to fall. These were reviewed in earlier chapters. This concluding chapter will summarize some of the key aspects, in hopes that this will help develop reasonable future HPR forecasts. Table $\mathbf{8 . 1}$ provides various estimated terminal prices, using a five-year forecast horizon, and the implications for corresponding HPRs resulting from various combinations of streams of dividend payments and estimated terminal dividend yields. The sections of this chapter provide discussions of the underlying considerations.

\section{Dividends}

With few exceptions, dividend payments represent a partial distribution of earnings. From 1926 through 1995, S\&P 400 dividends averaged 58.4 percent of earnings; if 1930-1932 are excluded (years in which dividends exceeded earnings), dividends averaged 55.3 percent of earnings. From 1971 through 1995 ( 25 years), however, dividends averaged about 47 percent of earnings. The pressures of inflation on financial resources were a major influence on the direction of the percentage of dividend payments between roughly 1971 and 1980, whereas corporate restructuring and stock-repurchase programs appear to have been major influences in the more recent years.

Based on S\&P 400 Index earnings of 41.15 , the dividend payout was only 37.9 percent in 1996 . The percentage payout, however, may increase in the next few years. One reason is that the rate of earnings growth should moderate substantially. For example, if earnings increase an average of 5 percent (3 percent real and 2 percent inflation) from 1996 through 2001 and dividends increase at 7 percent a year, the dividend payout ratio would be about 42 percent in 2001 . Table 8.1 considers possible dividend growth rates ranging from 5 percent to 10 percent. 
Table 8.1. Parameters of Future Stock Market Behavior, S\&P 400, 1997-2001

\begin{tabular}{|c|c|c|c|c|c|}
\hline \multicolumn{6}{|c|}{ Market conditions as of $2 / 31 / 96$ : } \\
\hline Price level & \multicolumn{2}{|c|}{870} & & & \\
\hline Dividend (1996) & \multicolumn{2}{|c|}{15.58} & & & \\
\hline Yield & \multicolumn{2}{|c|}{$1.79 \%$} & & & \\
\hline \multicolumn{6}{|l|}{ Market projections: } \\
\hline & \multicolumn{5}{|c|}{ Average Compound Dividend Growth Rate } \\
\hline Factor & $5 \%$ & $6 \%$ & $7 \%$ & $8 \%$ & $10 \%$ \\
\hline \multicolumn{6}{|c|}{ Dividend payment (\$) } \\
\hline First year & 16.36 & 16.51 & 16.67 & 16.83 & 17.14 \\
\hline Second year & 17.18 & 17.50 & 17.84 & 18.17 & 18.85 \\
\hline Third year & 18.04 & 18.56 & 19.09 & 19.63 & 20.74 \\
\hline Fourth year & 18.94 & 19.67 & 20.42 & 21.20 & 22.81 \\
\hline Fifth year & 19.88 & 20.85 & 21.85 & 22.89 & 25.09 \\
\hline \multicolumn{6}{|l|}{ Terminal yield (\%) } \\
\hline Set A & 3.50 & 3.25 & 3.00 & 2.75 & 2.50 \\
\hline Set B & 3.00 & 2.75 & 2.50 & 2.25 & 2.00 \\
\hline Set C & 2.50 & 2.25 & 2.00 & 1.75 & 1.50 \\
\hline Set D & 2.00 & 1.75 & 1.50 & 1.50 & 1.25 \\
\hline \multicolumn{6}{|l|}{ Terminal price level } \\
\hline Set A & 568 & 641 & 728 & 832 & 1,004 \\
\hline Set B & 663 & 758 & 874 & 1,017 & 1,254 \\
\hline Set $C$ & 795 & 927 & 1,092 & 1,308 & 1,673 \\
\hline Set D & 994 & 1,191 & 1,457 & 1,526 & 2,007 \\
\hline \multicolumn{6}{|c|}{ Holding-period return (\%) } \\
\hline Set A & -5.69 & -3.49 & -1.13 & 1.42 & 5.16 \\
\hline Set $B$ & -2.96 & -0.46 & 2.29 & 5.29 & 9.64 \\
\hline Set C & 0.37 & 3.36 & 6.65 & 10.41 & 15.81 \\
\hline Set D & 4.67 & 8.36 & 12.65 & 13.70 & 19.91 \\
\hline
\end{tabular}

Note: Each "set" provides a range of possible outcomes. The respective dividend yield assumptions are applied to the fifth-year dividend payments to indicate terminal price. The series of dividend payments and the terminal price determine the holding-period returns.

\section{Terminal Dividend Yield}

Dividend yield levels in the future should be reasonable within the context of the patterns (i.e., ranges and/or trends) of discount rates and expected growth rates in the past as well as the factors that have influenced those patterns. As suggested throughout this monograph, viewing such experiences on an inflation-adjusted basis (i.e., in real terms) is optimal for understanding and applying estimates of these variables to long-range forecasting. 
Discount Rates. As indicated in Appendix I, the real discount rates in the stock market averaged about 6.5 percent from 1871 to 1929 . Although it had its ups and downs, the basic trend was flat. The extreme abnormalities of the 1930s created difficult estimation problems, but the average rate in 1941 appears to have been about 7 percent. The fear of a severe depression after World War II caused unusually high discount rates between 1947 and 1955, with a peak of about 11.5 percent in 1950 . In contrast, after the disastrous inflation binge of the 1970s, dramatic changes in monetary and fiscal policies restored confidence in the early 1980 s. Thereafter, the below-average market discount rates seemed to reflect a return to more normal profitability expectations, which did come about.

In spite of some tumultuous periods since the early 1940s, the real discount rate trend has tended somewhat downward, at least since the mid1950s. As shown in Figure 4.1, the equilibrium real rate was probably 6.5-7.0 percent in 1941 and 5.0-5.5 percent in 1996. Behind this apparent decline lay some measurable reductions in the riskiness of common stock ownership. Greater stock price volatility inherent to small dividend yields might well hinder an extension of that trend when the downside of rising yields has been experienced.

Expected Growth Rates. Because of developments since the early 1970s, earnings (instead of dividends) have become the primary focus of attention. It is the earnings time series that most influences the future growth rate expectations implicit to the pricing mechanism in the stock market. As with the discount rate, the clearest view of relevant patterns is found in the real (inflation-adjusted) earnings time series. Although the S\&P 400's 19261996 real growth rate of 2.2 percent may be an interesting (indeed, surprising) statistic within its largely U.S. setting of 3 percent real GDP growth during the same period, it appears to have little significance in determining the level of stock prices. Instead, at any given time (but with two notable exceptions), it appears that the most recent 10-15 years of trailing earnings are most significant.

There have been two periods (1929-1941 and 1968-1981) in which the real earnings growth rate was negligible. At the other extreme, there were several years in the early 1950s in which trailing earnings growth was about 4 percent. The rest of the time, the trailing growth pattern was somewhere in the $0-4$ percent range. For the most part, trailing periods of experience appeared to influence the pricing of stocks. This was reflected in tendencies toward a strong inverse relationship between such trailing patterns and the respective (then) current level of the dividend yield. 
With the corporate restructuring that began in the early 1980 s, the stage was set for a renaissance in corporate earnings. During the 1984-96 period, the real earnings growth rate of the $S \& P 400$ was 3.46 percent. Whereas the average dividend yield was 4.9 percent in 1981 , it was down to 1.7 percent at the end of 1996. Only in the immediate (roughly 10-year) aftermath of World War II have such trailing earnings grown at more than 3.5 percent. That should justify some concern about what will happen to stock market levels when that rising growth rate pattern subsides-especially if it begins to erode, even only somewhat.

\section{Terminal Price}

The expected growth rate and the discount rate at the end of any forecast horizon will, presumably, determine the dividend yield at that time. To estimate a terminal price (or a range of terminal prices) at, say, the end of 2001, the dividend payment at that time is simply divided by the inferred dividend yield (or a range of dividend yields), as shown in Example 8.1.

Example 8.1: If the estimated then-current dividend payment is 20.85 and the dividend yield (inferred from the discount rate and future growth rate assumptions) is 2.25 percent, the forecast terminal level will be 927 .

If the estimated then-current dividend payment is 22.89 and the dividend yield is 1.75 percent, the forecast terminal level will be 1,308 .

\section{Holding-Period Returns}

Starting with the S\&P 400 market level of 870 on December 31, 1996, the assumed dividend experience and corresponding terminal figures may be used to calculate HPR forecasts, as illustrated in Example 8.2.

Example 8.2: Assuming a dividend stream with an average annual 6 percent growth rate and an estimated terminal level of 927 , the HPR forecast is 3.36 percent a year.

Assuming a dividend stream with an average annual 8 percent growth rate and an estimated terminal level of 1,308 , the HPR forecast is 10.41 percent a year.

The HPR forecasts should be viewed against the backdrop of inflation expectations for the next five years. For example, if you assumed a 3 percent rate of inflation, the real HPR would be negligible in the first example and about 7.4 percent in the second example. It may be interesting to note that, as reported by Ibbotson Associates (1997), 7.4 percent is exactly the average 
annual real HPRs large-company stocks (S\&P 500) generated between 1926 and 1996. However, that 70-year experience has no significance for 1997-2001 prospects.

\section{Concluding Observations}

If real HPRs in the 1997-2001 period are to be comparable to the 1926-96 average (7.4 percent), dividends will need to grow at least an average annual rate of 8 percent in that period and the dividend yield will have to be less than 2.0 percent in the year 2001 . This scenario is possible, but at this time, smaller HPRs seem more likely. 


\section{Appendix A. Yearly Average Expected Returns on the S\&P 400 Index}

At the beginning of the 57-year period shown in Table A.1, the estimated expected return on the S\&P 400 was 7 percent, and in 1996 , it was 5.46 percent. The expected return fell between 5 percent and 7 percent in 32 of the 57 years (that is, 56 percent of the time). The 1947-55 subperiod was quite abnormal. The expected return ranged between 7.83 percent and 11.42 percent. This period, which started shortly after World War II, was strongly affected by a widespread belief that another Great Depression was probable. The 1981-89 subperiod was also quite abnormal: The expected return ranged between 4.76 percent and 2.97 percent. This period started at the end of 13 disastrous years of generally rising inflation in the United States, and toward the end of the period, the market was greatly cheered by fundamental policy changes designed to lower inflation and marginal tax rates. Both were expected to improve growth rates in real U.S. gross domestic product and employment opportunities. As it turned out, from 1981 through 1989 (including the 198182 recession), real GDP increased 3.16 percent a year, and between 1968 and 1981 , it increased 2.83 percent a year. Since then through 1996 , it has increased about 1.89 percent a year.

The two abnormal periods account for 18 years out of the total. When those years are excluded from the 1941-96 time series, in 82 percent of the other 39 years, estimated expected stock returns fell between 5 percent and 7 percent.

These abnormal experiences indicate that future growth rate expectations may be driven by strong convictions that override the actual trends of the preceding two or three earnings cycles. 
Table A.1. Expected S\&P 400 Returns

\begin{tabular}{|c|c|c|c|c|c|c|c|}
\hline Year & $\begin{array}{l}\text { Average } \\
\text { Dividend } \\
\text { Yield }^{\mathrm{a}}\end{array}$ & $\begin{array}{l}\text { Trailing Real } \\
\text { Earnings } \\
\text { Growth Rate }\end{array}$ & $\begin{array}{l}\text { Expected } \\
\text { Return }^{\mathrm{c}}\end{array}$ & Year & $\begin{array}{l}\text { Average } \\
\text { Dividend } \\
\text { Yield }^{\mathrm{a}}\end{array}$ & $\begin{array}{l}\text { Trailing Real } \\
\text { Earnings } \\
\text { Growth Rate }\end{array}$ & $\begin{array}{l}\text { Expected } \\
\text { Return }^{\mathrm{c}}\end{array}$ \\
\hline 1940 & $5.9 \%$ & NA & NA & 1970 & $3.5 \%$ & $3.06 \%$ & $6.56 \%$ \\
\hline $1941^{\mathrm{d}}$ & 7.0 & $0.00 \%$ & $7.00 \%$ & 1971 & 2.9 & 2.92 & 5.82 \\
\hline 1942 & 6.3 & 0.40 & 6.70 & 1972 & 2.6 & 2.78 & 5.38 \\
\hline 1943 & 5.0 & 0.81 & 5.81 & 1973 & 2.9 & 2.63 & 5.53 \\
\hline 1944 & 4.9 & 1.21 & 6.11 & $1974^{\mathrm{d}}$ & 4.0 & 2.49 & 6.49 \\
\hline 1945 & 4.1 & 1.62 & 5.72 & 1975 & 3.9 & 2.10 & 6.00 \\
\hline 1946 & 3.9 & 2.03 & 5.93 & 1976 & 3.7 & 1.71 & 5.41 \\
\hline 1947 & 5.4 & 2.43 & 7.83 & 1977 & 4.6 & 1.32 & 5.92 \\
\hline $1948^{\mathrm{d}}$ & 6.3 & 2.84 & 9.14 & 1978 & 5.1 & 0.93 & 6.03 \\
\hline 1949 & 7.0 & 3.43 & 10.43 & 1979 & 5.2 & 0.54 & 5.74 \\
\hline $1950^{\mathrm{d}}$ & 7.4 & 4.02 & 11.42 & 1980 & 4.8 & 0.14 & 4.94 \\
\hline 1951 & 6.0 & 4.02 & 10.02 & $1981^{d}$ & 4.9 & -0.25 & 4.65 \\
\hline 1952 & 5.5 & 4.01 & 9.51 & 1982 & 5.3 & -0.54 & 4.76 \\
\hline 1953 & 5.4 & 4.01 & 9.41 & 1983 & 4.1 & -0.84 & 3.26 \\
\hline 1954 & 4.8 & 4.00 & 8.80 & $1984^{\mathrm{d}}$ & 4.1 & -1.13 & 2.97 \\
\hline $1955^{\mathrm{d}}$ & 4.1 & 4.00 & 8.10 & 1985 & 3.8 & -0.63 & 3.17 \\
\hline 1956 & 3.7 & 3.23 & 6.93 & 1986 & 3.1 & -0.13 & 2.97 \\
\hline 1957 & 4.1 & 2.46 & 6.56 & 1987 & 2.6 & 0.37 & 2.97 \\
\hline 1958 & 3.8 & 1.69 & 5.49 & 1988 & 3.2 & 0.87 & 4.07 \\
\hline $1959^{d}$ & 3.2 & 0.92 & 4.12 & $1989^{d}$ & 3.2 & 1.37 & 4.57 \\
\hline 1960 & 3.4 & 1.19 & 4.59 & 1990 & 3.3 & 1.69 & 4.99 \\
\hline 1961 & 3.0 & 1.46 & 4.46 & 1991 & 2.8 & 2.01 & 4.81 \\
\hline 1962 & 3.4 & 1.73 & 5.13 & 1992 & 2.7 & 2.33 & 5.03 \\
\hline 1963 & 3.2 & 2.00 & 5.20 & 1993 & 2.4 & 2.65 & 5.05 \\
\hline 1964 & 3.0 & 2.27 & 5.27 & 1994 & 2.4 & 2.97 & 5.37 \\
\hline 1965 & 3.0 & 2.54 & 5.54 & 1995 & 2.2 & 3.30 & 5.50 \\
\hline 1966 & 3.2 & 2.81 & 6.01 & 1996 & 2.0 & 3.46 & 5.46 \\
\hline 1967 & 3.0 & 3.07 & 6.07 & 1997 & & & \\
\hline $1968^{\mathrm{d}}$ & 2.9 & 3.34 & 6.24 & 1998 & & & \\
\hline 1969 & 3.0 & 3.20 & 6.20 & 1999 & & & \\
\hline
\end{tabular}

NA $=$ not available.

aDividend payment/average stock prices for respective calendar years.

${ }^{b}$ Based on peak-to-peak real earnings growth rates. For the peak years (denoted by a superscript $d$ ), the indicated rate represents such growth rates for the two to three cycles ending in those years (in each case, reflecting a time period of 10-12 years). For every other year, the indicated rate represents a straight-line interpolation between the growth rates shown for the peak years on either side of these other years. S\&P 400 inflation-adjusted earnings (1926-96) are shown in Appendix G.

'Expected return in each case represents an estimate of the average real expected return (i.e., discount rate) on the market (that is, the S\&P 400 Index).

${ }^{\mathrm{d}} \mathrm{S} \& \mathrm{P} 400$ earnings-cycle peak years. 


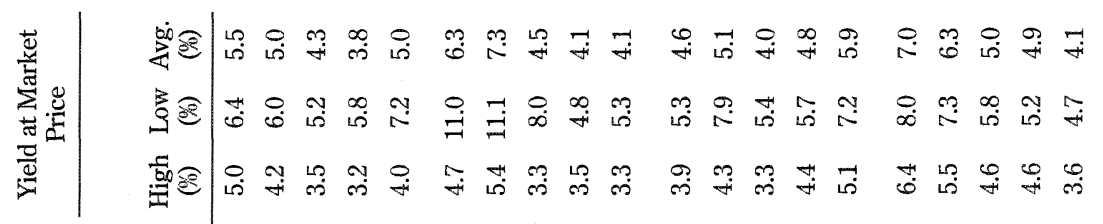

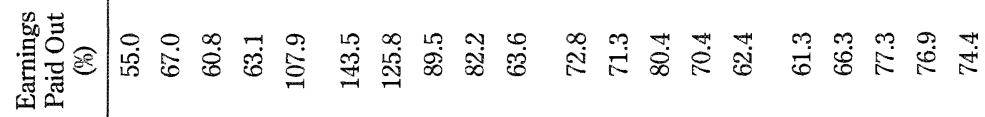

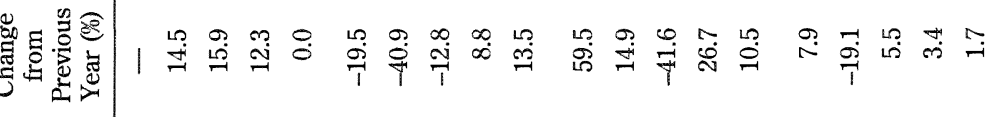

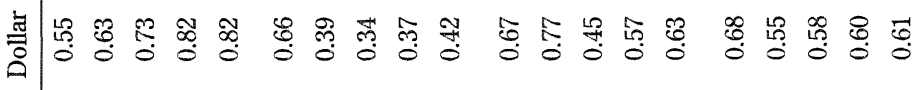

量

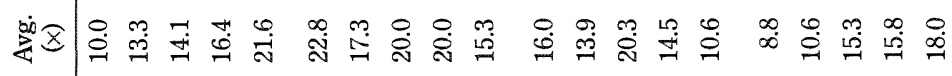

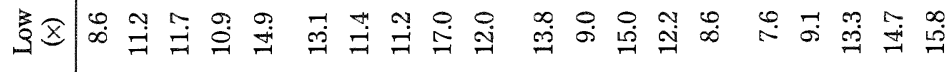

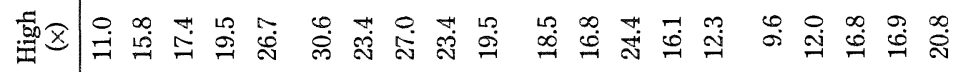

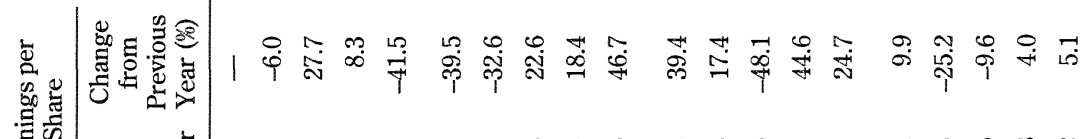

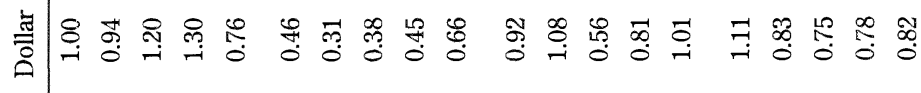

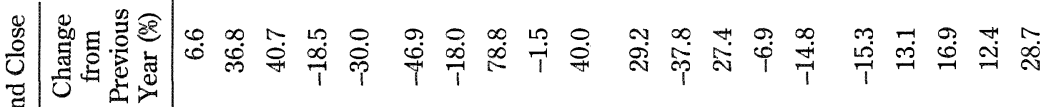

壳

竞

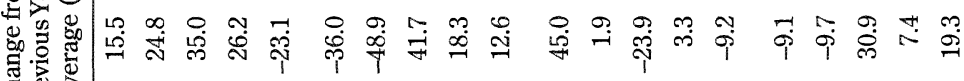

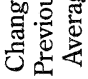

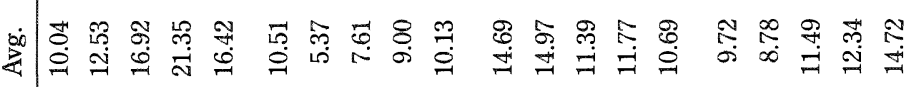

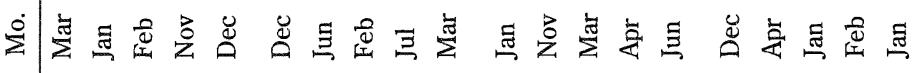

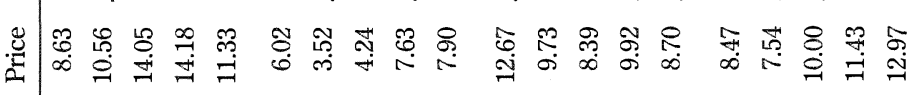

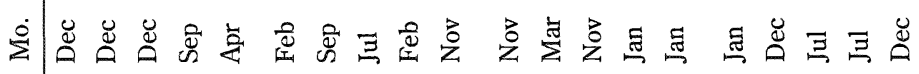

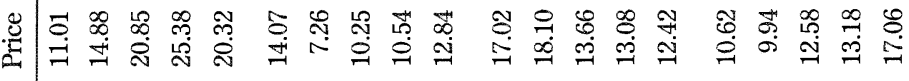

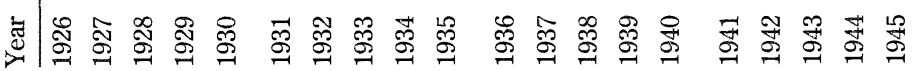




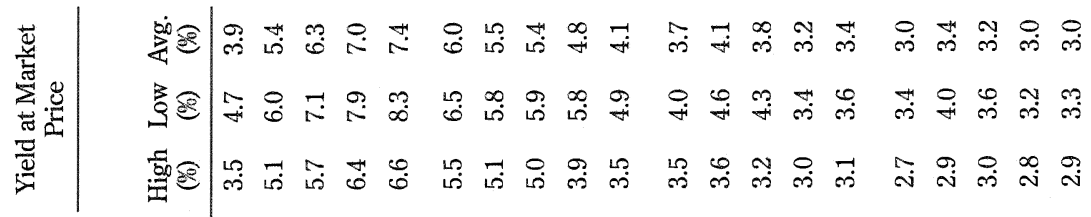

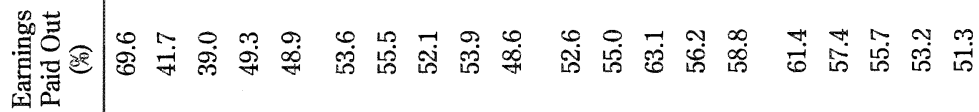

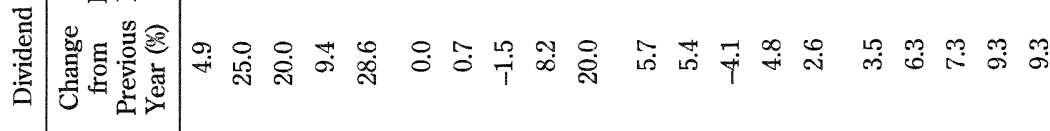

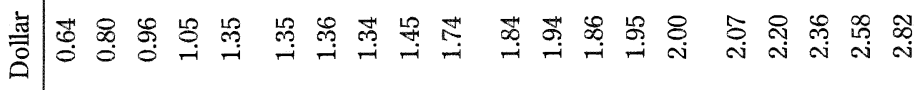

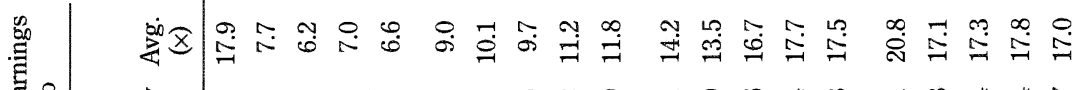

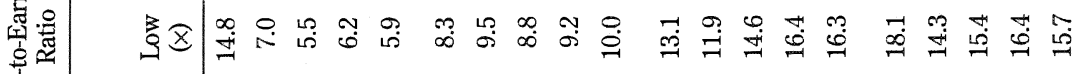

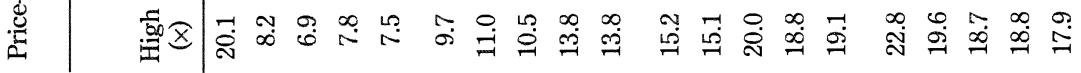

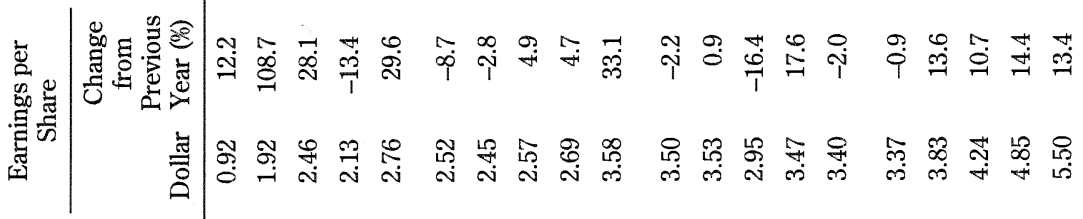

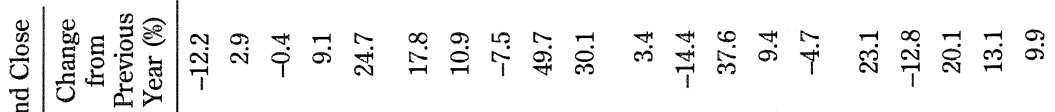

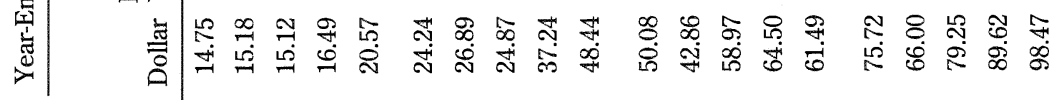

हี

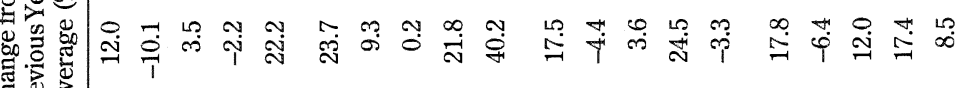

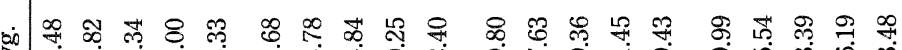

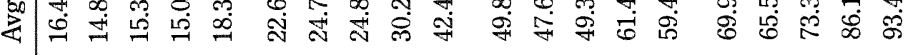

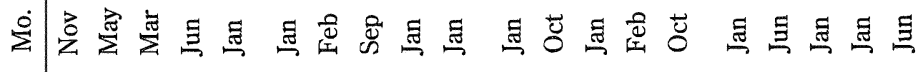

幽유

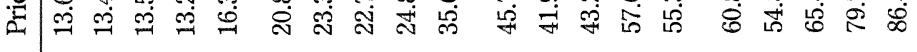

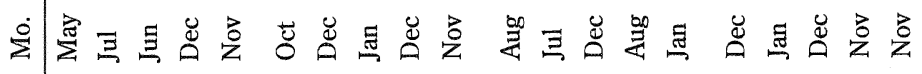

ఖ

茫

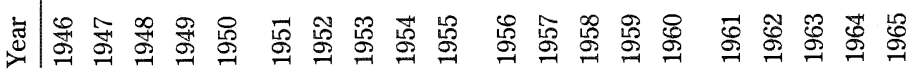




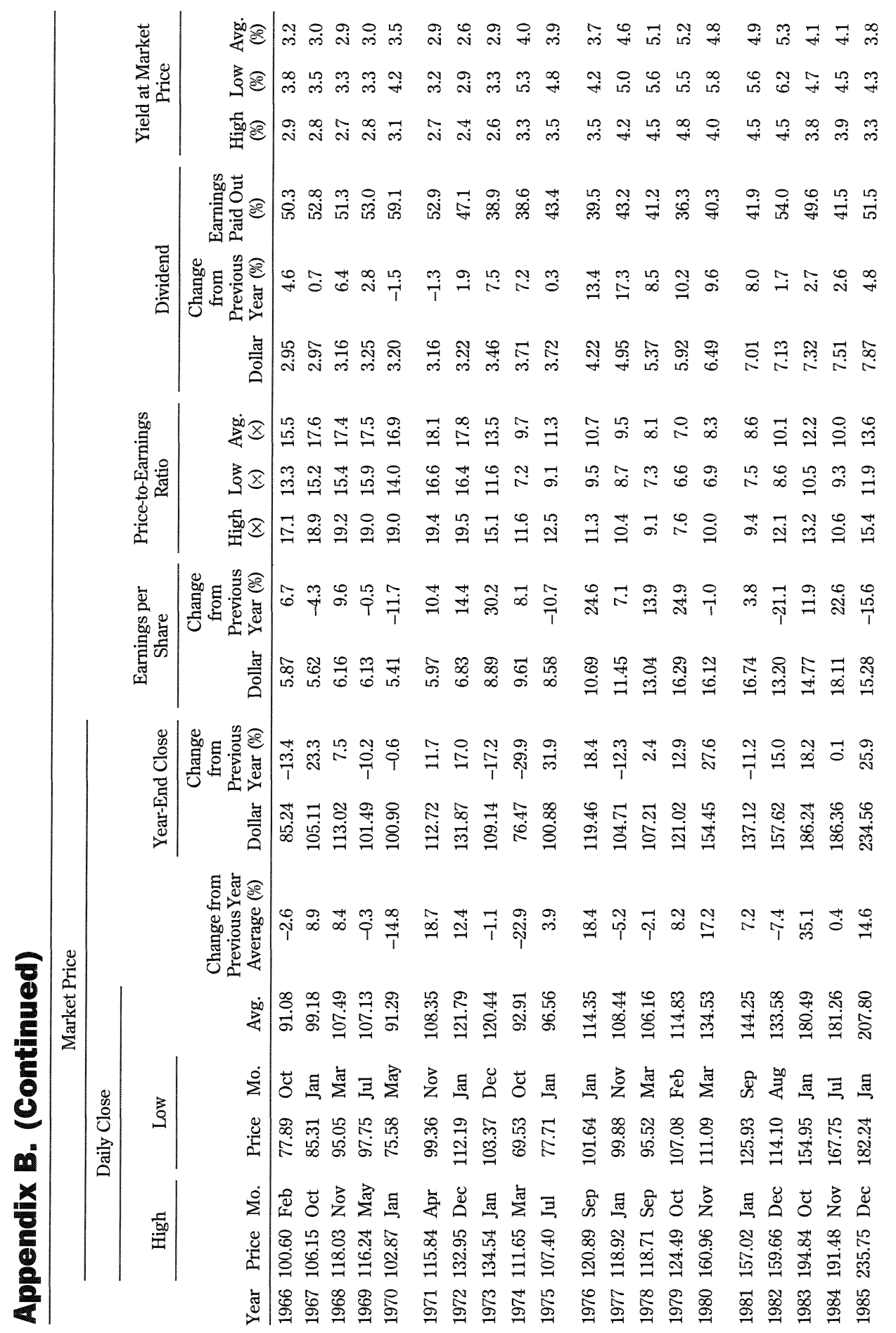




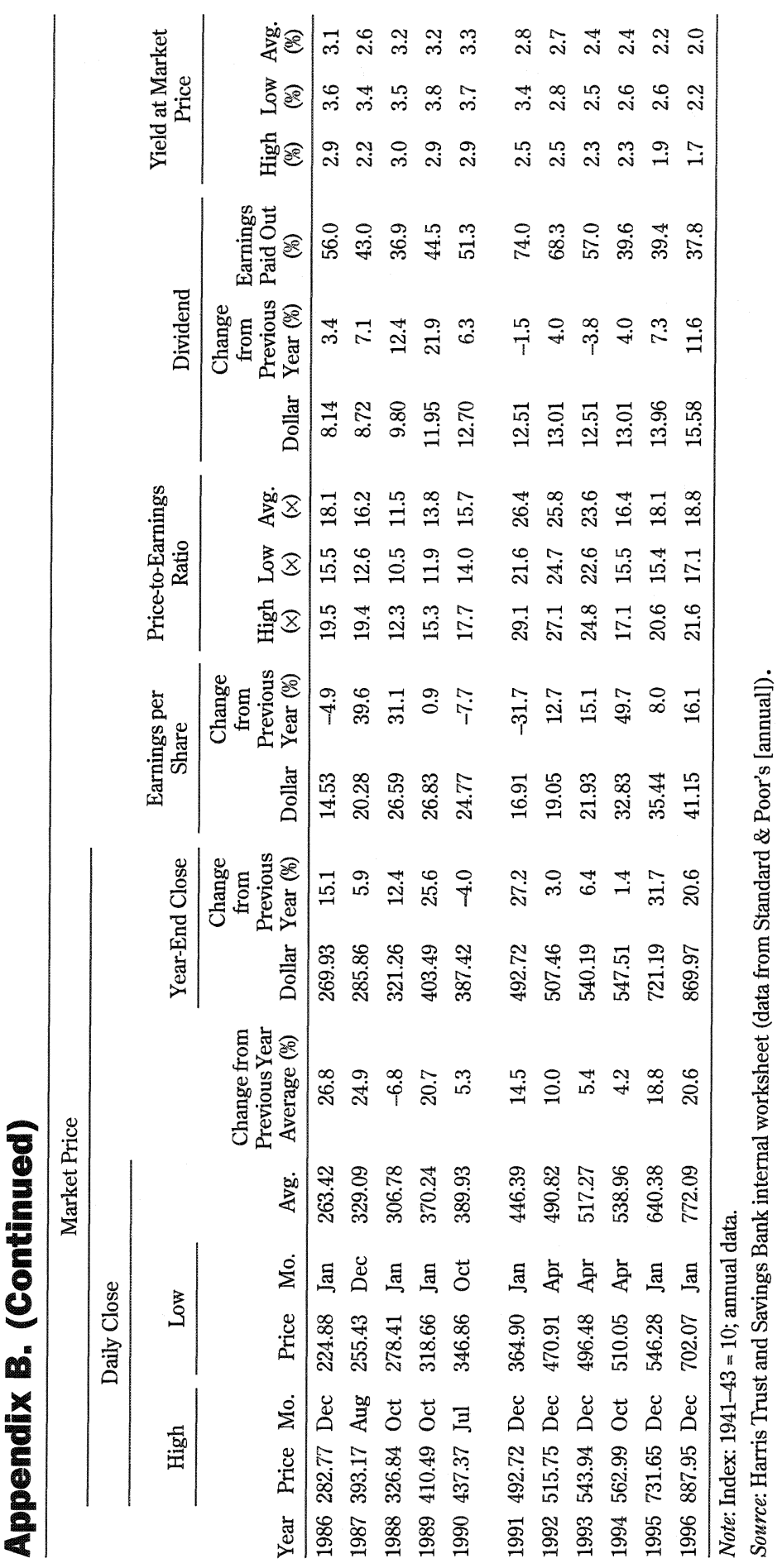




\section{Appendix C. The Tax Premium as a Component of the Discount Rate}

In theory, rational investors do not invest without the expectation of a rate of return that is satisfactory after expected inflation and applicable taxes have been taken into account. Because of differences in tax status, not all investors have the same requirements for a given rate of return; indeed, their requirements may differ considerably. Presumably, the pricing of stocks and bonds reflects such varied views. At any time, current prices are a major determinant of expected returns, which are often referred to as the markets' "required" returns.

The amount of required return is constantly changing. Usually, day-to-day changes are quite small, but they may be dramatic when significant changes in expectations take place. Expectations regarding future income payments and riskiness are the most important causes of change. Riskiness is defined by two factors-the inherent riskiness of an investment exposure and the risk tolerance of investors. The required return reflects the amount of expected reward that is needed to clear the market:

- Perceptions that riskiness is increasing (usually caused by deterioration in the economy or financial circumstances and/or the likelihood of significant war or military action) increase the required return.

- Perceptions that riskiness is decreasing (usually arising from an improving economy or financial circumstances and/or euphoric conditions) decrease the required return.

The evidence that changes in inflation expectations affect the bond market and also the stock market seems to be incontestable. With bonds, a measurable change in the yield to maturity is usually accompanied by somewhat changed stock prices. At times, inflation expectations' impact on the stock market can be difficult to discern, however, because changes in expectations may have roughly comparable effects on the expected growth rate and, perhaps, on the required discount rate. In that case, a change in expected stock returns occurs without a significant impact on stock prices.

The evidence on the impact of taxes and of changes in tax rates on return expectations is more ambiguous, at least for long periods of time. On the one hand (on the basis of my recollections), several commentators have noted that changes in tax rates are one of the important factors and have provided examples showing movements of investment asset prices that are inversely related to changes in tax rates (for example, prices have risen when tax rates were expected to decline or actually did decline). On the other hand, an 
examination of the stock market's real holding-period returns (HPRs) and estimated expected returns for the stock market in the past 125 years reveals the following perplexing anomalies:

- Real HPRs were 6.58 percent from 1871 to 1926 (Wilson and Jones 1987) and have been about 7.6 percent since then. Therefore, the real returns on the stock market during the earlier 56 years and the 70 years since 1926 show an increase of almost 100 basis points. Shouldn't taxation during the past 70 years ${ }^{1}$ (although rates have changed many times) have constrained real HPRs?

- The average real expected return on stocks was estimated to be about 6.5 percent during the 1871-1929 period (see Appendix I). The estimated real expected return on stocks in 1996 was about 5.5 percent (see Chapter 4). More importantly, the dividend yield component was 5.5 percent in 1926 but only 2.0 percent in 1996 . By itself, that reduction in the dividend yield accounted for about 1.5 percent a year of the annual 6.4 percent stock market appreciation during that 70-year period.

Clearly, factors beyond the tax premium have been working on expected stock returns in the past 70 years. The two major factors-the discount rate and the expected growth rate-can fully account for what has happened. The real discount rate has declined (stock holdings are less risky), and the real expected growth rate has risen (partly as a result of corporate restructuring since the early 1980s). Both have contributed to the dramatic decline in the dividend yield. If the discount rate reflected an important difference in a tax premium prior to and since 1926, it has been offset by other factors by a considerable margin.

Furthermore, keep in mind that a definitive determination of tax effects is hampered by the fact that enormous amounts of common stock are now subject to little, if any, taxation and/or have become partially sheltered. Such stocks include holdings in employee benefit plans, foundations, endowment funds, HR-10 plans, and 401(k) arrangements.

In any case, the long-term behavior of the stock market during the past 70 years is understandable without any effort to allow for a tax premium or changes in taxation. Also, the long-term forecasts made between 1977 and 1987, discussed in Chapter 4, proved to be quite successful despite paying little attention to changes in tax rates.

In the past, one reason that changes in tax rates may have had somewhat limited significance is that rates changed both up and down and any rate change might not survive more than a year or so. Therefore, a beneficial reduction in tax could not be relied on by investors with other than short horizons.

\footnotetext{
${ }^{1}$ Taxation has been significant in the United States only since 1926.
} 
Some recent considerations of possible tax reductions have given serious attention to the idea of indexing the cost basis of common stocks to the U.S. Consumer Price Index (CPI). Because the cost basis is such a fundamental aspect of calculating a capital gain, if the idea is adopted, this might be more enduring than simply changes in tax rates. ${ }^{2}$ So, the tax premium could possibly be significant in the future.

${ }^{2}$ Of course, the significance of any cost-basis indexing would be tempered if CPI figures were adjusted downward to correct the perceived overstatement of inflation in the figures calculated by the U.S. Bureau of Labor Statistics. 


\section{Appendix D. Expected Return Spread and Estimation of Two-Year Stock Market Forecast, 1978-79 (beginning year-end 1977)}

Historical dividend payments for the years just prior to 1978 for the S\&P 400 Index were as follows:

\begin{tabular}{ccc}
\hline Year & Payment & Percentage Increase \\
\hline 1972 & 3.22 & - \\
1973 & 3.46 & $7.5 \%$ \\
1974 & 3.71 & 7.2 \\
1975 & 3.72 & 0.3 \\
1976 & 4.22 & 13.7 \\
1977 & 4.95 & 17.3 \\
\hline
\end{tabular}

The 1976-79 spread was estimated as follows:

\begin{tabular}{lc}
\hline 1973-77 dividend growth rate & $8.98 \%$ \\
Dividend yield (1977 average) & $\frac{4.60}{13.58 \%}$ \\
Expected return & $13.58 \%$ \\
Common stock expected return & 8.34 \\
Corporate bond expected return & $5.24 \%$ \\
Equity risk premium & $10.11 \%$ \\
Estimated actual 1976-79 spread $^{1}$ & \\
\hline
\end{tabular}

The two-year (1978-79) return spread between the S\&P 500 Index and corporate bonds was estimated as follows: ${ }^{2}$

\begin{tabular}{|c|c|c|c|c|c|c|c|}
\hline & \multicolumn{3}{|c|}{$\begin{array}{l}\text { Actual Percentage Point } \\
\text { Spread }\end{array}$} & \multirow{2}{*}{$\begin{array}{c}\begin{array}{c}\text { Estimated } \\
\text { Actual }\end{array} \\
\begin{array}{c}1978-79 \\
\text { (per year) }\end{array}\end{array}$} & \multicolumn{3}{|c|}{$\begin{array}{l}\text { Actual Percentage Point } \\
\text { Spread }\end{array}$} \\
\hline & 1976 & 1977 & $\begin{array}{c}\text { 1976-77 } \\
\text { (per year) }\end{array}$ & & 1978 & 1979 & $\begin{array}{c}\text { 1978-79 } \\
\text { (per year) }\end{array}$ \\
\hline Common stock & 23.8 & -7.2 & 7.2 & & 6.6 & 18.4 & 12.3 \\
\hline Corporate bonds & $\underline{18.6}$ & $\underline{1.7}$ & $\underline{9.9}$ & & -0.1 & -4.2 & -2.1 \\
\hline Spread & $\overline{5.2}$ & $-\overline{8.9}$ & $-\overline{2.7}$ & 22.9 & $\overline{6.7}$ & 22.6 & 14.4 \\
\hline
\end{tabular}

\footnotetext{
${ }^{1}$ Based on 1952-75 regression: Expected return spread $\times 1.7929+0.7175$.

${ }^{2}$ The mixing of the S\&P 500 rates of return with estimates of the S\&P 400 return for comparison with corporate bond returns may arouse some concern. The holding-period returns for the two stock indexes have been fairly similar, however, over long periods of time. In the table, the estimated actual 1978-79 spread was found by subtracting the actual 1976-77 return spread from the estimated 1976-79 return spread, $10.1-(-2.7)=12.8$, and adding the difference to the estimated 1976-79 return spread, $12.8+10.1=22.9$.
} 


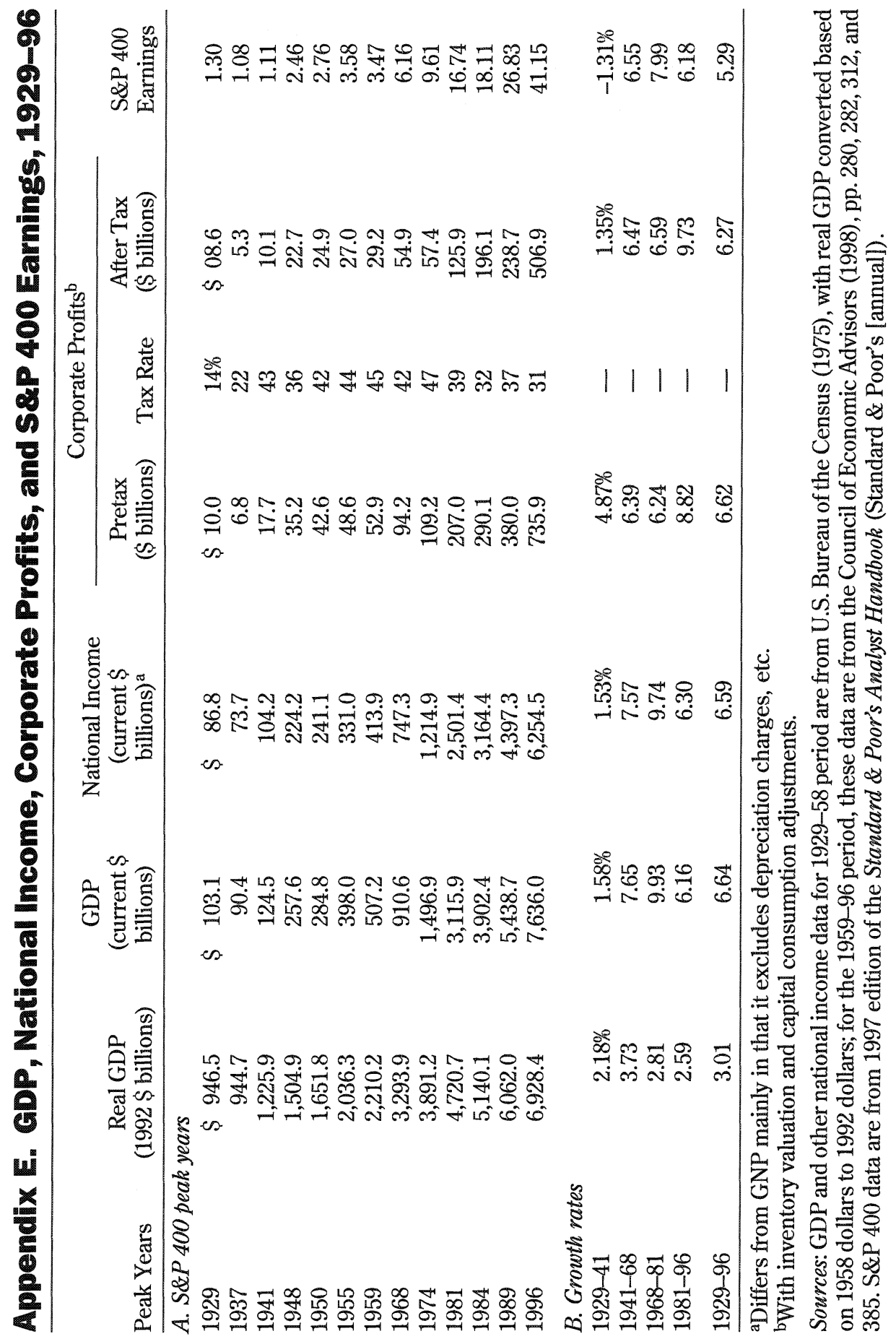




\section{Appendix F. Historical Relationships among GDP, National Income, Corporate Profits, and S\&P 400 Earnings, 1929-1996}

\begin{tabular}{|c|c|c|c|c|}
\hline Peak Years & $\begin{array}{l}\text { National Income } \\
\text { as a Percent of } \\
\text { GDP }\end{array}$ & $\begin{array}{l}\text { Pretax Corporate } \\
\text { Profits as a } \\
\text { Percent of } \\
\text { National Income }\end{array}$ & $\begin{array}{c}\text { After-Tax } \\
\text { Corporate Profits } \\
\text { as a Percent of } \\
\text { Pretax Profits }\end{array}$ & $\begin{array}{c}\text { S\&P } 400 \\
\text { Earnings as a } \\
\text { Percent of After- } \\
\text { Tax Profits }\end{array}$ \\
\hline 1929 & 84.2 & 11.5 & 86.0 & 15.1 \\
\hline 1937 & 81.5 & 9.2 & 77.9 & 20.4 \\
\hline 1941 & 83.7 & 17.0 & 57.1 & 11.0 \\
\hline 1948 & 87.0 & 15.7 & 64.5 & 10.8 \\
\hline 1950 & 84.7 & 17.7 & 58.5 & 11.1 \\
\hline 1955 & 83.2 & 14.7 & 55.6 & 13.3 \\
\hline 1959 & 81.6 & 12.8 & 55.2 & 11.9 \\
\hline 1968 & 82.1 & 12.6 & 58.3 & 11.2 \\
\hline 1974 & 81.2 & 9.0 & 52.6 & 16.7 \\
\hline 1981 & 80.3 & 8.3 & 60.8 & 13.3 \\
\hline 1984 & 81.1 & 9.7 & 67.6 & 9.2 \\
\hline 1989 & 80.8 & 8.6 & 62.8 & 11.2 \\
\hline 1996 & 81.9 & 11.8 & 68.9 & 8.1 \\
\hline \multicolumn{5}{|c|}{ Average of peak years } \\
\hline 1929-96 & 82.6 & 12.2 & 63.5 & 12.6 \\
\hline $1948-96$ & 82.4 & 12.1 & 60.5 & 11.7 \\
\hline \multicolumn{5}{|c|}{$\begin{array}{l}\text { Changes in relationships } \\
\text { (percentage points) }\end{array}$} \\
\hline $1929-41$ & -0.5 & 5.5 & -28.9 & -4.1 \\
\hline $1941-68$ & -1.6 & -4.4 & 1.2 & 0.2 \\
\hline $1968-81$ & -1.8 & -4.3 & 2.5 & 2.1 \\
\hline $1981-96$ & 1.6 & 3.5 & 8.1 & -5.2 \\
\hline
\end{tabular}

Sources: Council of Economic Advisors (1998); Standard \& Poor's (1997). 
Appendix G. S\&P 400 Earnings, 1926-1996

\begin{tabular}{|c|c|c|c|c|c|c|c|}
\hline Year & $\begin{array}{l}\text { Reported } \\
\text { Earnings }^{\mathrm{a}}\end{array}$ & $\mathrm{CPI}^{\mathrm{b}}$ & $\begin{array}{l}\text { Earnings } \\
\text { (inflation } \\
\text { adjusted) }\end{array}$ & Year & $\begin{array}{l}\text { Reported } \\
\text { Earnings }^{\mathrm{a}}\end{array}$ & $\mathrm{CPI}^{\mathrm{b}}$ & $\begin{array}{l}\text { Earnings } \\
\text { (inflation } \\
\text { adjusted) }\end{array}$ \\
\hline $1926^{c}$ & 1.00 & 17.7 & 1.00 & 1961 & 3.37 & 29.9 & 1.99 \\
\hline 1927 & 0.94 & 17.4 & 0.96 & 1962 & 3.83 & 30.2 & 2.24 \\
\hline 1928 & 1.20 & 17.2 & 1.24 & 1963 & 4.24 & 30.6 & 2.43 \\
\hline $1929^{c}$ & 1.30 & 17.2 & 1.34 & 1964 & 4.85 & 31.0 & 2.77 \\
\hline 1930 & 0.76 & 16.7 & 0.81 & 1965 & 5.50 & 31.5 & 3.09 \\
\hline 1931 & 0.46 & 15.2 & 0.54 & 1966 & 5.87 & 32.4 & 3.21 \\
\hline 1932 & 0.31 & 13.7 & 0.40 & 1967 & 5.62 & 33.4 & 2.98 \\
\hline 1933 & 0.38 & 13.0 & 0.52 & $1968^{c}$ & 6.16 & 34.8 & 3.13 \\
\hline 1934 & 0.45 & 13.4 & 0.59 & 1969 & 6.13 & 36.7 & 2.96 \\
\hline 1935 & 0.66 & 13.7 & 0.85 & 1970 & 5.41 & 38.8 & 2.47 \\
\hline 1936 & 0.92 & 13.9 & 1.17 & 1971 & 5.97 & 40.5 & 2.61 \\
\hline $1937^{c}$ & 1.08 & 14.4 & 1.33 & 1972 & 6.83 & 41.8 & 2.89 \\
\hline 1938 & 0.56 & 14.1 & 0.70 & 1973 & 8.89 & 44.4 & 3.54 \\
\hline 1939 & 0.81 & 13.9 & 1.03 & $1974^{c}$ & 9.61 & 49.3 & 3.45 \\
\hline 1940 & 1.01 & 14.0 & 1.28 & 1975 & 8.58 & 53.8 & 2.82 \\
\hline $1941^{\mathrm{c}}$ & 1.11 & 14.7 & 1.34 & 1976 & 10.69 & 56.9 & 3.33 \\
\hline 1942 & 0.83 & 16.3 & 0.90 & 1977 & 11.45 & 60.6 & 3.34 \\
\hline 1943 & 0.75 & 17.3 & 0.77 & 1978 & 13.04 & 65.2 & 3.54 \\
\hline 1944 & 0.78 & 17.6 & 0.78 & 1979 & 16.29 & 72.6 & 3.97 \\
\hline 1945 & 0.82 & 18.0 & 0.81 & 1980 & 16.12 & 82.4 & 3.46 \\
\hline 1946 & 0.92 & 19.6 & 0.83 & $1981^{c}$ & 16.74 & 90.9 & 3.26 \\
\hline 1947 & 1.92 & 22.4 & 1.52 & 1982 & 13.20 & 96.5 & 2.42 \\
\hline $1948^{c}$ & 2.46 & 24.1 & 1.81 & 1983 & 14.77 & 99.6 & 2.62 \\
\hline 1949 & 2.13 & 23.9 & 1.58 & $1984^{\mathrm{c}}$ & 18.11 & 103.9 & 3.08 \\
\hline $1950^{c}$ & 2.76 & 24.1 & 2.03 & 1985 & 15.28 & 107.6 & 2.51 \\
\hline 1951 & 2.52 & 26.0 & 1.72 & 1986 & 14.53 & 109.6 & 2.35 \\
\hline 1952 & 2.45 & 26.5 & 1.64 & 1987 & 20.28 & 113.6 & 3.16 \\
\hline 1953 & 2.57 & 26.7 & 1.70 & 1988 & 26.59 & 118.3 & 3.98 \\
\hline 1954 & 2.69 & 26.9 & 1.77 & $1989^{c}$ & 26.83 & 124.0 & 3.83 \\
\hline $1955^{\mathrm{c}}$ & 3.58 & 26.8 & 2.36 & 1990 & 24.77 & 130.7 & 3.35 \\
\hline 1956 & 3.50 & 27.2 & 2.28 & 1991 & 16.91 & 136.2 & 2.20 \\
\hline 1957 & 3.53 & 28.1 & 2.22 & 1992 & 19.05 & 140.3 & 2.40 \\
\hline 1958 & 2.95 & 28.9 & 1.81 & 1993 & 21.93 & 144.5 & 2.69 \\
\hline $1959^{c}$ & 3.47 & 29.1 & 2.11 & 1994 & 31.84 & 148.2 & 3.80 \\
\hline \multirow[t]{2}{*}{1960} & 3.40 & 29.6 & 2.03 & 1995 & 35.09 & 152.4 & 4.08 \\
\hline & & & & 1996 & 41.15 & 156.9 & 4.64 \\
\hline
\end{tabular}

Annual compound 1926-96 increase: $2.22 \%$

aStandard \& Poor's (annual).

bU.S. Consumer Price Index: 1982-1984 = 100 (linked with $1967=100$ series for years prior to 1950). Data from U.S. Department of Labor, Bureau of Labor Statistics.

'Earnings-cycle peak years. 


\section{Appendix H. S\&P 400 Dividends, 1926-1996}

\begin{tabular}{|c|c|c|c|c|c|c|c|}
\hline Year & $\begin{array}{l}\text { Reported } \\
\text { Dividends }{ }^{\mathrm{a}}\end{array}$ & $\mathrm{CPI}^{\mathrm{b}}$ & $\begin{array}{l}\text { Dividends } \\
\text { (inflation } \\
\text { adjusted) }\end{array}$ & Year & $\begin{array}{l}\text { Reported } \\
\text { Dividends }^{\mathrm{a}}\end{array}$ & $\mathrm{CPI}^{\mathrm{b}}$ & $\begin{array}{l}\text { Dividends } \\
\text { (inflation } \\
\text { adjusted) }\end{array}$ \\
\hline $1926^{\mathrm{c}}$ & 0.55 & 17.7 & 0.55 & 1961 & 2.07 & 29.9 & 1.22 \\
\hline 1927 & 0.63 & 17.4 & 0.64 & 1962 & 2.20 & 30.2 & 1.29 \\
\hline 1928 & 0.73 & 17.2 & 0.75 & 1963 & 2.36 & 30.6 & 1.36 \\
\hline $1929^{c}$ & 0.82 & 17.2 & 0.84 & 1964 & 2.58 & 31.0 & 1.47 \\
\hline 1930 & 0.82 & 16.7 & 0.87 & 1965 & 2.82 & 31.5 & 1.58 \\
\hline 1931 & 0.66 & 15.2 & 0.77 & 1966 & 2.95 & 32.4 & 1.61 \\
\hline 1932 & 0.39 & 13.7 & 0.50 & 1967 & 2.97 & 33.4 & 1.57 \\
\hline 1933 & 0.34 & 13.0 & 0.46 & $1968^{c}$ & 3.16 & 34.8 & 1.61 \\
\hline 1934 & 0.37 & 13.4 & 0.49 & 1969 & 3.25 & 36.7 & 1.57 \\
\hline 1935 & 0.42 & 13.7 & 0.54 & 1970 & 3.20 & 38.8 & 1.46 \\
\hline 1936 & 0.67 & 13.9 & 0.85 & 1971 & 3.16 & 40.5 & 1.38 \\
\hline $1937^{\mathrm{c}}$ & 0.77 & 14.4 & 0.95 & 1972 & 3.22 & 41.8 & 1.36 \\
\hline 1938 & 0.45 & 14.1 & 0.56 & 1973 & 3.46 & 44.4 & 1.38 \\
\hline 1939 & 0.57 & 13.9 & 0.73 & $1974^{c}$ & 3.71 & 49.3 & 1.33 \\
\hline 1940 & 0.63 & 14.0 & 0.80 & 1975 & 3.72 & 53.8 & 1.22 \\
\hline $1941^{\mathrm{c}}$ & 0.68 & 14.7 & 0.82 & 1976 & 4.22 & 56.9 & 1.31 \\
\hline 1942 & 0.55 & 16.3 & 0.60 & 1977 & 4.95 & 60.6 & 1.44 \\
\hline 1943 & 0.58 & 17.3 & 0.59 & 1978 & 5.37 & 65.2 & 1.46 \\
\hline 1944 & 0.60 & 17.6 & 0.60 & 1979 & 5.92 & 72.6 & 1.44 \\
\hline 1945 & 0.61 & 18.0 & 0.60 & 1980 & 6.49 & 82.4 & 1.39 \\
\hline 1946 & 0.64 & 19.6 & 0.58 & $1981^{c}$ & 7.01 & 90.9 & 1.36 \\
\hline 1947 & 0.80 & 22.4 & 0.63 & 1982 & 7.13 & 96.5 & 1.31 \\
\hline $1948^{c}$ & 0.96 & 24.1 & 0.70 & 1983 & 7.32 & 99.6 & 1.30 \\
\hline 1949 & 1.05 & 23.9 & 0.78 & $1984^{c}$ & 7.51 & 103.9 & 1.28 \\
\hline $1950^{c}$ & 1.35 & 24.1 & 0.99 & 1985 & 7.87 & 107.6 & 1.29 \\
\hline 1951 & 1.35 & 26.0 & 0.92 & 1986 & 8.14 & 109.6 & 1.31 \\
\hline 1952 & 1.36 & 26.5 & 0.91 & 1987 & 8.72 & 113.6 & 1.36 \\
\hline 1953 & 1.34 & 26.7 & 0.89 & 1988 & 9.80 & 118.3 & 1.46 \\
\hline 1954 & 1.45 & 26.9 & 0.95 & $1989^{c}$ & 11.95 & 124.0 & 1.70 \\
\hline $1955^{\mathrm{c}}$ & 1.74 & 26.8 & 1.15 & 1990 & 12.70 & 130.7 & 1.72 \\
\hline 1956 & 1.84 & 27.2 & 1.20 & 1991 & 12.51 & 136.2 & 1.62 \\
\hline 1957 & 1.94 & 28.1 & 1.22 & 1992 & 13.01 & 140.3 & 1.64 \\
\hline 1958 & 1.86 & 28.9 & 1.14 & 1993 & 12.51 & 144.5 & 1.53 \\
\hline $1959^{c}$ & 1.95 & 29.1 & 1.18 & 1994 & 13.01 & 148.2 & 1.55 \\
\hline \multirow[t]{2}{*}{1960} & 2.00 & 29.6 & 1.20 & 1995 & 13.96 & 152.4 & 1.62 \\
\hline & & & & 1996 & 15.58 & 156.9 & 1.76 \\
\hline
\end{tabular}

Annual compound 1926-96 increase: $1.68 \%$

aStandard \& Poor's (annual).

bU.S. Consumer Price Index: 1982-84 =100 (linked with $1967=100$ series for years prior to 1950). Data from U.S. Department of Labor, Bureau of Labor Statistics.

'Earnings-cycle peak years. 


\section{Appendix I. Expected Growth Rate and Expected Return in 1929}

One of the most important uncertainties in the stock market is the expected real growth rate. As for other things we might like to know about the future, the best we can achieve for the expected real growth rate is a credible estimate.

Chapter 4 reviews the history of the stock market from 1929 through 1996 in the framework of the investment value models (IVMs). The conclusion is that future growth rate expectations draw heavily from past growth rates, especially those of the previous 10-12 years, and that for long-term analysis, the focus should be on inflation-adjusted rates. The quality of information available since the mid-1920s made such a review an easily manageable task. But what of the history before 1929 ?

Because of the role of historical rates, estimates of the expected real growth rate in 1929 should benefit from knowing the actual experience prior to that time. Unfortunately, financial and economic statistics for earlier periods are not readily available; the data are sketchy and suspect from a quality standpoint. Nevertheless, some sources provide information on the behavior of the pre-1929 U.S. stock market.

One of the best sources is the collected papers of Nicholas Molodovsky, edited by Milne (1974). Figure I.1 is a redrawing of that book's fascinating graphic on relationships in the stock market for the 1871-1970 period. With semilogarithmic ruling on the vertical scale, annual data on market level, earnings, and dividends are plotted. The least-squares regression lines show the average annual compound growth rate for each of them. Market level grew at an average compound rate of 3.04 percent, earnings grew at 3.00 percent, and dividends grew at 2.84 percent. All are nominal growth rates, but inflation during 1871-1970 was negligible by current standards-an average 1.54 percent a year (Ibbotson and Brinson 1993). The growth of the real economy during that period was about 3 percent a year, which was significantly greater than the rate of real growth in market level, earnings, and dividends.

Ibbotson and Brinson (1987) reported that the value-weighted annual return for the New York Stock Exchange (NYSE) for 1871-1925 was 6.89 percent-5.04 percent from dividends and 1.80 percent from price appreciation. After adjustment for inflation (1.33 percent a year), real appreciation was only about 0.50 percent a year, less than $1 / 10$ th of the total real return. With such a high proportion of the real return coming from dividends, the 16.08 percent a year standard deviation of these NYSE stocks may be surprising. 


\section{Figure I.1. Basic Relationships in the Stock Market, 1870-1970}

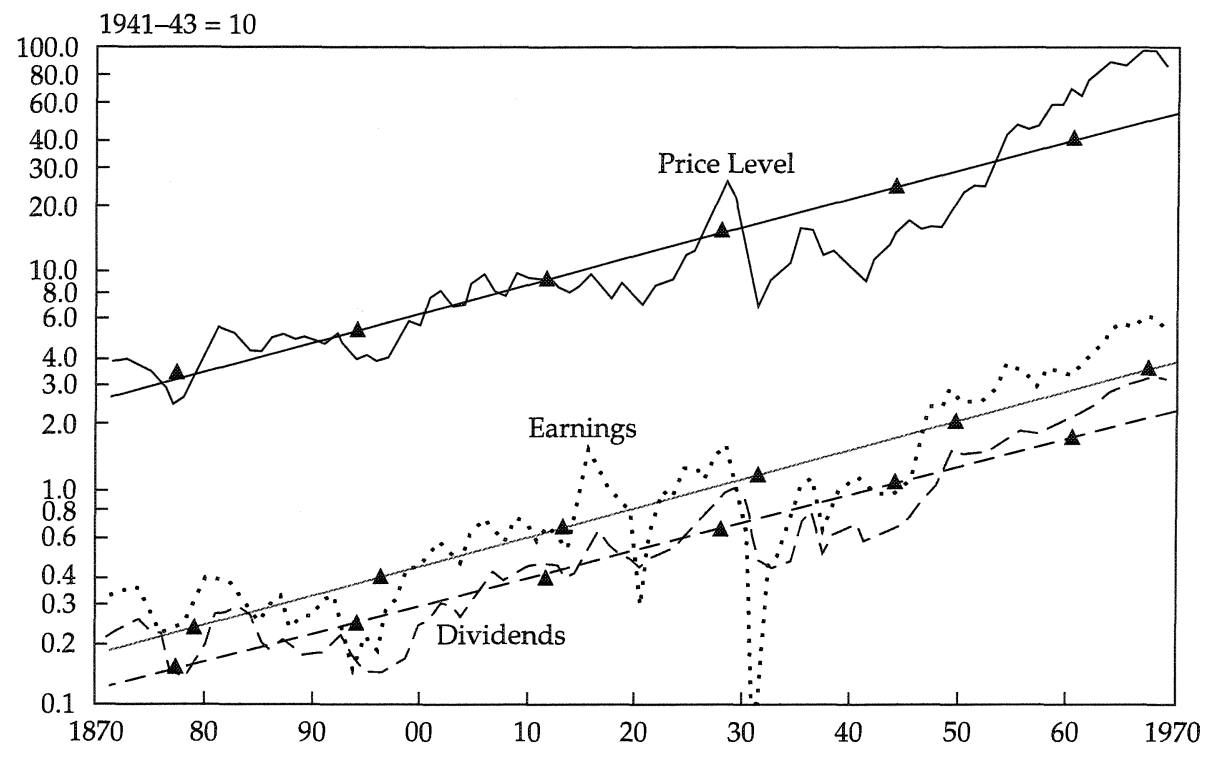

Notes: Semilogarithmic scale. Earnings for 1931 dipped to $\$ 0.05$.

Source: Based on Cowles Commission data adjusted to 1941-43 base through 1917 and spliced to the S\&P 500 Index for 1918 and thereafter (Milne 1974).

(The standard deviation of the NYSE stocks between 1926 and 1985 was 21.12 percent.) In the earlier period, when earnings and dividends, especially dividends, were much more volatile, the volatility was more than offset by the structure of the return, which was clearly affected by a high ( 5 percent) absolute dividend yield.

With this background in mind, this appendix will examine the pre-1929 period somewhat as the 1929-96 period was reviewed in Chapter 4. The examination uses estimates of peak-to-peak earnings from visual inspection of Figure I.1 and uses the corresponding dividends to calculate approximate dividend yields. The data are in Table I.1.

Based on the 1880-1929 stock market data, a real growth rate expectation of 1.00-1.25 percent might have been a reasonable estimate for 1929 except for one development not evident in Table I.1. The real earnings growth from 1925 to 1929 was about 8.74 percent a year. Surges of that kind have usually affected long-term growth rate expectations in a favorable way. Therefore, an additional increment of 0.50 percent a year could have been justified, which would lead to a real earnings growth rate expectation in 1929 close to the 1871-1929 average of 1.67 percent. 
Table I.1. U.S. Stock Market Statistics, 1880-1929

\begin{tabular}{|c|c|c|c|c|c|c|c|c|}
\hline \multirow[b]{2}{*}{$\begin{array}{l}\text { Periods of } \\
\text { Peak-to-Peak } \\
\text { Earnings }\end{array}$} & \multirow[b]{2}{*}{$\begin{array}{l}\text { Number } \\
\text { of Years }\end{array}$} & \multicolumn{2}{|c|}{ Earnings $^{\mathrm{a}}$} & \multirow[b]{2}{*}{$\begin{array}{l}\text { Earnings } \\
\text { Growth } \\
\text { Rate }\end{array}$} & \multirow[b]{2}{*}{$\begin{array}{l}\text { Annual } \\
\text { Inflation } \\
\text { Rate }^{\mathrm{b}}\end{array}$} & \multirow{2}{*}{$\begin{array}{l}\text { Real } \\
\text { Earnings } \\
\text { Growth } \\
\text { Rate }\end{array}$} & \multicolumn{2}{|c|}{ Dividend Yield ${ }^{c}$} \\
\hline & & Begin & End & & & & Begin & End \\
\hline $1880-92$ & 12 & 0.42 & 0.34 & $-1.75 \%$ & $-0.31 \%$ & $-1.44 \%$ & $3.84 \%$ & $3.78 \%$ \\
\hline $1892-1906$ & 14 & 0.34 & 0.73 & 5.61 & 0.93 & 4.68 & 3.78 & 3.63 \\
\hline $1906-16$ & 10 & 0.73 & 1.68 & 8.69 & 3.48 & 5.21 & 3.63 & 5.49 \\
\hline $1916-29$ & 13 & 1.68 & 1.72 & 0.18 & 3.36 & -3.18 & 5.49 & 3.69 \\
\hline $\begin{array}{l}\text { Total period } \\
\quad(1880-1929)\end{array}$ & 49 & 0.42 & 1.72 & 2.92 & 1.78 & 1.14 & 3.84 & 3.69 \\
\hline
\end{tabular}

Note: All earnings and dividend yield figures are approximate.

${ }^{a}$ Cowles Commission data adjusted to $1941-43$ base through 1917 and spliced to the S\&P 500 Index for 1918 and thereafter.

bU.S. Price Index assembled by Ibbotson and Brinson (1993), p. 254.

"Using S\&P Composite Index "average" prices for each year.

Source: Based on data in Milne (1974) shown in Figure I.1.

In the IVM framework, the estimated discount rate for the stock market would have been about 5.36 percent $(1.67$ percent +3.69 percent for dividend yield), but one further adjustment seems appropriate: The average stock market price in 1929 was at least 25 percent above the trend line of prior peakmarket-year averages since 1871. Thus, a "normal" peak-market dividend yield would have been about 100 basis points higher than the first estimate, or 4.69 percent. On that basis, the estimate of expected equity return for 1929 would have been about 6.36 percent.

Because the equity returns discussed in this monograph are largely the returns on the S\&P 400 Index and this analysis of early stock market behavior is based primarily S\&P 500 Index returns, another modest adjustment to arrive at a reasonable estimation of expected equity returns in 1929 is warranted: Considerations of risk relative to the $S \& P 500$ would seem to justify a slightly higher expected return for the S\&P 400 than the S\&P 500 . The figure 6.5 percent, as used in Figure 4.1, is believed to be appropriate. 1

\footnotetext{
${ }^{1}$ When the IVM approach to estimating expected equity return is used, the average during the 1871-1929 period appears to have been about 6.53 percent. The average dividend yield between 1871 and 1958 reported in Milne (1974) was 4.96 percent, but yields were apparently a bit higher between 1929 and 1958. A reasonable estimate for 1871-1929 would be 4.86 percent, to which the real earnings growth rate of 1.67 percent should be added.
} 


\section{References}

AIMR. 1996. Standards of Practice Handbook. Seventh Edition. Charlottesville, VA: AIMR.

Bernstein, Peter L. 1996a. Against The Gods: The Remarkable Story of Risk. New York: John Wiley \& Sons.

1996b. "What Prompts Paradigm Shifts?" Financial Analysts Journal, vol. 52 , no. 5 (November/December):7-13.

Coleman, Thomas S., Lawrence Fisher, and Roger G. Ibbotson. 1993. Historical U.S. Treasury Yield Curves. Ibbotson Associates and Moody's Investor Service.

Council of Economic Advisors. 1996, 1997, and 1998. Economic Report of the President. Washington, DC: U.S. Government Printing Office.

Diermeier, Jeffrey J. 1990. "Capital Market Expectations: The Macro Factors." In Managing Investment Portfolios: A Dynamic Process. 2nd edition. Edited by John L. Maginn and Donald L. Tuttle. Boston, MA: Warren, Gorham \& Lamont.

Gray, William S. 1974. "The Application of Discount Rates in Forecasting Returns for Stocks and Bonds." Financial Analysts Journal, vol. 30, no. 3 (May/ June):53-61.

1979. "Developing a Long-Term Outlook for the U.S. Economy and Stock Market." Financial Analysts Journal, vol. 35, no. 4 (July/August):29-39.

- 1984. "The Stock Market and the Economy in 1988." Journal of Portfolio Management, vol. 10, no. 4 (Summer):73-80.

1987-1995. Various columns of "Stock/Bond Values." Harris Insight (August 14, 1987; October 20, 1987; July 17, 1989; July 20 1990; June 12, 1995).

- 1989. "The Anatomy of a Stock Market Forecast." Journal of Portfolio Management, (Fall):36-44. 
1993. "Historical Returns, Inflation, and Future Return Expectations." Financial Analysts Journal, vol. 49, no. 4 (July/August):35-45.

Ibbotson Associates. 1997. Stocks, Bonds, Bills, and Inflation: 1997 Yearbook. Chicago, IL: Ibbotson Associates.

Ibbotson, Roger G., and Gary P. Brinson. 1987. Investment Markets. New York: McGraw-Hill.

1993. Global Investing. New York: McGraw-Hill.

Ibbotson, Roger G., and Rex A. Sinquefield. 1977. Stocks, Bonds, Bills, and Inflation: The Past (1926-76) and The Future (1977-2000). Charlottesville, VA: Financial Analysts Research Foundation.

1982. Stocks, Bonds, Bills, and Inflation: The Past and the Future. Charlottesville, VA: Research Foundation of the Institute of Chartered Financial Analysts.

Markowitz, Harry S. 1959. Portfolio Selection: Efficient Diversification of Investments. New York: John Wiley \& Sons.

Milne, Robert D., ed. 1974. Investment Values in a Dynamic World: The Collected Papers of Nicholas Molodovsky. Research Foundation of the Institute of Chartered Financial Analysts. Homewood, IL: Richard D. Irwin.

Standard \& Poor's Corporation. Annual. Standard \& Poor's Analyst Handbook. New York: McGraw-Hill.

U.S. Bureau of the Census. 1975. Historical Statistics of the U.S.: Colonial Times to 1970, Part 1. Washington, DC: U.S. Bureau of the Census.

U.S. Government Printing Office. 1997. Economic Indicators. Washington, DC: U.S. Government Printing Office (June).

Vandell, Robert F., and George W. Kester. 1983. A History of Risk-Premia Estimates for Equities: 1944-78. Charlottesville, VA: Research Foundation of the Institute of Chartered Financial Analysts.

Williams, John B. 1938. The Theory of Investment Value. Cambridge, MA: Harvard University Press.

Wick, Thomas A. 1995. Office correspondence. Harris Investment Management, Harris Bank. Chicago, IL (February 15-16, February 28).

Wilson, Jack W., and Charles P. Jones. 1987. "A Comparison of Annual Common Stock Returns: 1871-1925 with 1926-1985.” Journal of Business, vol. 50, no. 2:239-258. 